\title{
Soziale Ungleichheit im Bildungssystem
}

In den folgenden Unterkapiteln werden zunächst empirische Schlaglichter auf aktuelle Befunde zu sozialer Ungleichheit im deutschen Bildungssystem geworfen (Abschnitt 1.1). Anschließend erfolgt eine kritische Auseinandersetzung mit der Frage nach der Herstellung und Abschwächung sozialer Ungleichheit in der Schule. Hierbei werden die Theorie der rationalen Entscheidung von Raymond Boudon sowie der gesellschaftskritische Erklärungsansatz von Pierre Bourdieu ausgeführt und entsprechende empirische Untersuchungen präsentiert. Zusätzlich werden Studien mit dem Fokus auf Lehrer*innen-Schüler*innen-Interaktionen herangezogen (Abschnitt 1.2). Auf Grundlage der theoretischen Rahmung und der empirischen Befundlage werden schließlich die zentralen Anknüpfungspunkte für das eigene Forschungsvorhaben herausgearbeitet (Abschnitt 1.3).

\section{1 Überblick über den Zusammenhang von sozialer Herkunft und Schul(miss)erfolg}

Dieses Unterkapitel umfasst eine kursorische Darstellung sozialer Disparitäten in der Bildungsbeteiligung, dem schulischen Kompetenzerwerb und den Schulabschlüssen als Indikatoren für Schulerfolg. ${ }^{1}$ Berücksichtigt werden vorrangig

\footnotetext{
${ }^{1}$ Bei der folgenden Darstellung handelt es sich um eine Vereinfachung der komplexen Realität. In der vorliegenden Arbeit können nur ausgewählte Facetten von sozialer Ungleichheit im Bildungssystem berücksichtigt werden. Auf weitere ungleichheitsrelevante Dimensionen wie etwa die sexuelle oder politische Orientierung sowie auf regionale Disparitäten kann in dieser Arbeit nicht eingegangen werden. Darüber hinaus können aufgrund der föderalen Organisation des deutschen Bildungssystems und der dadurch bedingten Abweichungen zwischen den einzelnen Bundesländern Einschränkungen der Reichweite und Aussagekraft der nachstehenden quantitativen Daten folgen.
}

S. Rutter, Sozioanalyse in der pädagogischen Arbeit, Bildung und Gesellschaft, https://doi.org/10.1007/978-3-658-32065-2_1 
Ergebnisse aus den internationalen Grundschulleseuntersuchungen IGLU, der PISA-Studien sowie der Schulstatistiken der Kultusministerkonferenz.

\section{Bildungsbeteiligung}

Anfangs ist von Interesse, inwiefern Kinder und Jugendliche mit Behinderung bzw. einem sonderpädagogischen Förderbedarf in das System allgemeinbildender Schulen aufgenommen und nicht durch eine separate Beschulung an Förderschulen exkludiert werden. Rechtlich wird diese Form der gemeinsamen Beschulung über das im Jahr 2009 von Deutschland ratifizierte „Übereinkommen über die Rechte von Menschen mit Behinderungen" der Vereinten Nationen hergestellt (Berkemeyer, Bos, Manitius, Hermstein, \& Khalatbari, 2013)². Bedeutsam ist, dass das Förderschulsystem in Deutschland neben der Organisation allgemeinbildender Schulen noch einmal ein hochgradig differenziertes System darstellt, das nach unterschiedlichen Förderschwerpunkten gegliedert ist (Bos, Müller, \& Stubbe, 2010). Insgesamt erhielten im Schuljahr 2015/2016, bezogen auf die Jahrgangsstufen 1 bis 10, deutschlandweit 517.384 Schüler*innen sonderpädagogischen Förderbedarf. Gemessen an allen Schüler*innen im allgemeinbildenden Schulsystem entspricht das einem Anteil von 7,1 Prozent. Tendenziell steigt die Förderquote für Deutschland in den letzten Jahren leicht, bei gleichzeitig sinkender absoluter Schüler*innenzahl (Kultusministerkonferenz, 2016a). Die Gründe für den Anstieg der Förderquote sind hierbei unklar: Möglicherweise besteht ein Zusammenhang zwischen modifizierten Kriterien der Begutachtung und Diagnose des sonderpädagogischen Förderbedarfs, medizinischem Fortschritt, besserem sonderschulischen Angebot oder bildungspolitischem Interesse am anhaltenden Fördersystem (Berkemeyer, Bos, Manitius, Hermstein, \& Khalatbari, 2013).

Wie die untenstehende Abbildung verdeutlicht, wird ein Großteil der Schüler*innen mit sonderpädagogischem Förderbedarf in Förderschulen unterrichtet im Jahr 2013 sind es nahezu 70 Prozent. Zugleich werden aber auch immer mehr Heranwachsende mit sonderpädagogischem Förderbedarf in allgemeinbildenden Schulen beschult, wobei insbesondere seit dem Berichtsjahr 2010 starke Zuwächse festzustellen sind. So wurden im Jahr 2005 14,5 Prozent der Schüler*innen mit sonderpädagogischem Förderbedarf in allgemeinbildenden Schulen unterrichtet,

\footnotetext{
${ }^{2}$ Anzumerken ist, dass sonderpädagogischer Förder- bzw. Unterstützungsbedarf den gängigen schulinternen Begriff für Behinderung darstellt. Damit verbunden ist zumeist ein enges Verständnis von Behinderung und Inklusion, dass sich vorrangig auf den ,richtigen" Förderort bezieht. Ein weites Verständnis von Behinderung und Inklusion, das auch dem Übereinkommen der Vereinten Nationen zugrunde liegt, setzt sich grundsätzlich mit dem schulischen Umgang mit Vielfalt auseinander und richtet sich insbesondere an marginalisierte Schüler*innengruppen (Bremm, Racherbäumer, \& van Ackeren, 2017).
} 
im Jahr 2013 sind es mit 31,4 Prozent doppelt so viele (Kultusministerkonferenz, 2016b; 2012) (Abbildung 1.1).

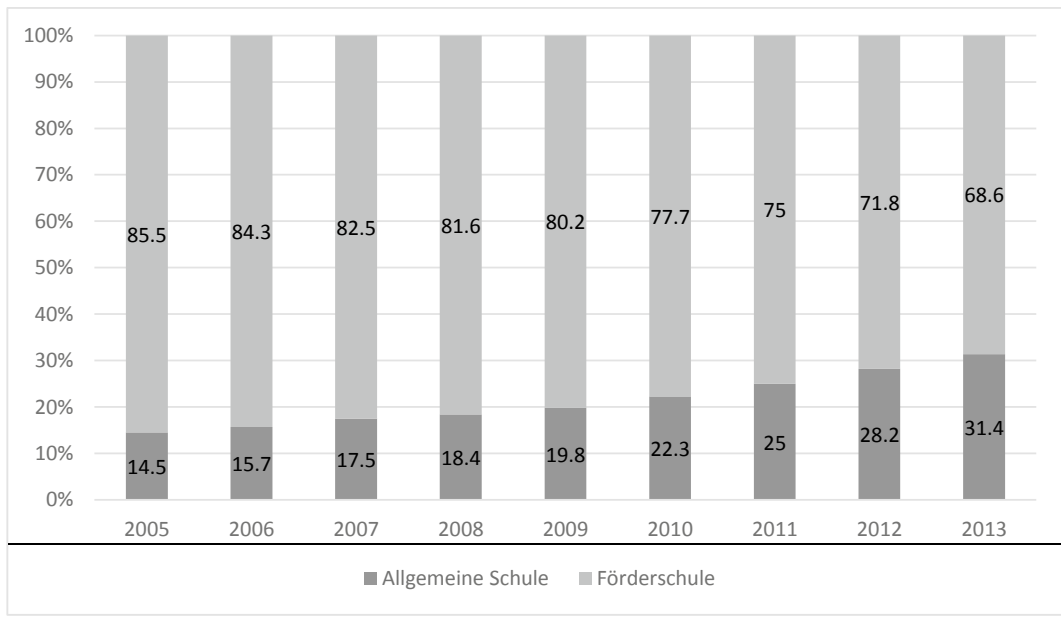

Abbildung 1.1 Prozentuale Verteilung von Schüler*innen mit sonderpädagogischem Förderbedarf auf Förderschulen und allgemeinbildenden Schulen von 2005 bis 2013. (Eigene Darstellung auf Grundlage von: Kultusministerkonferenz, 2016b; 2012)

Die Kultusministerkonferenz (2016b) weist jedoch darauf hin, dass die Anzahl der Heranwachsenden in Förderschulen im Verhältnis zur Gesamtschüler*innenschaft trotz steigender Tendenz, Schüler*innen mit sonderpädagogischem Förderbedarf in allgemeinbildenden Schulen zu unterrichten, stabil bleibt. Die zeitliche Entwicklung der Förderschulbesuchsquote wird in der folgenden Tabelle dargestellt (Tabelle 1.1).

Tabelle 1.1 Bundesweite Förderschulbesuchsquote im Zeitverlauf von 2005 bis 2013. (Eigene Darstellung auf Grundlage von: Kultusministerkonferenz, 2016b)

\begin{tabular}{|c|c|c|c|c|c|c|c|c|c|}
\hline Jahr & 2005 & 2006 & 2007 & 2008 & 2009 & 2010 & 2011 & 2012 & 2013 \\
\hline $\begin{array}{c}\text { Förderschul- } \\
\text { besuchsquote }\end{array}$ & 4,8 & 4,8 & 4,9 & 4,9 & 4,9 & 4,9 & 4,8 & 4,7 & 4,6 \\
\hline
\end{tabular}


Der Tabelle ist zu entnehmen, dass die Förderschulbesuchsquote zwischen den Jahren 2005 und 2013 lediglich um 0,3 Prozentpunkte schwankte, es aber einen leichten Trend gibt, Schüler*innen mit sonderpädagogischem Förderbedarf weniger in Förderschulen zu unterrichten. Insgesamt ist das Risiko, separat unterrichtet zu werden, für Schüler*innen mit sonderpädagogischem Förderbedarf dennoch hoch: Gut drei Viertel aller Lernenden mit sonderpädagogischem Förderbedarf werden in Förderschulen unterrichtet (ebd.).

Komplexer werden die Analysen, betrachtet man die Verteilung der Schüler*innen mit sonderpädagogischem Förderbedarf auf die unterschiedlichen Förderschwerpunkte. Seit 1994 wird die sonderpädagogische Förderung auf Empfehlung der Kultusministerkonferenz in sieben Förderschwerpunkten organisiert: Lernen, Sehen, Hören, Sprache, körperliche und motorische Entwicklung, geistige Entwicklung sowie emotionale und soziale Entwicklung (Bos, Müller, \& Stubbe, 2010) (Tabelle 1.2).

Tabelle 1.2 Verteilung der Schüler*innen mit sonderpädagogischem Förderbedarf auf die Förderschwerpunkte im Schuljahr 2015/2016. (Eigene Darstellung auf Grundlage von: Kultusministerkonferenz, 2016a)

\begin{tabular}{|c|c|c|c|}
\hline Förderschwerpunkte & $\begin{array}{c}\text { Schüler*innen mit } \\
\text { sonderpädagogischer } \\
\text { Förderung } \\
\text { insgesamt }\end{array}$ & $\begin{array}{c}\text { Schüler*innen mit } \\
\text { sonderpädagogischer } \\
\text { Förderung } \\
\text { in Förderschulen }\end{array}$ & $\begin{array}{c}\text { Schüler*innen mit } \\
\text { sonderpädagogischer } \\
\text { Förderung } \\
\text { in allgemeinbildenden } \\
\text { Schulen }\end{array}$ \\
\hline $\begin{array}{c}\text { Alle Förderschwerpunkte } \\
\text { zusammen }\end{array}$ & 517.384 & 322.518 & 194.866 \\
\hline Lernen & 190.376 & 104.742 & 85.634 \\
\hline Sehen & 8.004 & 4.604 & 3.400 \\
\hline Hören & 19.160 & 10.528 & 8.632 \\
\hline Sprache & 56.098 & 30.560 & 25.538 \\
\hline $\begin{array}{l}\text { Körperliche und } \\
\text { motorische Entwicklung }\end{array}$ & 36.678 & 24.181 & 12.497 \\
\hline Geistige Entwicklung & 84.362 & 75.297 & 9.065 \\
\hline $\begin{array}{c}\text { Emotionale und soziale } \\
\text { Entwicklung }\end{array}$ & 85.644 & 38.006 & 47.638 \\
\hline Sonstiges & 37.062 & & \\
\hline
\end{tabular}

Der Förderschwerpunkt Lernen ist der mit Abstand am stärksten vertretene Förderschwerpunkt, gefolgt von den Förderschwerpunkten geistige Entwicklung, 
emotionale und soziale Entwicklung sowie Sprache. Bei der Verteilung der Schüler*innen mit sonderpädagogischer Förderung in Förderschulen und in allgemeinbildenden Schulen auf die einzelnen Förderschwerpunkte ergeben sich zum Teil deutliche Unterschiede: Schüler*innen mit dem Förderschwerpunkt geistige Entwicklung sowie körperliche und motorische Entwicklung werden verhältnismäßig selten in allgemeinbildenden Schulen unterrichtet. In diesen Bereichen wird überwiegend auf die spezielle Unterstützung in Förderschulen gesetzt; im Gegensatz dazu lernen Schüler*innen mit dem Förderschwerpunkt emotionale und soziale Entwicklung überwiegend im System allgemeinbildender Schulen (Kultusministerkonferenz, 2016a).

Überdies ist auf teilweise starke bundeslandspezifische Schwankungen hinsichtlich der Förderquote und der Förderschulbesuchsquote, auch innerhalb der verschiedenen Förderschwerpunkte, hinzuweisen (Kultusministerkonferenz, 2016a; 2016b). Die Länderunterschiede deuten auf eine uneinheitliche Zuteilung des sonderpädagogischen Förderbedarfs hin und können auf vielfache Gründe zurückzuführt werden: bundeslandspezifische Unterschiede bei der Umsetzung der schulgesetzlichen Regelungen des Rechts auf inklusive Bildung, unterschiedliche Berechnungsgrundlagen der Exklusions- und Inklusionsanteile in den Bundesländern, ungleiche Kriterien der Begutachtung und Diagnose des sonderpädagogischen Förderbedarfs sowie differente Bildungsangebote und Überweisungspraxen (Bos, Müller, \& Stubbe, 2010). In diesem Kontext steht der zentrale Kritikpunkt an die förderschwerpunktbezogene Differenzlogik, dass es sich bei den Förderschwerpunkten Sehen, Hören oder körperliche und motorische Entwicklung um weithin physisch feststellbare Beeinträchtigungen handelt, wohingegen die Förderschwerpunkte Lernen, Sprache, geistige Entwicklung sowie emotionale und soziale Entwicklung zur ,normalen" kindlichen Ausbildung schwieriger abzugrenzen sind (ebd.). Letztgenannte Förderschwerpunkte sind zudem nicht trennscharf zu unterscheiden und es kommt häufiger zu einem „Overlap“ (Ricking, 2005) von Lernbeeinträchtigungen und Verhaltensstörungen, d. h. Schwierigkeiten, die den Schwerpunkten Lernen, Sprache, geistige Entwicklung sowie emotionale und soziale Entwicklung zugeordnet werden (ebd.). Aus einer bildungssoziologischen Perspektive hängt die Interpretation der Kategorie Behinderung bzw. sonderpädagogischer Förderbedarf immer auch von gesellschaftlichen Deutungs- und Zuschreibungsprozessen ab. So wird ein Kind mit geringen Lese- und Schreibkompetenzen im deutschen Schulsystem als lernbehindert wahrgenommen. In einer Kultur mit einer hohen Rate an Analphabet*innen erscheint dasselbe Kind hingegen nicht als stark normabweichend (Textor, 2015).

Prinzipiell verfolgt eine sonderpädagogische Förderung das Ziel, den Schüler*innen die volle Entfaltung ihrer Persönlichkeit, ein selbstbestimmtes Leben 
sowie eine aktive gesellschaftliche Teilhabe zu ermöglichen (Kultusministerkonferenz, 2011). Die individuellen Bildungs- und Lebensverläufe der Förderschüler*innen konterkarieren jedoch dieses bildungspolitische Bestreben, denn überwiegend führt der Besuch einer Förderschule nicht zu einem Schulabschluss: Im Jahr 2014 verließen rund 70 Prozent der Absolvent*innen die Förderschule ohne qualifizierenden Abschluss die Förderschule, ca. 25 Prozent erwarben den Hauptschulabschluss (Kultusministerkonferenz, 2016b). Aufgrund der einstigen Schulzugehörigkeit folgt überwiegend eine prekäre Berufsbiografie; die Mehrheit der Förderschulabgänger*innen befindet sich im Übergangssystem der Berufsbildung. Die Bildungsangebote des Übergangsystems vermitteln jedoch keinen qualifizierten Ausbildungsabschluss und sichern somit auch keine Ansprüche in der Berufsausbildung oder auf dem Arbeitsmarkt (Autorengruppe Bildungsberichterstattung, 2010). Merkliche Unterschiede bestehen zwischen Jugendlichen aus allgemeinbildenden Schulen und Förderschulen: Schüler*innen aus allgemeinbildenden Schulen erreichen im Verhältnis zu Jugendlichen aus Förderschulen höhere Schulabschlüsse und beginnen öfter eine Berufsausbildung (Ginnold, 2009). Pfahl und Powell (2005) konstatieren, dass die Besonderung an Förderschulen nach der Schulzeit aufgrund mangelnder qualifizierender Abschlüsse und einer daraus folgenden Exklusion vom Arbeitsmarkt für einige Förderschüler*innen zur individuellen „Scheiternsbiographie“ (ebd., S. 69) wird.

Den starken Einfluss der sozialen Herkunft auf die Feststellung des sonderpädagogischen Förderschwerpunktes Lernen weist Wocken (2005) in seinen vergleichenden Untersuchungen in den Bundesländern Brandenburg, Hamburg und Niedersachsen nach: Ein niedrigerer Schul-, Ausbildungs- und Erwerbsstatus der Eltern, eine höhere Arbeitslosenquote der Eltern, mehr Geschwister bei weniger Wohnraum sowie Alleinerziehende sind statistisch signifikante soziale Merkmale von Schüler*innen mit dem Förderschwerpunkt Lernen (ebd.). Bemerkenswert sind ebenfalls Unterschiede in der bundesweiten Förderschulbesuchsquote je nach Staatsangehörigkeit. Insbesondere Schüler*innen mit der Staatsangehörigkeit mazedonisch, marokkanisch, italienisch, syrisch, libanesisch, serbisch und albanisch weisen im Vergleich zu Schüler*innen mit deutscher Staatsangehörigkeit zwei- bis mehr als dreimal so hohe Förderschulbesuchsquoten auf. Generell werden Förderschulen überproportional häufig von Schüler*innen mit Migrationshintergrund besucht (Weishaupt \& Kämper, 2009).

Eine systematische Benachteiligung von bestimmten Schüler*innengruppen wird darüber hinaus mit Blick auf die strukturellen Optionen des Systems, Schüler*innen zu verteilen und entsprechende Zugänge zu ermöglichen, offenkundig (Berkemeyer, Bos, Manitius, Hermstein, \& Khalatbari, 2013). Der einmal ergriffene Bildungsweg scheint schwer korrigierbar, so verbleiben ca. 90 Prozent der 
Schüler*innen, trotz der formalen Möglichkeit eines Schulwechsels, in der nach der Grundschule gewählten Schulform (El-Mafaalani, 2014). Bundesweit wechselten im Schuljahr 2011/2012 insgesamt 62.786 Schüler*innen der Klassenstufen 7 bis 9 die Schulform. Hierbei erfolgten mit 57,5 Prozent die meisten Wechsel in eine niedrigere Schulart, der Anteil der Aufwärtswechsel belief sich lediglich auf 13,6 Prozent. Die Differenz zu 100 Prozent ergibt sich dadurch, dass nur echte Wechsel und nicht auch Umstiege gezählt wurden (Berkemeyer, Bos, Manitius, Hermstein, \& Khalatbari, 2013). Anders formuliert kommen auf einen Aufwärtswechsel durchschnittlich 4,2 Wechsel in eine niedrigere Schulform, wobei das Verhältnis innerhalb der Ländergruppen sehr unterschiedlich ist. Trotz der formalen Möglichkeit eines Schulwechsels treten demnach Aufstiege in höhere Schulformen statistisch seltener ein als Korrekturen nach unten (vgl. hierzu auch: Baumert, Trautwein, \& Artelt, 2003; Tillmann \& Meier, 2001). Insbesondere Förderschüler*innen gelingt der Aufstieg in das System allgemeinbildender Schulen nur zu einem geringen Anteil: Im Schuljahr 2011/2012 vollzogen, im Hinblick auf die Jahrgangsstufen 7 bis 9, insgesamt 2.299 Schüler*innen den Wechsel von der Förderschule in das System allgemeinbildender Schulen. Dies entspricht einer Wechselquote von 2,2 Prozent (Berkemeyer, Bos, Manitius, Hermstein, \& Khalatbari, 2013). Betrachtet man zudem die Praxis der Klassenwiederholungen, ist ein weiterer sozial selektiv wirkender Mechanismus festzustellen: 21 Prozent aller befragten 15-Jährigen haben die Erfahrung einer Klassenwiederholung gemacht (ebd.), wobei überdurchschnittlich häufig Schüler*innen mit Migrationshintergrund (u. a. Diefenbach, 2010; Gomolla \& Radtke, 2009; Krohne, Meier, \& Tillmann, 2004) und niedrigem sozioökonomischen Status betroffen sind (u. a. Ditton, 2010b; Hillmert \& Jacob, 2005).

\section{Schulischer Kompetenzerwerb}

Darüber hinaus soll dargestellt werden, inwiefern es dem deutschen Schulsystem gelingt, alle Schüler*innen in ihrem Kompetenzerwerb zu fördern. Hierbei wird beispielhaft auf die Lesekompetenz von Schüler*innen am Ende der Primarstufe Bezug genommen. So ist einer der wichtigsten Befunde der PISA-Studien die für Deutschland im internationalen Vergleich enge Kopplung zwischen der sozialen Herkunft und dem Kompetenzstand (ebd.). Im Allgemeinen erzielen Kinder aus Familien der oberen Sozialschichten deutlich höhere Kompetenzwerte als Schüler*innen aus unteren sozialen Schichten. Vergleicht man die beiden Statusgruppen EGP-Klassen I-II sowie EGP-Klassen V-VII ${ }^{3}$ als Referenz für

\footnotetext{
${ }^{3}$ Für die Feststellung des sozialen Hintergrundes wird der Klassenindex von Erikson, Goldthorpe und Portocarero (1979), kurz: EGP-Klassenkonzept, verwendet. Das Schema
} 
die Darstellung oberer und unterer Sozialschichten miteinander, zeigt sich bundesweit ein durchschnittlicher Kompetenzunterschied von 81 Punkten, wobei zwischen den Bundesländern relativ große Differenzen bestehen (Berkemeyer, Bos, Manitius, Hermstein, \& Khalatbari, 2013). Die IGLU-Studie aus dem Jahr 2011 zeigt zudem, dass der Leistungsvorsprung im Leseverständnis der Schüler*innen aus Familien der oberen und unteren Dienstklasse (EGP-Klassen I-II) und Kindern aus Facharbeiter*innen- beziehungsweise un- und angelernten Arbeiter*innenfamilien (EGP-Klassen V-VII) bereits in der Grundschule zwischen 62 und 92 Punkten variiert, was etwa ein bis zwei Lernjahren entspricht (Wendt, Stubbe, \& Schwippert, 2012).

Ein weiterer zentraler Befund der PISA-Studien sind die hohen Leistungsrückstände von Schüler*innen mit Migrationshintergrund im Vergleich zu Schüler*innen ohne Migrationshintergrund ${ }^{4}$. Die Leistungsdifferenz in den erreichten Lesekompetenzpunkten zwischen Viertklässler*innen mit und ohne Migrationshintergrund bei gleichen sozioökonomischen Ressourcen liegt in Deutschland bei durchschnittlich 40 Leistungspunkten. Zwischen den Bundesländern variiert der Kompetenzrückstand von Schüler*innen mit Migrationshintergrund zwischen 36 und 53 Punkte. Das bedeutet, dass Schüler*innen mit Migrationshintergrund im Hinblick auf ihre Lesekompetenzen durchschnittlich ein Schuljahr hinter ihren Mitschüler*innen ohne Migrationshintergrund zurückliegen (Berkemeyer, Bos, Manitius, Hermstein, \& Khalatbari, 2013). Es muss jedoch berücksichtigt werden, dass Schüler*innen mit Migrationshintergrund in Deutschland durchschnittlich sozioökonomisch schlechtergestellt sind als Schüler*innen ohne Migrationshintergrund. So hängt ein signifikanter Anteil der Leistungsunterschiede zwischen Schüler*innen mit Migrationshintergrund und Schüler*innen ohne Migrationshintergrund vom sozioökonomischen Status ab (Vock \& Gronostaj, 2017).

Dezidierte Längsschnittstudien zur Leistungsentwicklung in der Schulzeit sind rar. Ditton und Krüsken (2009) können anhand ihrer Untersuchung in der Primarstufe zwar beträchtliche Leistungszuwächse in Mathematik und Deutsch sowie

basiert auf der beruflichen Klassifikation der Eltern, geordnet nach Art der Tätigkeit, der jeweiligen Stellung im Beruf, der Weisungsbefugnis sowie den erforderlichen Qualifikationen (Ehmke \& Jude, 2010).

${ }^{4}$ Kritisch anzumerken ist, dass es sich bei der Kategorie Schüler*innen mit Migrationshintergrund um keine homogene Gruppe handelt: Verschiedene Determinanten wie beispielsweise die Dauer des Aufenthaltes beziehungsweise der Aufenthaltsstatus, die Religionszugehörigkeit sowie die sozioökonomische Lage sind mit ungleichen Bildungschancen verbunden. Als Schüler*innen mit Migrationshintergrund werden nachkommend diejenigen Kinder berücksichtigt, die mindestens einen im Ausland geborenen Elternteil haben (Berkemeyer, Bos, Manitius, Hermstein, \& Khalatbari, 2013). 
einen Ausgleich des zuvor bestehenden Leistungsgefälles nachweisen, jedoch markieren sie auch einen deutlichen Zusammenhang zwischen schulischen Leistungen und sozialer Herkunft, wobei die Herkunftseffekte im Zeitverlauf nicht ab-, sondern bei gleichen Eingangsleistungen sogar zunehmen (ebd.). Die Analysen der Studie „Evaluation eines Vorschultrainings zur Prävention von Schriftspracherwerbsproblemen sowie Verlauf und Entwicklung des Schriftspracherwerbs in der Grundschule (EVES)“ von Zöller und Roos (2009) kommen zu sehr ähnlichen Ergebnissen: Sozioökonomische Merkmale der Herkunftsfamilie beeinflussen den deutschen Schriftspracherwerb erheblich. Kinder, deren Eltern ein vergleichsweise hohes Schulbildungsniveau aufweisen, erzielen im Verlauf der Primarstufe bessere Ergebnisse in Lese- und Rechtschreibtests als Schüler*innen aus schulbildungsfernen Familien. Zudem sind für Kinder aus schulbildungsfernen Familien trotz vergleichbarer intellektueller Voraussetzungen geringere Leistungszuwächse in der Schule zu verzeichnen (ebd.). Eine Vergrößerung der sozialen Disparitäten während der Schulzeit belegen auch Vergleiche der Ergebnisse aus der IGLUUntersuchung und der PISA-Studien im Zeitverlauf. So haben in der vierten Jahrgangsstufe Kinder un- und angelernter Arbeiter*innen im Lesen 14 Leistungspunkte weniger als Schüler*innen mit Eltern der oberen Dienstklasse, während bei den 15-Jährigen bereits eine Differenz von 33 Leistungspunkten besteht. Vergleichbare Tendenzen zeichnen sich in den Kompetenzbereichen Mathematik und Naturwissenschaften ab (Weißhuhn \& Große Rövekamp, 2004).

Die Befunde zur Schulleistungsentwicklung legen den Schluss nahe, dass soziale Ungleichheit hinsichtlich des Schulleistungsniveaus auch durch institutionelle bzw. schulsystemische Effekte verursacht werden. In der repräsentativen Längsschnittstudie „Bildungsverläufe und psychosoziale Entwicklung im Jugendalter (BIJU)“ können Baumert, Stanat und Watermann (2006) ,differenzielle Lern- und Entwicklungsmilieus“ (ebd.) für Schüler*innen je nach Schulform (Realschulen, Gymnasien und Gesamtschulen) im Zeitraum von der siebten bis zur zehnten Jahrgangsstufe dokumentieren. Das bedeutet, dass Heranwachsende unabhängig von und zusätzlich zu ihren individuellen Ressourcen je nach besuchter Schulform unterschiedliche Entwicklungschancen bekommen, die zum Beispiel durch unterschiedliche Lehrpläne, Unterrichtskulturen und Kompetenzen der Lehrkräfte bedingt sind. Etwa erreichen Realschüler*innen bis zum Ende der zehnten Klasse im Vergleich zu Jugendlichen an Gesamtschulen in Mathematik einen Leistungsvorsprung von ca. zwei Schuljahren; der Vorsprung des Fördereffekts an Gymnasien liegt bei mehr als zwei Schuljahren (ebd.). 


\section{Schulabschlüsse}

Mit der Zertifikatsvergabe des Schulsystems wird eine weitere statistisch signifikante Dimension von sozialer Ungleichheit beschrieben: Höherwertige Schulabschlüsse führen zu mehr beruflichen Anschlussmöglichkeiten und bestimmen demnach maßgeblich die weiteren formal möglichen gesellschaftlichen Teilhabechancen (Berkemeyer, Bos, Manitius, Hermstein, \& Khalatbari, 2013). Tabelle 1.3 gibt einen Überblick über die Abschlüsse der Absolvent*innen allgemeinbildender Schulen im Jahr 2011.

Tabelle 1.3 Abschlüsse der Absolvent*innen allgemeinbildender Schulen in Deutschland für das Jahr 2011. (Eigene Darstellung auf Grundlage von: Berkemeyer, Bos, Manitius, Hermstein, \& Khalatbari, 2013)

\begin{tabular}{|c|c|c|}
\hline Erreichter Abschluss & Anzahl & $\begin{array}{c}\text { Anteil an der gleichaltrigen } \\
\text { Wohnbevölkerung in Prozent }\end{array}$ \\
\hline Hauptschulabschluss & 163.284 & 21,2 \\
\hline $\begin{array}{c}\text { Realschulabschluss/ } \\
\text { mittlerer Abschluss }\end{array}$ & 338.071 & 41,5 \\
\hline Fachhochschulreife & 13.616 & 1,9 \\
\hline Allgemeine Hochschulreife & 310.811 & 31,8 \\
\hline & $\begin{array}{c}\text { Abgänger*innen und } \\
\text { Absolvent*innen insgesamt }\end{array}$ & davon Absolvent*innen \\
\hline & 875.254 & 96,4 \\
\hline
\end{tabular}

Insgesamt verließen im Jahr 2011 deutschlandweit 96,4 Prozent der Absolvent*innen die allgemeinbildenden Schulen mit einem Abschluss. Gemessen an der gleichaltrigen Wohnbevölkerung erwerben hierbei 21,2 Prozent der Schüler*innen einen Hauptschulabschluss, 41,5 Prozent einen mittleren Abschluss, 1,9 Prozent die Fachhochschulreife und 31,8 Prozent die allgemeine Hochschulreife. Somit stehen der steigenden Zahl an Absolvent*innen mit höherer Qualifikation immer weniger Absolvent*innen mit Hauptschulabschluss gegenüber. Der mittlere Abschluss gewinnt zunehmend an Bedeutung und macht mit 41,5 Prozent an der gleichaltrigen Bevölkerung die mit Abstand größte Gruppe unter allen Absolvent*innen aus. Bemerkenswert ist zudem, dass nahezu ein Drittel der Absolvent*innen eine Studienberechtigung erhalten. Bundesweit verließen im Jahr 2011 aber auch rund 49.560 Schüler*innen das allgemeinbildende Schulwesen ohne einen Hauptschulabschluss, wobei 57,9 Prozent der Abgänger*innen ohne Hauptschulabschluss aus der Förderschule stammen (Berkemeyer, 
Bos, Manitius, Hermstein, \& Khalatbari, 2013). Werden die Abgänger*innen differenziert nach ihrer Staatsangehörigkeit betrachtet, dokumentiert sich darüber hinaus eine hohe Differenz zwischen Schüler*innen mit deutscher und nichtdeutscher Staatsangehörigkeit: Schüler*innen nichtdeutscher Staatsangehörigkeit erlangen seltener die allgemeine Hochschulreife und tragen im Vergleich zu Jugendlichen mit deutscher Staatsangehörigkeit ein höheres Risiko, die Schule ohne Abschluss zu verlassen (Autorengruppe Bildungsberichterstattung, 2012). Zudem lassen sich Korrelationen zwischen den Schulabschlüssen der Eltern und denen der Kinder feststellen. So bleiben ca. 15 Prozent der Schüler*innen von Eltern ohne Schulabschluss ebenfalls ohne Schulabschluss, mit ca. 45 Prozent ist der Hauptschulabschluss in dieser Gruppe am verbreitetsten. Eine besonders hohe Schulbildungsvererbung ist bei Schüler*innen von Eltern mit der allgemeinen Hochschulreife sichtbar: 67 Prozent erwerben erneut die allgemeine Hochschulreife (Solga \& Dombrowski, 2009).

\section{Zwischenfazit}

Zusammengefasst zeigen die in dieser Darstellung ausgewählten Ergebnisse einschlägiger Schulleistungsstudien und die einbezogenen amtlichen Schulstatistiken, dass die soziale Herkunft für die Bildungsbiografie eine entscheidende Rolle spielt. Dem deutschen Bildungssystem gelingt es kaum, kompensierend zu wirken und herkunftsbedingte Nachteile auszugleichen - im Gegenteil: Innerhalb und zwischen den Bildungseinrichtungen wird soziale Ungleichheit während der Schulzeit sogar noch verstärkt. Der Überblick über soziale Disparitäten im Bildungssystem markiert nach wie vor großen Handlungsbedarf: Etwa besteht für Schüler*innen aus sozioökonomisch benachteiligten Lebensverhältnissen und Schüler*innen mit Migrationshintergrund durch die Feststellung des sonderpädagogischen Förderbedarfs ein erhöhtes Risiko, schulisch exkludiert zu werden, denn ein großer Anteil an Kindern und Jugendlichen mit sonderpädagogischem Förderbedarf wird nicht im System allgemeinbildender Schulen unterrichtet. Darüber hinaus haben diese Kinder und Jugendliche durchschnittlich schlechtere Bildungschancen als Gleichaltrige mit einem hohen sozioökonomischen Status bzw. ohne Migrationshintergrund: Sie sind häufiger von Klassenwiederholungen betroffen, zeigen über die gesamte Schullaufbahn geringere Kompetenzen im Lesen und verlassen die Schule häufiger ohne einen allgemeinbildenden Abschluss. 


\subsection{Erklärungen und Befunde zur Rolle der Schule und Lehrkräfte bei der Entstehung und Verstärkung sozialer Ungleichheit}

Bereits in den 1960er Jahre machten bildungssoziologische Studien im Kontext der im internationalen Vergleich geringen Bildungsbeteiligung in den weiterführenden Schulen auf ausgeprägte soziale Disparitäten im deutschen Bildungssystem aufmerksam (Geißler, 2005). Mit der Veröffentlichung der Ergebnisse der ersten PISA-Studie im Jahr 2001 (Baumert, et al., 2001) ist die soziale Ungleichheit in Schule von Neuem in das Blickfeld von Politik, Öffentlichkeit und Wissenschaft gerückt (Maaz, Baumert, \& Trautwein, 2010). Trotz reger Forschungstätigkeit und gleichwohl damit einhergehende Diagnosen und Befunde längst Eingang in das schulische Feld und in bildungs- und sozialpolitische Debatten und Reformen gefunden haben (Betz, 2015), wurde der „Teufelskreis von intra- und intergenerationaler Reproduktion von sozialen Ungleichheiten und Bildungsungleichheiten" (Solga \& Dombrowski, 2009, S. 7) in den letzten Jahrzehnten nicht ansatzweise aufgebrochen. Die Erforschung bildungsbezogener Ungleichheit ist längst nicht abgeschlossen und es besteht nach wie vor die Notwendigkeit, Erklärungsmodelle für den Reproduktionszusammenhang von sozialen Herkunftsbedingungen und schulischen Erfolgsaussichten sowie Möglichkeiten zum Abbau von sozialer Ungleichheit im deutschen Bildungssystem zu identifizieren (Betz, 2015).

Im Folgenden werden zwei klassische theoretische Zugangswege erörtert, die sich mit der Frage auseinandersetzen, wie die fortdauernde hohe soziale Selektivität im Bildungssystem erklärt werden kann: der Rational-Choice-Ansatz nach Raymond Boudon (Abschnitt 1.2.1) sowie Pierre Bourdieus Theorie der sozialen Praxis (Abschnitt 1.2.2). An das jeweilige Teilkapitel anschließend werden einzelne empirische Untersuchungen zusammengetragen, die sich (vorwiegend) entweder auf der Seite der quantitativen oder der qualitativen Sozialforschung verorten lassen. Mithilfe der Erklärungsansätze und Erkenntnisse soll systematisch die Rolle der Schule und Lehrkräfte bei der Perpetuierung und der Verringerung sozialer Ungleichheit herausgearbeitet werden. Wie noch genauer dargelegt wird, ist die Vorstellung gerade dieser zum Teil unterschiedlichen paradigmatischen Perspektiven deshalb vielversprechend, da sie sich nicht wechselseitig ausschließen, sondern in Beziehung zueinander setzen lassen. Dieses Teilkapitel abrundend werden ausgewählte, für diese Arbeit besonders bedeutsame Studien vorgestellt, die mit unterschiedlicher theoretischer Perspektive und Methodik Sichtweisen auf und den praktischen Umgang mit Schüler*innen ungleicher sozialer Herkunft in 
Schule und Unterricht analysieren und somit einen Beitrag zur Erklärung sozialer Bildungsungleichheit leisten (Abschnitt 1.2.3).

\subsubsection{Bildungsungleichheit aus der Perspektive des Rational-Choice-Ansatzes von Raymond Boudon}

In der Bildungs- und Sozialstrukturforschung besteht Einigkeit über die zentrale Bedeutung von Bildungsübergängen für die Entstehung und Persistenz von Bildungsungleichheit (Becker \& Lauterbach, 2010). Bereits in den 1970er Jahren setzte sich Boudon mit den Selektionsentscheidungen im Bildungssystem auseinander und analysierte herkunftsbedingte Unterschiede bei der Wahl von Bildungswegen (Maaz, Baumert, \& Trautwein, 2010). Boudon (1974) zufolge wird Bildungsungleichheit als Ergebnis familialer Entscheidungen verstanden, die innerhalb des institutionellen Rahmens des Bildungssystems getroffen werden müssen (ebd.). Hierbei ergeben sich die Bildungsentscheidungen ,,aus der gezeigten schulischen Leistung, den Selektionsmechanismen des jeweiligen Bildungssystems und der familiären Bewertung von Bildung“ (Maaz, Baumert, \& Trautwein, 2010, S. 71). Zur Erklärung dieses Zusammenspiels und der Reproduktion sozialer Ungleichheit im Bildungssystem unterscheidet Boudon primäre und sekundäre Herkunftseffekte. Unter primären Herkunftseffekten wird der unmittelbare Einfluss der sozialen Herkunft auf die Kompetenzentwicklung und Schulleistungen der Schüler*innen verstanden. Je nach Sozialschicht variierende Kompetenz- und Leistungsunterschiede resultieren aus der unterschiedlichen Ausstattung von Familien mit materiellen und immateriellen Ressourcen und der schichtspezifischen Bezugnahme auf Kultur, Lernen und Bildung (Maaz, Baumert, \& Trautwein, 2010b). Sekundäre Herkunftseffekte benennen im Unterschied dazu schichtspezifisch ungleiche Bildungsaspirationen und davon abhängige Entscheidungsprozesse, in denen Schüler*innen und Eltern erwartete Kosten und Nutzen höherer Bildung und die Erfolgswahrscheinlichkeit im Sinne einer rational-ökonomischen Investition abwägen. Ein hohes Bildungsziel anzusteuern, ist für Familien aus sozial benachteiligten Lebensverhältnissen mit höheren Kosten bei gleichzeitiger Sorge, zu scheitern verbunden. Sie müssen demnach über höhere Bildungsaspirationen verfügen, da die soziale Distanz größer ist als bei sozial privilegierten Familien (Boudon, 1974). Die folgende Abbildung gibt einen Überblick über Boudons Konzept für die Entstehung und Reproduktion von Bildungsungleichheit (Abbildung 1.2). 


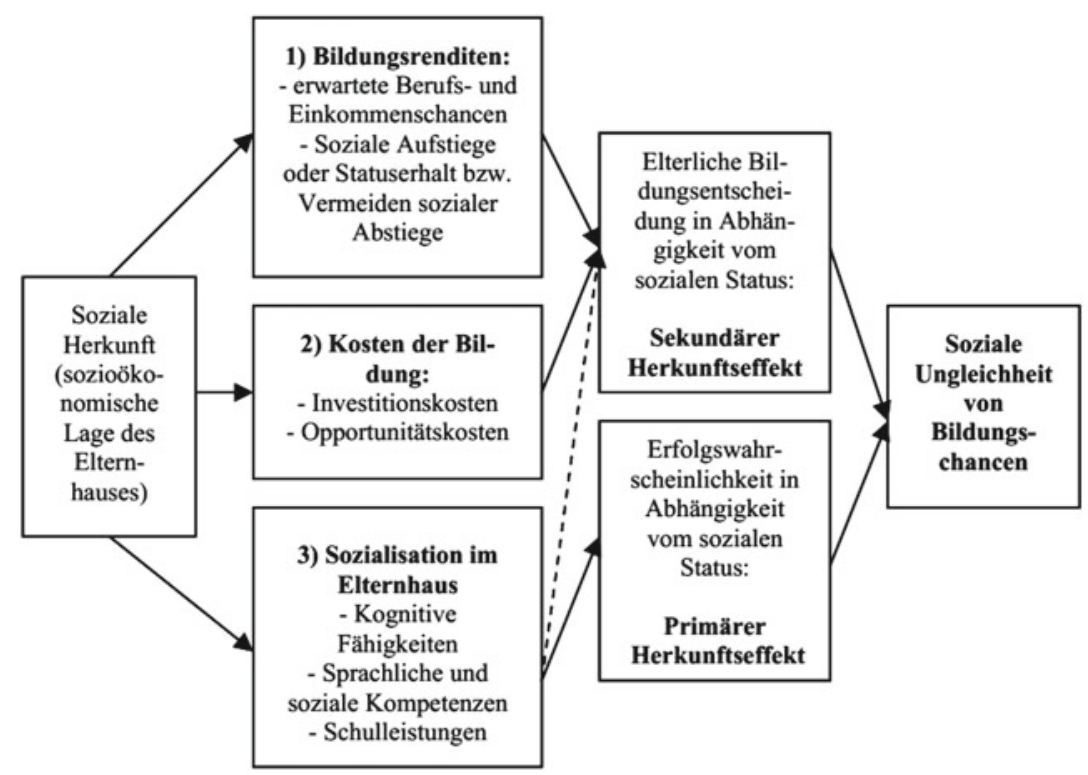

Abbildung 1.2 Modell für die Entstehung und Reproduktion von sozialer Ungleichheit der Bildungschancen nach Boudon (Becker, 2010)

Unmittelbar anknüpfend an Boudons konzeptionelle Unterscheidung zwischen primären und sekundären Herkunftseffekten entstanden in Folge weitere ausdifferenziertere werterwartungstheoretische Erklärungsmodelle, die sich in zahlreichen empirischen Studien bewährten (Becker, 2000; Esser, 1999; Breen \& Goldthorpe, 1997; Erikson \& Jonsson, 1996). Unterschiede zwischen den Modellen bestehen in der Gewichtung von primären und sekundären Herkunftseffekten, der Erweiterung um zusätzliche Variablen und in der Berücksichtigung institutioneller Regelungen des Bildungssystems (Maaz, Baumert, \& Trautwein, 2010). Da für die vorliegende Untersuchung die Rolle der Lehrkräfte bei Reproduktionsprozessen sozialer Ungleichheit von besonderem Interesse ist, werden im Folgenden empirische Studien betrachtet, die die Leistungsbewertungen und Übergangsempfehlungen der Lehrkräfte ausdrücklich in ihren Analysen miteinbeziehen. 


\section{Der Forschungsstand zu Wirkungsweisen der Lehrkräfte auf primäre und sekundäre Herkunftseffekte}

Der hier knapp skizzierte Rational-Choice-Ansatz basiert auf einer umfangreichen empirischen Grundlage; in Bezug auf die Übergänge im deutschen Bildungssystem liegen zahlreiche Studien vor (u. a. Mudiappa \& Artelt, 2014; Kleine, Birnbaum, Zielonka, Doll, \& Blossfeld, 2010; Paulus \& Blossfeld, 2007). So wurde die Relevanz der sozialen Herkunft für die Schulleistungen von Kindern und Jugendlichen anhand internationaler Schulleistungsstudien wie PISA, TIMSS und IGLU sowie nationaler Untersuchungen wiederholt und eindrücklich nachgewiesen (u. a. Hußmann, et al., 2017; Wendt, et al., 2016; Vieluf, Ivanov, \& Nikolova, 2014; Lehmann, Peek, Gänsfuß, \& Husfeldt, 2011; Klieme, et al., 2010). In Abschnitt 1.1 wurde exemplarisch anhand der Grundschulstudie IGLU 2011 gezeigt, dass sich der sozioökonomische Status nachteilig auf die schulische Kompetenz- und Leistungsentwicklung der Schüler*innen auswirkt und Schüler*innen aus sozial bessergestellten Familien am Ende der vierten Klasse im Durchschnitt leistungsstärker im Lesen sind als Schüler*innen aus sozial schlechtergestellten Familien. Zwischen den Schüler*innen aus der oberen und unteren Dienstklasse und Schüler*innen aus Familien un- und angelernter Arbeiter*innen klafft im Leseverständnis in der vierten Klasse eine Kompetenzlücke von bis zu 92 Testpunkten, was etwa zwei Lernjahren entspricht (Wendt, Stubbe, \& Schwippert, 2012). Die schulischen Leistungen determinieren überdies in beträchtlichem Maß den Übergansprozess von der Grundschule in die weiterführende Schule. Etwa belegt dieselbe Grundschulstudie auch, dass bei vergleichbaren kognitiven Fähigkeiten und Lesekompetenzen die Chance, eine Empfehlung der Lehrkräfte für das Gymnasium zu erhalten, für Schüler*innen aus der oberen Dienstklasse 3,14-mal so hoch ist wie für Schüler*innen aus der Klasse der (Fach-)Arbeiter*innen. Die Chance für eine Gymnasialpräferenz der Eltern aus der oberen Dienstklasse ist 3,76-mal so hoch wie in der Klasse der (Fach-)Arbeiter*innen und damit etwas stärker als die Empfehlung der Lehrkräfte (ebd.).

Aus den Ergebnissen der IGLU-Studie leiten einige Vertreter*innen des Rational-Choice-Ansatzes ab, ,dass die Empfehlungen der Lehrer sehr viel weniger an die soziale Herkunft gekoppelt sind als die Bildungsaspirationen der Eltern [...] und „sozial korrigierend“ und sozial selektiv zugleich“ (Maaz, Baumert, \& Trautwein, 2010, S. 77) wirken. Je nachdem, welche weiteren empirischen Studien bzw. Autor*innen herangezogen werden, lässt sich diese Annahme stützen. Etwa analysieren Ditton, Krüsken und Schauenberg (2005) in einer Längsschnittuntersuchung an bayerischen Grundschulen die Bildungspräferenzen der Eltern in der Gegenüberstellung zu den Grundschulempfehlungen. Bei vergleichbaren Schulleistungen der Kinder war die Chance, dass sich Eltern mit der 
Hochschulreife für ihr Kind das Gymnasium anstelle einer anderen Schulform wünschen, 8,84-mal so groß wie die von Eltern mit einem Hauptschulabschluss. Für die Empfehlung der Lehrkräfte zeigt sich ein deutlich schwächer ausgeprägter sekundärer Herkunftseffekt: Schüler*innen, deren Eltern die Hochschulreife vorweisen, haben eine 3,92-mal höhere Chance auf eine Gymnasialempfehlung als Schüler*innen, deren Eltern einen Hauptschulabschluss haben. Die Autor*innen entnehmen den Befunden, dass sich die Empfehlungen der Lehrkräfte stärker an den schulischen Leistungen der Kinder orientieren als die Bildungsaspirationen der Eltern (ebd.). Dumont, Maaz, Neumann und Becker (2014) kommen in ihrem Überblick über den aktuellen Forschungsstand zu sozialen Disparitäten beim Übergang in die Sekundarstufe I ebenfalls zu dem Schluss, dass „,trotz der familiären Herkunftseffekte auf die Schullaufbahnempfehlungen [...] jedoch gesagt werden [muss], dass die Empfehlungen von Lehrkräften weitaus weniger durch die familiäre Herkunft beeinflusst sind als die Schullaufbahnwünsche der Eltern.“ (ebd., S. 149). Die Autor*innen untermauern ihre Position, indem sie auf schichtspezifische Abweichungen von der Schullaufbahnempfehlung bei dem Übergangsprozess in die Sekundarstufe I hinweisen. So zeigen Pietsch und Stubbe (2007) anhand der IGLU-Daten für ausgewählte Bundesländer, dass sich Eltern aus privilegierteren Sozialschichten häufiger für eine höhere Schulform als die von der Lehrkraft empfohlene entscheiden, wohingegen sozial benachteiligte Eltern zu Abweichungen nach unten neigen (vgl. hierzu auch: Harazd \& van Ophuysen, 2008; Cortina, 2003). Hierbei ist kein Effekt von verbindlichen im Vergleich zu unverbindlichen Übergangsempfehlungen nachweisbar (u. a. Roth \& Siegert, 2015; Maaz, Baumert, Gresch, \& McElvany, 2010). Pietsch und Stubbe (2007) stellen bezüglich des Einflusses des sozialen Hintergrundes eine dreifache Benachteiligung fest: Erstens bringen Schüler*innen aus sozioökonomisch benachteiligten Verhältnissen aufgrund ihrer Sozialisation geringere Kompetenzen für das schulische Lernen mit, zweitens erhalten sie bei gleichen Schulleistungen schlechtere Noten und Schullaufbahnempfehlungen und drittens wechseln sie bei gleichen Empfehlungen häufiger auf eine niedrigere Schulform (ebd.).

Gegen diesen Standpunkt lässt sich einwenden, dass seit der ersten IGLUStudie 2001 im Zeitverlauf eine Zunahme der sozialen Disparitäten bei den Empfehlungen der Lehrkräfte zu beobachten ist. So ist in der IGLU-Studie 2001 unter Kontrolle der kognitiven Fähigkeiten und der Lesekompetenzen die Chance für eine Gymnasialempfehlung der Lehrkräfte für Schüler*innen aus der oberen Dienstklasse im Vergleich mit Schüler*innen aus der Klasse der (Fach)Arbeiter*innen 2,63-mal höher - in der IGLU-Studie 2016 ist die Chance eines Kindes aus der oberen Dienstklasse, eine Gymnasialempfehlung der Lehrkräfte zu erhalten, hingegen 3,37-mal höher (Stubbe, Bos, \& Schurig, 2017). Zugleich 
lässt sich ein umgekehrter Trend seit der IGLU-Studie 2006 für die Schullaufbahnpräferenzen der Eltern konstatieren. Ebenfalls unter Kontrolle der kognitiven Fähigkeiten und der Lesekompetenz ist die Chance für eine Gymnasialpräferenz der Eltern aus der oberen Dienstklasse in der IGLU-Studie 2006 3,83-mal so hoch wie in der Klasse der (Fach-)Arbeiter*innen. Im Gegensatz dazu ist in der IGLUStudie 2016 in der oberen Dienstklasse die Chance 3,44-mal so hoch wie in der Klasse der (Fach-)Arbeiter*innen (ebd.).

Es gibt auch am Rational-Choice-Ansatz orientierte Studien, die den Beitrag der Lehrkräfte bei der Perpetuierung sozialer Ungleichheit an den Übergängen im deutschen Schulsystem differenzierter betrachten. Zum Beispiel konkretisieren Maaz, Baeriswyl und Trautwein (2011) in der Studie „Herkunft zensiert? Leistungsdiagnostik und soziale Ungleichheit in der Schule“ das Verhältnis von primären und sekundären Herkunftseffekten. Hierbei weisen die Autoren selbst nach Kontrolle der Leistung in standardisierten Leistungstests einen statistisch signifikanten Zusammenhang zwischen sozialer Herkunft und Benotung, Schullaufbahnempfehlung sowie tatsächlich realisierten Übergangsentscheidungen nach. Für alle drei Aspekte können primäre und sekundäre Effekte belegt werden, wobei bei den Leistungsbewertungen der Anteil primärer Effekte größer ist als der der sekundären Effekte. Bei der Empfehlungsvergabe sind beide Herkunftseffekte gleich groß und beim Übergangsverhalten überwiegt der sekundäre Effekt (ebd.). Die Sekundäranalyse verschiedener Schulleistungsstudien ermöglicht darüber hinaus, eine relative Bedeutung und Chronologie primärer und sekundärer Effekte in Bezug auf den Übergang von der Grundschule in die weiterführende Schule genauer darzulegen. So werden Herkunftseffekte auf die Übergangsempfehlung zur Hälfte auf Leistungsunterschiede bzw. den primären Effekt zurückgeführt, ein Viertel auf schichtabhängige Benotungspraxen sowie ein Viertel auf schichtabhängige Laufbahnempfehlungen. Das bedeutet, dass rund die Hälfte unerwünschter sozialer Disparitäten beim Übergang in die Sekundarstufe I auf sozialschichtabhängigen Verzerrungen der Schüler*innenbewertungen basieren (ebd.). Beim tatsächlichen Übergang geht offenbar der Anteil des primären Effekts und vor allem derjenige der ungleichen Einbeziehung in dem sekundären Effekt auf. Im Hinblick darauf, dass Schulleistungen in die elterliche Entscheidung einfließen, bereiten Lehrkräfte mit leistungsfremder Notengebung nicht nur ihre eigene Empfehlung vor, sondern beeinflussen auch die Elternentscheidung.

Bereits zu Beginn der siebziger Jahre macht Ingenkamp (1971) auf die „Fragwürdigkeit der Zensurengebung“" aufmerksam. Auf Grundlage deutschsprachiger Forschung stellt er fest, dass es sich zumeist um subjektive Bewertungen handelt und Lehrkräfte auf ein klasseninternes Bezugssystem zurückgreifen, sodass es zu erheblichen Unterschieden zwischen einzelnen Lehrpersonen und 
Unterrichtsfächern kommt. Für die Leistungsbeurteilungen und Übergangsempfehlungen sind Persönlichkeitseigenschaften entscheidend, mit der die Lehrkräfte ihre Verhaltenserwartungen an die Schüler*innen bestimmen. Dabei werden auch geschlechts- und herkunftsspezifische Stereotype wirksam (ebd.). Diese Befunde haben an Aktualität nicht verloren, etwa präzisiert rezente Forschung zu Lehrer*innenurteilen leistungsfremde Kriterien wie beispielsweise je nach sozialer Herkunft variierende Einschätzungen von Begabung, Lernmotivation und Anstrengungsbereitschaft (Anders, McElvany, \& Baumert, 2010), antizipierte elterliche Unterstützungsmöglichkeiten (Nölle, Hörstermann, Krolak-Schwerdt, \& Gräsel, 2009) und ökonomische Ressourcen der Familie (Bos \& Pietsch, 2007), die von den Lehrkräften leistungsbezogen gewendet werden. Einen ungleichheitsverstärkenden Effekt können hier sogenannte Cooling-Out-Prozesse (Goffman, 1952) haben, die eine Abnahme der Bildungsaspiration, Motivation und Anstrengungsbereitschaft sowie Störungen in der Entwicklung eines positiven Selbstkonzepts für solche Schüler*innen beschreiben, die während ihrer Schullaufbahn wiederholt Misserfolgserfahrungen durchleben (Bremm, Racherbäumer, \& van Ackeren, 2017). Dass Lernfähigkeit und Schulleistungen nicht einwandfrei korrelieren zeigen Uhlig, Solga und Schupp (2009) darüber hinaus unter dem Stichwort des Underachievement. Den Autor*innen zufolge besucht etwa ein Viertel aller Haupt- und Realschüler*innen in Deutschland eine Schulform, die unterhalb ihrer kognitiven Fähigkeiten liegt. Das Risiko für Underachievement ist für Schüler*innen, bei denen kein Elternteil die allgemeine Hochschulreife hat, drei Mal so hoch wie bei Schüler*innen, bei denen mindesten ein Elternteil Abitur hat (ebd.). Für den anglo-amerikanischen Raum kann Sorhagen (2013) Zusammenhänge zwischen Fehleinschätzungen der Leistungsfähigkeit von Kindern in der dritten Klasse und ihren gemessenen Schulleistungen im Alter von 15 Jahren nachzeichnen. Wurde die Leistungsfähigkeit in der frühen Schulzeit verglichen mit Leistungstest unterschätzt, erreichten Schüler*innen in der neunten Klasse signifikant schlechtere Schulleistungen in Mathematik, im Leseverständnis und im Wortschatz sowie im verbalen Argumentieren. Zudem zeigt sich, dass die Fehleinschätzungen von Lehrkräften in der dritten Klasse einen signifikant stärkeren Einfluss auf die Leistungsentwicklung von Schüler*innen aus sozial benachteiligten Familien hat (ebd.).

Überdies seien noch qualitative Studien erwähnt, die die Sichtweisen und Entscheidungskriterien von Lehrkräften bei schulischen Übergängen beleuchten und somit zur Erklärung beitragen, weshalb Kinder aus einem schulbildungsnahen Elternhaus eher auf ein Gymnasium überwiesen werden. Etwa kommt Hollstein (2008) auf Grundlage von Interviews mit Grundschullehrkräften und Schulleiter*innen zu dem Schluss, dass Lehrkräfte unterschiedliche Kriterien bei 
den Grundschulempfehlungen heranziehen, z. B. das Arbeitsverhalten und die Motivation, die psychische Belastbarkeit oder das Durchsetzungsvermögen der Schüler*innen, aber auch das spezifische Angebot an weiterführenden Schulen. Des Weiteren stellen Vorstellungen der Lehrkräfte vom sozialen Kontext ein Kriterium dar, wenn sogenannte Grenzfälle vorliegen. Beispielsweise werden bei Schüler*innen, die von ihren Schulleistungen her nicht eindeutig für eine höhere Schulform überzeugen, Vermutungen darüber angestellt, über welche Art von familialer Unterstützung das Kind im Bedarfsfall verfügt. Meist fällt „zum Wohle des Kindes“ (ebd., S. 2610) die Wahl auf die niedrigere Schulform, um das Kind vor Belastungen und Misserfolge zu schützen. Hierbei argumentieren die Lehrkräfte, dass aufgrund der Durchlässigkeit des Schulsystems kein Nachteil entsteht (ebd.). Gomolla und Radtke (2009) rekonstruieren ähnliche Muster wie Hollstein. Die Autor*innen stellen heraus, dass zwar die Zuteilung von Schüler*innen auf weiterführende Schulen ressourcengesteuert und unabhängig von kultureller Differenz verläuft, aber Lehrkräfte vermeintlich defizitäre deutsche Sprachkenntnisse beziehungsweise Defizite in der Bildungssprache sowie kulturalisierende Deutungen als Indikatoren für das Lern- und Leistungsvermögen der Schüler*innen mit Migrationshintergrund nutzen, um mehrdeutige Übergangsentscheidungen zu plausibilisieren und zu legitimieren. So werden in Schulen ohne separate Vorbereitungs-, Auffang- oder Förderklassen Kinder mit mangelnden Deutschkenntnissen vermehrt in den Schulkindergarten oder in den Kindergarten zurückgestellt. Eine gängige Begründung für die Zurückstellung ist die Verknüpfung von deutschsprachlichen Defiziten mit anderen Entwicklungsrückständen (ebd.). Mit der Argumentation, dass „,perfekte Deutschkenntnisse“ (ebd., S. 244) und eine „angemessene Arbeitshaltung und -motivation im Elternhaus" (ebd., S. 254) für den Übergang auf ein Gymnasium notwendige Kriterien seien, werden darüber hinaus selbst bei guten Schulleistungen häufiger Haupt- und Realschulempfehlungen statt Gymnasialempfehlungen seitens der Schule ausgesprochen (ebd.). Die Studie zur institutionellen Diskriminierung von Gomolla und Radtke wird oft zitiert und bestätigt. Beispielsweise untersucht Weber (2005) aus einer intersektionalen Perspektive das Zusammenspiel ethnischer, geschlechtlicher und sozialer Dimensionen in schulischen Selektionsprozessen und rekonstruiert, wie Kinder aufgrund des familialen Hintergrundes nicht auf das Gymnasium zugelassen und zudem aufgrund sozialer Konflikte vom Gymnasium abgeschult werden. Den Lehrkräften scheint hierbei ihr Einfluss auf ungleichheitsreproduzierende Wahrnehmungsmuster und Rechtfertigungen nicht bewusst zu sein, so legitimieren sie ihre Entscheidung bspw. mit nicht ausreichender „Begabung“ (ebd., S. 72). 


\section{Zwischenfazit}

Grundsätzlich ändern die Studien zur sozialen Ausrichtung schulischer Leistungsbewertungen und Übergangsempfehlungen der Lehrkräfte wenig daran, dass Lehrkräfte aus der Perspektive des Rational-Choice-Ansatzes kaum für die Entstehung und Verstärkung von Bildungsungleichheiten verantwortlich gemacht werden (Kramer, 2015). Der zentralen Annahme von Boudon (1974) folgend, dass die elterlichen Bildungsentscheidungen in Form von individuellen KostenNutzen-Kalkulationen zum Zeitpunkt des Übergangs in die Sekundarstufe I ausschlaggebend für die Entstehung und Verstärkung von Bildungsungleichheit sind, gewichten die Vertreter*innen des Rational-Choice-Ansatzes die sekundären Herkunftseffekte stärker als die primären Herkunftseffekte (Becker \& Lauterbach, 2010). Aufgrund dieser Hierarchisierung der Relevanz primärer und sekundärer Herkunftseffekte wird den Lehrkräften nach Kramer (2015) ein eher kompensatorischer Einfluss auf Bildungsungleichheit zugeschrieben. Zugespitzt formuliert er, dass die Lehrkräfte aus dem Blickwinkel des Rational-Choice-Ansatzes als „Transformationsakteure“ (ebd., S. 344) von Bildungsungleichheit erscheinen. Aus Kramers Sicht liegt jedoch in der stärkeren Gewichtung der sekundären Herkunftseffekte ,ein folgenreicher Kategorienfehler, weil damit etwas zum zentralen Primat erhoben wird, was doch theoretisch-konzeptionell ein sekundärer Effekt wäre" (Kramer, 2011, S. 119). Der blinde Fleck des Rational-Choice-Ansatzes besteht demnach darin, dass Leistung als Herkunftsmerkmal modelliert wird und damit der Anteil der innerschulischen Konstruktion von Leistung keine Beachtung erfährt.

Neben der Konzeptionierung der sekundären Herkunftseffekte als zentrales Problem von Bildungsungleichheit, mag dieses Desiderat auch forschungspraktischen Aspekten geschuldet sein: Die Prozessierung der primären Herkunftseffekte in der Schule können in den Schulleistungsstudien ungleich schwerer in den Blick genommen werden als die Bildungsentscheidungen im Übergang zwischen Primar- und Sekundarstufe (Dietrich, Heinrich, \& Thieme, 2013). Ungeachtet dieser forschungspraktischen Herausforderung erscheint die systematische Betrachtung der Wirkung der pädagogischen Arbeit auf die Schulleistungen und die Lernentwicklung auch im Kontext des deutschen Bildungssystems aufschlussreich. Denn obgleich schulischer Lernerfolg multikausal bedingt ist (Lotz \& Lipowsky, 2015), stellen zahlreiche Untersuchungen im englischsprachigen Raum den bedeutsamen Beitrag der Lehrkräfte im Vergleich zu anderen Einflussquellen heraus. Hervorzuheben ist hierbei die ausgesprochen umfangreiche Studie „Visible Learning“ von Hattie (2008), der auf Basis einer Synthese von über 800 Metaanalysen zu dem Schluss kommt, dass positive Beziehungen zwischen Lehrkräften und Schüler*innen, die auf Kooperation und Akzeptanz 
beruhen, die Glaubwürdigkeit der Lehrperson bei den Schüler*innen, das im Unterrichtsprozess gegebene Feedback an die Schüler*innen sowie die Klarheit und Verständlichkeit der Lehrer*innensprache wesentlich für gelingendes schulisches Lernen sind (ebd.). Insbesondere internationale Forschung zu Schulen in sozial benachteiligter Lage, denen es trotz herausfordernder Rahmenbedingungen gelingt, messbar gute Leistungsergebnisse und Lernfortschritte von Schüler*innen zu erreichen, weist ebenfalls auf die Ebene der Lehrkräfte hin. So kann neben klassischen Merkmalen der Schul- und Unterrichtsqualität (bspw. Innovationsbereitschaft, Kooperationspraxis und adaptive Unterrichtsgestaltung) die Fähigkeit von Lehrkräften, eine tragfähige Beziehung zu ihren Schüler*innen aufzubauen, sowie hohe Erwartungen an die schulische Leistungsfähigkeit als Schlüsselfaktoren für den Lernerfolg identifiziert werden (u. a. Racherbäumer \& van Ackeren, 2015; Rutledge, Cohen-Vogel, Osborne-Lampkin, \& Roberts, 2015; Smyth, 2014; Roorda, Koomen, Spilt, \& Oort, 2011). Vor dem Hintergrund, dass positive Lehrer*innen-Schüler*innen-Beziehungen erwiesenermaßen förderlich für die Lernbereitschaft und das Selbstkonzept und somit auch für die Entwicklungsprozesse der Schüler*innen sind (u. a. Kuhn \& Fischer, 2014; Sabol \& Pianta, 2012; Pianta \& Allen, 2008), geben einzelne Untersuchungen überdies Hinweise darauf, dass sie eine Möglichkeit darstellen, der sozialen Benachteiligung der Schüler*innen zu begegnen. Etwa legen Befunde aus der Schulstudie „Handlungs- und Bildungskompetenzen funktionaler Analphabeten (HaBil)“ (Drucks, Osipov, \& Quenzel, 2010) den Schluss nahe, dass Lehrkräfte die Entwicklung von Bildungschancen begünstigen können: In der HaBil-Untersuchung kann nachgewiesen werden, dass insbesondere die Bereitschaft von Lehrkräften, Schüler*innen unabhängig von deren schulischen Leistungsstand individuell wahrzunehmen und für schulische Bemühungen anzuerkennen, die Lernmotivation fördert und Schulentfremdung verhindert. Lehrkräfte haben den Autor*innen zufolge großen Einfluss auf die Voraussetzungen zu lebenslangem Lernen und somit auf die Lebenschancen insbesondere von sozial benachteiligten Schüler*innen (ebd.). Auch mit Blick auf Kinder und Jugendliche mit sonderpädagogischem Förderbedarf in allgemeinbildenden Schulen zeigt sich, dass der professionelle Umgang der Lehrkraft mit der Vielfalt in der Klasse und die Gestaltung der Beziehung zwischen Lehrenden und Lernenden wichtige Determinanten für die Lernmotivation und eine gelingende soziale Integration in der Schule sind (Gronostaj, Kretschmann, Westphal, \& Vock, 2015). Können Schüler*innen hingegen keine positiven Beziehungen zu ihren Lehrkräften aufbauen, führt dies im Umkehrschluss zu geringerer Motivation, einem schlechteren Selbstkonzept und einer minimaleren Leistungsentwicklung (u. a. Baker, 2006; DiLalla, Marcus, \& Wright-Philipps, 2004). In diesem Zusammenhang ermitteln McGrath und Van Bergen (2015) 
auf Grundlage einer Revision des englischsprachigen Forschungsstandes folgende Risikomerkmale für instabilere Beziehungen zu Lehrkräften: männliches Geschlecht, Angehörigkeit zu einer gesellschaftlichen Minoritätsgruppe, niedriger sozioökonomischer Status, diagnostizierte Lernauffälligkeiten und schlechtere Schulleistungen (ebd.). Studien, die sich mit negativen und positiven Erwartungseffekten beschäftigen, können seit Ende der 1960er Jahren darüber hinaus wiederholt zeigen, dass hohe Erwartungen von Lehrkräften an die Lernfähigkeit von Schüler*innen einen positiven Einfluss auf die Schulleistungen haben (u. a. Archambault, Pagani, \& Fitzpatrick, 2013; Demanet \& Van Houtte, 2012; erstmals zum sogenannten Pygmalion-Effekt: Rosenthal \& Jacobson, 1968). Demgegenüber steht die Erkenntnis, dass geringe Erwartungen von Lehrkräften als selbsterfüllende Prophezeiung (Merton, 1948) negativ auf den Lernerfolg der Schüler*innen wirken (Becker \& Birkelbach, 2013). Unterdessen sind die Vorannahmen der Lehrkräfte in Bezug auf die zukünftige Leistungsfähigkeit der Schüler*innen durch stereotype Einstellungen entlang der Differenzlinien Ethnizität, soziale Herkunft und Geschlecht geprägt (u. a. Brault, Janosz, \& Archambault, 2014; Agirdag, van Avermaet, \& Van Houtte, 2013; Tenenbaum \& Ruck, 2007).

Bemerkenswert ist darüber hinaus, dass das herkunftsspezifische Entscheidungsverhalten nur aufseiten der Schüler*innen- und Elternschaft untersucht und als relevant erachtet wird und sich nahezu keine Arbeiten finden, die dem sozialen Hintergrund von Lehrkräften eine vergleichbare Beachtung schenken. So spielt die soziale Herkunft der Lehrkräfte innerhalb des Rational-ChoiceAnsatzes hinsichtlich des beruflichen Handelns bzw. bei der Modellierung von Leistungsbewertungen und Übergangsempfehlungen der Lehrkräfte und ihrem Einfluss auf die Reproduktion von Bildungsungleichheit keine Rolle (Betz, 2015). Obschon ein ähnlich sozial selektives Entscheidungsverhalten wie im Fall der Eltern auch für die Übergangsempfehlungen der Lehrkräfte nachgewiesen werden kann, wäre nach Ditton (2010a) erst noch zu prüfen, ,,inwieweit das Modell auch zur Erklärung von Handlungsweisen und Bildungsempfehlungen von Lehrkräften verwendet werden kann“ (ebd., S. 254). Dabei gibt er zu bedenken, dass eine rationale Entscheidung im Sinne einer Nutzenmaximierung über den weiteren Bildungsweg eines Kindes nach der Grundschule für Lehrkräfte und Eltern eine unterschiedliche Bedeutung hat. Je nachdem, ob die Perspektive der Eltern oder der Lehrkräfte eingenommen wird, könnte der Bezugspunkt der Kalkulation das einzelne Kind, die Familie, die abgebende und aufnehmende Schule oder schließlich die gesamte Gesellschaft sein (ebd.).

Ferner macht Rieger-Ladich (2011) darauf aufmerksam, dass die meisten Lehrkräfte nicht um den Grad ihrer Involviertheit in Reproduktionsmechanismen wissen. Auch Ditton (2010a) betont, dass Lehrkräfte nicht bewusst sozial selektiv 
entscheiden und handeln, sondern vielmehr den strukturellen Zwängen des deutschen Schulsystems ausgesetzt sind (ebd.). So zeigen empirische Studien, dass Lehrkräfte bei Grundschulempfehlungen Faktoren der schulsystemischen Ebene berücksichtigen, wie z. B. die Entsprechung von angebotenen und nachgefragten Plätzen an weiterführenden Schulen (Maaz, Baumert, Gresch, \& McElvany, 2010). Des Weiteren muss nach Ansicht von Ditton (2010a) die Unschärfe der offiziell verfügbaren Kriterien für die Schullaufbahnempfehlungen bedacht werden. So heißt es in den Beschlüssen der Kultusministerkonferenz (2015), dass neben „Kenntnisse und Fertigkeiten“ (ebd., S. 5) auch die „Eignung, Neigung und Wille des Kindes zu geistiger Arbeit insgesamt“ (ebd.) sowie „das jeweilige Umfeld, die Lernausgangslagen und die Lernmöglichkeiten der Schülerinnen und Schüler" (ebd., S. 6) als Kriterien für die Übergangsempfehlung zu berücksichtigen seien. Die Empfehlungen der Kultusministerkonferenz verdeutlichen zwar, dass nicht allein die Schulleistungen ausschlaggebend sein sollen, jedoch sind weder die weiteren Kriterien noch der Entscheidungsprozess expliziert, sodass die Anwendung der Kriterien von Lehrkraft zu Lehrkraft unterschiedlich erfolgen kann (Ditton, 2010a).

Damit rücken Prozesse und Mechanismen in den Mittelpunkt, die beleuchten, warum Lehrkräfte für Schüler*innen unterschiedliche Bewertungsmaßstäbe ansetzen sowie gegebenenfalls, welche Bedeutung die soziale Herkunft der Lehrkräfte hierbei hat. So sind die auf dem Rational-Choice-Ansatz basierenden Untersuchungen zu Einschätzungen von Schüler*innen im Hinblick auf (nicht) leistungsadäquate Bewertungen zwar aufschlussreich, welche Haltungen Lehrkräfte gegenüber sozial benachteiligten Schüler*innen einnehmen, d. h. welche Deutungen und Bezugnahmen sie in ihrer pädagogischen Arbeit auf die Heranwachsenden richten, bleibt jedoch unklar. Im Folgenden werden die konzeptionellen Schwächen bzw. die Unterkomplexität der Entscheidungstheorie inhaltlich durch eine an Pierre Bourdieu ungleichheitsorientierte Bildungsforschung ergänzt. Der Anschluss an Bourdieu vermag Licht in die Entstehung und Varianz sowohl primärer als auch sekundärer Herkunftseffekte zu bringen, die bis hierhin noch als ,black box ' (Kramer, 2013) erscheinen. Es wird aufgezeigt, inwiefern die Überlegungen Bourdieus ein genaueres Verständnis über den ,Modus Operandi‘, also die Art und Weise der Herstellung von Bildungsungleichheit und insbesondere über die Rolle von Lehrkräften bei Prozessen der Reproduktion sozialer Ungleichheit, ermöglichen. 


\subsubsection{Schulischer Reproduktionsmechanismus sozialer Ungleichheit aus der Perspektive von Pierre Bourdieu}

Gleichwohl in den letzten Jahrzehnten eine umfassende empirische Befundlage entstanden ist, ist der Rational-Choice-Ansatz nicht unumstritten. Der wesentliche Kritikpunkt bezieht sich auf die theoretische Grundannahme des Ansatzes, dass es sich bei Bildungsentscheidungen durch Eltern und Lehrkräfte um individuelle, rationale Entscheidungen handelt (Burkart, 1994). Wie in diesem Teilkapitel noch genauer ausgeführt wird, berücksichtigt die Auffassung einer rationalen Wahl strukturelle Hindernisse individuellen Handelns nur ungenügend. Denn versteht man unter Rationalität ein bewusstes, von Vernunft bestimmtes sowie an subjektive Zwecke gebundenes Denken und Handeln und legt dieses Begriffsverständnis der Analyse von Bildungsentscheidungen zugrunde, wird verkannt, dass soziale Akteure aufgrund von Aufwachsens- und Lebensbedingungen spezifische Wahrnehmungsweisen, Einstellungen und Handlungsdispositionen vorweisen, die sich auch in unterschiedlichen Bildungsstrategien und -zugängen niederschlagen (u. a. Kramer, Helsper, Thiersch, \& Ziems, 2009; Grundmann, Groh-Samberg, Bittlingmayer, \& Bauer, 2003; Bourdieu \& Passeron, 1971). Bourdieus Theorien und Konzepte zielen hingegen darauf, eine Verbindung zwischen der Ebene der Gesellschaft und der Ebene der Handlungspraxis der Akteure zu schaffen.

Im Folgenden werden diejenigen Argumentationslinien von Bourdieu in ihren Grundzügen erörtert, die für die eigene Untersuchung als wesentlich erachtet werden. Es geht vorrangig darum, unter Einbezug der Eigenlogik des Bildungssystems den Beitrag der Lehrkräfte zur Entstehung von Bildungsungleichheit darzustellen. So nimmt in Bourdieus Forschungsperspektive das Bildungssystem eine zentrale Funktion in den Prozessen der Reproduktion sozialer Ungleichheit ein, wobei sich zwei Analyseebenen unterscheiden lassen, die Bourdieu als komplexes Zusammenspiel beschreibt: Einerseits untersucht Bourdieu auf einer strukturtheoretischen Ebene die gesellschaftliche Relevanz von Bildungseinrichtungen. Andererseits rücken auf einer Akteurs- und Handlungsebene Bewältigungsstrategien schulischer Bildungsanforderungen der Schüler*innen, die Beziehungen und Interaktionen zwischen Lehrkräften und Schüler*innen sowie Praktiken der Beurteilung und Selektion von Schüler*innen in das Zentrum der Betrachtung (Bauer, 2012). Dreh- und Angelpunkt ist die Annahme, dass sowohl die Wahrnehmungs-, Denk- und Handlungsmuster der Schüler*innen als auch der Lehrkräfte stets im Zusammenhang mit der Struktur der sozialen Situationen, speziell mit der Asymmetrie der Machtverhältnisse, betrachtet werden müssen. Im Folgenden werden zunächst grundlegende theoretische Annahmen und Konzeptionen Bourdieus zur 
Erklärung von (schulischen) Reproduktionsmechanismen sozialer Ungleichheitsverhältnisse vorgestellt, um darauf aufbauend die Bedeutung der pädagogischen Arbeit der Lehrkräfte für die Herstellung, Verstärkung und auch Verringerung von Bildungsnachteilen herauszuarbeiten.

\section{Das Konzept des sozialen Raumes - Kapitalarten, das Verhältnis von Position und Lebensstil, symbolische Kämpfe}

Bourdieu entwirft die Gesellschaft und ihre Sozialstruktur als einen Sozialraum, in dem Individuen relational zueinander angeordnete Positionen einnehmen. Der gesamtgesellschaftliche Raum lässt sich auch als Macht- und Spielfeld beschreiben, in dem um die „Wahrung oder Veränderung der Kräfteverhältnisse gerungen wird" (Bourdieu, 1985, S. 74). Die Positionierung im sozialen Raum ist abhängig von einer ungleichen Verteilung materieller und immaterieller Ressourcen, die Bourdieu als Kapital(ien) bezeichnet und den ,Spieleinsatz' darstellen. Hierbei unterscheidet Bourdieu grundsätzlich drei Kapitalsorten, die in der sozialen Laufbahn akkumuliert werden: das ökonomische, das kulturelle und das soziale Kapital (Bourdieu, 1982). Das ökonomische Kapital ist von zentraler Bedeutung für die soziale Positionierung, es umfasst $u$. a. Geldvermögen und materiellen Besitz und ist eng mit Berufspositionen verbunden (Bourdieu, 1983). Das kulturelle Kapital, das auch als Bildungskapital bezeichnet werden kann, existiert in einem inkorporierten, objektivierten und institutionalisierten Zustand (ebd.). Die Akkumulation von inkorporiertem Kulturkapital setzt einen Verinnerlichungsprozess voraus und ist grundsätzlich körpergebunden. Durch persönlich investierte Zeit wird das inkorporierte Kulturkapital zu einem festen Bestandteil der Person und kann daher, im Gegensatz zu ökonomischem Kapital, nicht kurzfristig weitergegeben werden (Bourdieu, 1992). Die Übertragung des Kulturkapitals erfolgt Bourdieu zufolge nicht nur während des Schulbesuchs, sondern vor allem in der Familie (Bourdieu, 1983). Bourdieu spricht hierbei auch von der ,,sozialen Vererbung“ (Bourdieu, 1992, S. 57), die meist diskret und indirekt stattfindet. Das objektivierte Kulturkapital kommt in vergegenständlichter Form kultureller Güter vor, z. B. Schriften, Gemälde, Instrumente, und ist demnach materiell übertragbar. Inkorporiertes Kulturkapital ist jedoch notwendig, um den eigentlichen Sinn zu erschließen (Bourdieu, 1983). Institutionalisiertes Kulturkapital bezeichnet schulische oder akademische Titel, die das Bildungsniveau bzw. die Berufsqualifikation ausweisen sollen und so dem Kulturkapital eines Akteurs institutionelle Anerkennung verleihen. Die Titel ermöglichen zudem einen unmittelbaren sozialen Vergleich der Akteure (Bourdieu, 1992). Soziales Kapital ist das Netz von Beziehungen, das für persönliche Zwecke instrumentalisierbar ist. Es handelt sich um Ressourcen, die auf der Zugehörigkeit zu einer Gruppe beruhen (Bourdieu, 1983). 
Darüber hinaus ist das symbolische Kapital ,als wahrgenommene und als legitim anerkannte Form der drei vorgenannten Kapitalien“ (Bourdieu, 1985, S. 11) zu nennen. Das symbolische Kapital steht für die allgemeine Anerkennung derjenigen Kapitalsorten, die zu Macht und Ansehen in der Gesellschaft führen, wobei jede beliebige Sorte von Kapital kontextspezifisch die Qualität von symbolischem Kapital annehmen kann (Barlösius, 2004). Die unterschiedlichen Kapitalsorten sind mit mehr oder weniger großem Aufwand an Transformationsarbeit ferner untereinander konvertierbar. So kann etwa inkorporiertes Kulturkapital nicht nur in hohe Bildungstitel, sondern auch aufgrund einer daraus resultierenden begehrten Berufsposition in ökonomisches Kapital umgewandelt werden (Bourdieu, 1983).

Die untenstehende Abbildung veranschaulicht die Teilungs- und Strukturierungsprinzipien des sozialen Raumes: Das personengebundene Kapitalvolumen aller drei Kapitalsorten (vertikale Dimension) einerseits sowie die Kapitalstruktur (horizontale Dimension), also das Mengenverhältnis von ökonomischen und kulturellem Kapital andererseits, bestimmen die Position im sozialen Raum. Das soziale Kapital bleibt bei der horizontalen Darstellung bei Bourdieu unberücksichtigt. Eine dritte Dimension bildet die zeitliche Entwicklung von Kapitalvolumen und -struktur ab, das heißt die vergangene oder potenzielle soziale Laufbahn von Individuen oder Gruppen (Bourdieu, 1982). Anhand der zeitlichen Dimension können Auf- und Abstiegsprozesse innerhalb des sozialen Raums nachgezeichnet warden (Abbildung 1.3).

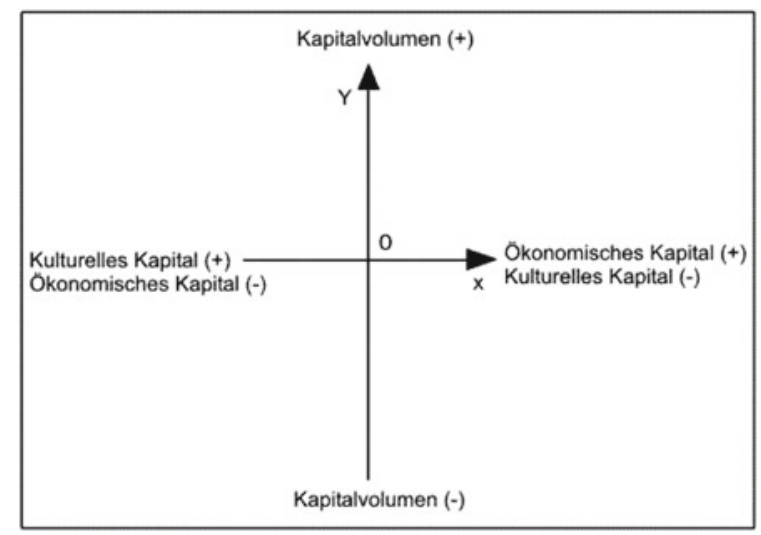

Abbildung 1.3 Der soziale Raum nach Bourdieu (Schwingel, 2003, S. 108) 
In Abgrenzung zu der Strukturierung des Sozialraums nach objektiven Kriterien der Kapitalausstattung unterscheidet Bourdieu den Raum der Lebensstile resp. den symbolischen Raum (Bourdieu, 1982). Lebensstile korrelieren mit objektiven Lebensbedingungen und sind symbolische Merkmale der Lebensführung. Sie stellen wahrnehmbare Ausdrucks- und Handlungsformen wie etwa Konsum-, Freizeit- und Ernährungsgewohnheiten sowie Grundprinzipien der Lebensgestaltung dar (ebd.). Mit der Unterscheidung zwischen der objektiven sozialen Position und des symbolischen Lebensstils eröffnet Bourdieu eine wichtige theoretische Perspektive: Ungleichheit in der beruflichen Stellung, im ökonomischen und kulturellem Kapital sowie differente individuelle Handlungsmuster werden miteinander in Beziehung gesetzt. Beide Dimensionen des Sozialraums befinden sich entlang des Prinzips der Homologie in einem wechselseitigen Abhängigkeitsverhältnis zueinander (ebd.).

Die wesentlichen Merkmale der miteinander verbundenen sozialen Positionen und Lebensstile lassen sich im Sozialraum zu einem übergeordneten Raster gesellschaftlicher Großgruppen zusammenfassen - Bourdieu spricht von sozialen Klassen, wobei es sich um theoretisch konstruierte Klassen und nicht um real existierende, politisch mobilisierbare Klassen handelt (Bourdieu, 1985). Mit der Kategorie des Geschmacks können Unterschiede in der Lebensführung und Vorlieben der Klassen begründet werden. In „Die feinen Unterschiede“ stellt Bourdieu (1982) für die französische Gesellschaft der 1960er und 1970er Jahre detailliert den legitimen Geschmack der herrschenden Klasse, den mittleren bzw. den Prätentionsgeschmack des Kleinbürgertums sowie den populären Geschmack der Volksklasse dar, wobei der legitime Geschmack die gesellschaftlichen Standards festlegt (ebd.). Die aufwendigen statistischen Analysen zu Einkommen, Schul- und Berufsbildung, Wohnverhältnissen, bevorzugten Nahrungsmitteln, Musik- und Literaturpräferenzen, praktizierten Sportarten etc. demontieren hierbei die Illusion der Beliebigkeit und Autonomie des Lebensstils einzelner Akteure, und verweisen auf systematische Zusammenhänge zwischen sozialen Positionen sowie Praktiken und Objekten der symbolischen Lebensführung (Bauer, 2012).

\section{Die Milieulandkarte der deutschen Gesellschaft - Anschlüsse an Bourdieus Konzept des sozialen Raumes}

Für Deutschland liegt mit dem Konzept der sozialen Milieus eine aktuellere Darstellung des Raumes der Positionen und Lebensstile vor - gerade mit Blick auf die bis dato eher unterbelichteten horizontalen Unterschiede zwischen sozialen Großgruppierungen. Empirisch erforscht wurden die sozialen Milieus erstmals durch die Sinus-Lebensweltforschung, wobei sich schnell herausstellte, dass sich in den Milieus ältere sozialhistorische Mentalitätstraditionen halten. 
Das Modell der Sinus-Lebensweltforschung wurde in den letzten Jahren stetig weiterentwickelt, sodass unterschiedliche Abfassungen mit divergierenden Milieubenennungen, Einschätzungen und Ergebnissen existieren (Bremer, 2007). Im Folgenden wird auf das Milieu-Konzept von Vester, von Oertzen, Geiling, Hermann und Müller (2001) Bezug genommen, da es unmittelbar an Bourdieus ungleichheitstheoretischen Überlegungen anschließt. Auf Grundlage einer umfangreichen repräsentativen Befragung im Jahr 1991 von der hannoverschen Milieuforschung mit knapp 2.700 teilnehmenden Personen und zahlreichen weiterführenden Untersuchungen (u. a. Calmbach, Thomas, Borchard, \& Flaig, 2012; Geiling, Gardemin, Meise, \& König, 2011; Wiebke, 2002) konnte der soziale Raum nach Bourdieu mehrdimensional konstruiert werden. Hierbei lassen sich nach Art der Strategien der Lebensführung fünf gesellschaftliche Großgruppen der Milieus unterscheiden, die nachfolgend in einer vereinfachten Typologie beschrieben werden. Auf der Milieu-Landkarte in der untenstehenden Abbildung sind die Milieus nach zwei grundlegenden Dimensionen gegliedert: zum einen in drei vertikale Schichtungsstufen (obere bürgerliche Milieus, respektable Volks- und Arbeitnehmermilieus und unterprivilegierte Volksmilieus), zum anderen in deren jeweilige horizontale Auffächerung. Differenziert werden fünf Traditionslinien, in denen frühere Klassenstrukturen erkennbar sind (Vester, von Oertzen, Geiling, Hermann, \& Müller, 2001) (Abbildung 1.4).

Nach oben grenzen sich die mit Blick auf Bildung, Eigentum und Berufsstellung privilegierten, besonders sozial gesicherten bürgerlichen Milieus ab. Mit zusammen gut 20 Prozent bilden sie die Gruppen institutioneller Herrschaft mit Führungsansprüchen. Sie praktizieren einen distinktiven Lebensstil, mit dem sie sich von dem gewöhnlichen Geschmack der breiten Masse distanzieren. Verfestigt hat sich innerhalb der oberen bürgerlichen Milieus eine Traditionslinie der Macht und des Besitzes (ca. 7 Prozent) und eine Traditionslinie der Bildung (ca. 8 Prozent) sowie ein aus beiden Traditionslinien hervorgegangener Ableger - das Avantgardemilieu (ca. 6 Prozent) (Vester, von Oertzen, Geiling, Hermann, \& Müller, 2001). Die Angehörigen der Milieus von Macht und Besitz, die sich im Sozialraum oben rechts befinden, nehmen seit Generationen zumeist führende Machtpositionen im privaten und öffentlichen Management ein, gehören zu den höchsten Einkommensklassen und befinden sich zudem in prestigereichen freien Berufen wie in der Justiz und Medizin. Sie betonen Disziplin, Ordnung, Autorität und Einordnung in Hierarchien und pflegen einen repräsentativen exklusiven Lebensstil, der imponiert, ohne zu protzen. In dieser Traditionslinie dominiert ein klares Elite- und Machtbewusstsein bei gleichzeitig patriarchalischer Verantwortung für Angehörige unterer sozialer Milieus (Vester, 2015). In den benachbarten Milieus der Traditionslinie akademische Intelligenz oben 


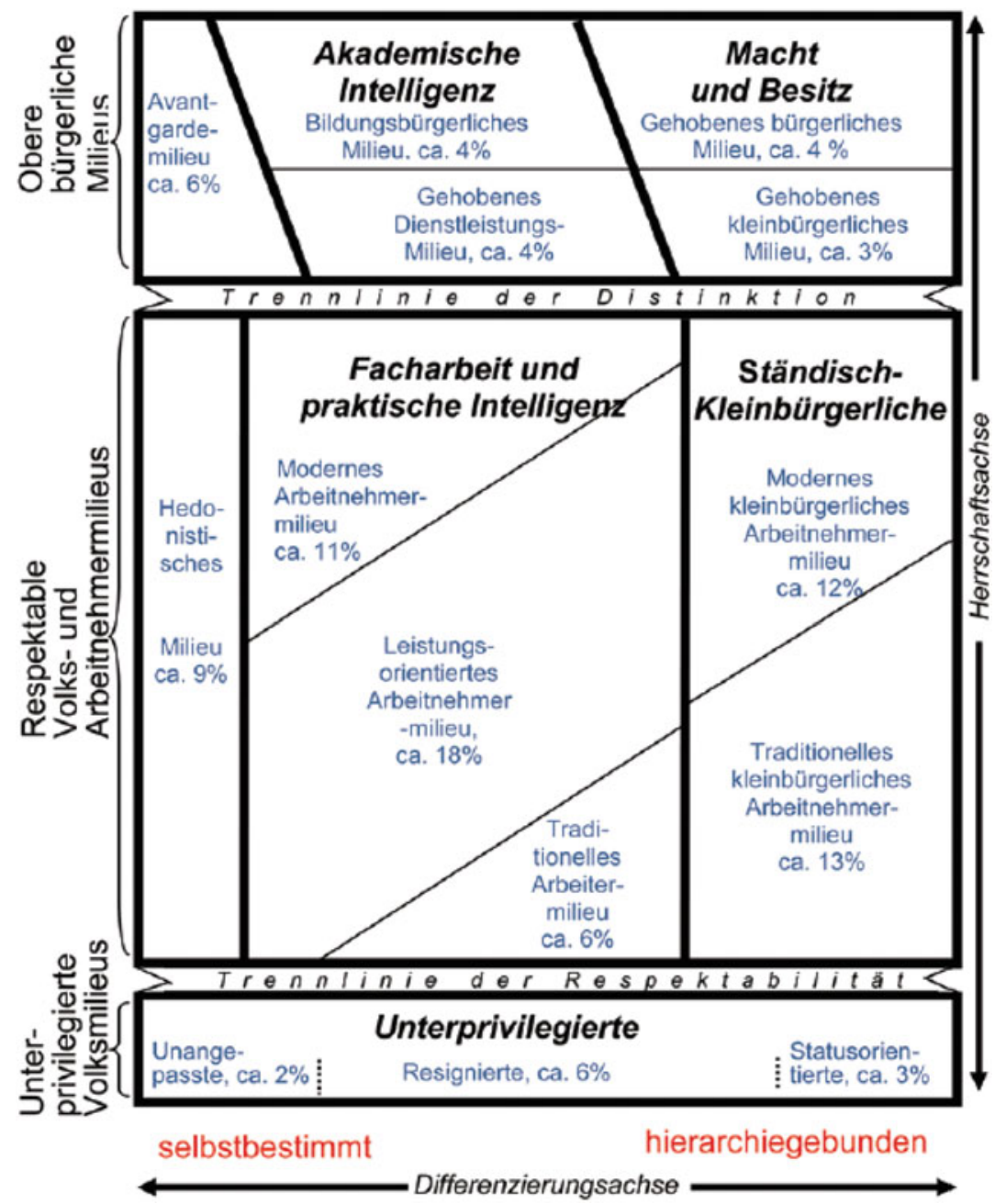

Abbildung 1.4 Die fünf Traditionslinien der sozialen Milieus (Vester, 2015, S. 149)

links im Sozialraum werden Berufe im Bereich der gehobenen humanistischen und dienstleistenden Berufe in höheren Einkommensklassen ausgeübt. Es handelt sich vor allem um Expert*innen- und Lehrberufe der Bildung und Kultur, 
der Kommunikation, der Gesundheit und des Sozialwesens sowie der Technologie und der Naturwissenschaften. Die Angehörigen dieser Traditionslinie folgen stärker idealistischen Zielen und grenzen sich entsprechend vom Konkurrenz- und Machtstreben der rechts oben angesiedelten Milieus ab. Auch sie beanspruchen eine führende Rolle in der Gesellschaft, die im Gegensatz zur Traditionslinie von Macht und Besitz jedoch als geistige oder kulturelle Führung zu verstehen ist. Sie bevorzugen eine umwelt- und gesundheitsbewusste Lebensführung und lehnen den , sinnentleerten“ Materialismus der Volksmilieus ab. Ferner zeigen sie sich weltoffen und tolerant und betonen, dass sozialer Aufstieg durch Leistung statt durch ererbte Machtstellungen möglich sei (ebd.). Die kulturellen Avantgardemilieus repräsentieren keine eigene Traditionslinie, sondern haben sich vielmehr in Abgrenzung zu den bildungs- bzw. machtorientierten benachbarten Traditionslinien immer wieder neu gebildet. Die Angehörigen der kulturellen Avantgarde stammen mehrheitlich aus Familien der oberen Milieus. Es handelt sich vorwiegend um junge Akademiker*innen in den Bereichen Ausbildung, Forschung, Kultur, Sozial- und Gesundheitswesen sowie in psychologischen und therapeutischen Berufen. Wegbereitend engagieren sich die Angehörigen dieser Milieus politisch, sozial und kulturell für postmaterialistische, emanzipatorische Ideale. Grundlegend ist das Bestreben, intensive zwischenmenschliche Beziehungen in sämtlichen gesellschaftlichen Kreisen zu pflegen. Zentrale Werte in der Lebensführung sind Selbstverwirklichung und Persönlichkeitsentfaltung, eine anspruchsvolle Kommunikation über politische, soziale und kulturelle Themen sowie Authentizität und ,Konsumaskese“ (ebd.). Trotz der inneren Differenzierungen und Differenzen der oberen bürgerlichen Milieus haben sich fast alle Teilgruppen, insbesondere die Milieus der Traditionslinie von Macht und Besitz, seit Generationen gegen Neuzugänge gesichert (Vester, von Oertzen, Geiling, Hermann, \& Müller, 2001). Die Trennlinie der Distinktion grenzt die oberen, privilegierten Milieus deutlich von den mittleren Milieus ab.

Die respektablen Volks- und Arbeitnehmermilieus bilden mit knapp 70 Prozent die große gesellschaftliche Mittelschicht und umfassen überwiegend Arbeitnehmer*innen und nur noch einen geringen Anteil an kleinen Selbstständigen (Vester, 2015). Die respektablen Volks- und Arbeitnehmermilieus werden aus zwei Traditionslinien gebildet: die Traditionslinie der Facharbeit und der praktischen Intelligenz (ca. 35 Prozent) und die ständisch-kleinbürgerliche Traditionslinie (ca. 25 Prozent). Sozialräumlich ganz links findet sich ebenfalls ein Ableger beider Traditionslinien - das eher jüngere hedonistische Milieu (zwischen ca. 9 und 11 Prozent) (Vester, von Oertzen, Geiling, Hermann, \& Müller, 2001). In der ständisch-kleinbürgerlichen Traditionslinie auf der rechten Seite 
des Sozialraumes befinden sich vor allem kleine Beschäftigte und Selbstständige in traditionellen Berufen mit eher geringen materiellen und kulturellen Ressourcen. Oft gehören sie zu den Verlierer*innen der ökonomischen Modernisierung. Das traditionelle kleinbürgerliche Arbeitnehmermilieu ist hierbei das konservativste und am meisten überalterte Milieu der Traditionslinie. Grundsätzlich suchen die Angehörigen der ständisch-kleinbürgerlichen Milieus durch die Einordnung in die Hierarchien der Familie, der Arbeit und der Politik Statussicherheit. Vorgesetzte und Politiker*innen gelten noch als Vorbilder, die jedoch auch die Pflicht zur Fürsorge gegenüber ihren Untergebenen haben. Demzufolge besteht bei den Angehörigen dieser Milieus die Bereitschaft, Verantwortung nach oben zu delegieren. Die Angehörigen der kleinbürgerlichen Milieus pflegen eine konventionelle Lebensweise im engen Kreis von Familie, Verwandt- und Nachbarschaft. Das ständisch-konservative Gesellschaftsbild lockert in den jüngeren Generationen der modernen kleinbürgerlichen Arbeitnehmermilieus zunehmend auf, so erwarten Angehörige dieses Milieus als Gegenleistung für ihre Loyalität von den Autoritäten mehr sozialen Ausgleich und Mitwirkungsrechte. Dagegen haben Verunsicherung und Angst vor sozialem Abstieg zu starken Ressentiments gegen sozial Schwächere und Randgruppen geführt (Vester, 2015). Die Angehörigen der Traditionslinie der Facharbeit und der praktischen Intelligenz auf der linken Seite des Sozialraumes sind Arbeitnehmer*innen in sich modernisierenden Berufen, aber auch moderne kleinere Selbstständige. Zentraler Wert dieser Milieus ist ein realistischer Grad von Autonomie. Die relative Unabhängigkeit von Autoritäten und äußeren Zwängen soll über berufliche Qualifikation, Arbeitsleistung sowie anhaltende Bildungsanstrengungen erreicht werden. Für die mit dem asketischen Arbeitsethos verbundene hohe Leistungsbereitschaft verlangen die Angehörigen der Traditionslinie der Facharbeit und praktischen Intelligenz im Gegenzug soziale Teilhabe. Sie folgen einer Art von demokratischem Universalismus: Jeder Mensch soll unabhängig von Geschlecht, Altersgruppe, Ethnie oder Klasse nach seinem praktischen Tun beurteilt werden. Wichtige Prinzipien der Lebensführung sind über die Generationen und Modernisierungen der Traditionslinie hinweg Solidarität in Familie, Nachbarschaft und kollegialem Kreis. Im Gegensatz zur ältesten Generation des traditionellen Arbeitermilieus haben die leistungsorientierten Arbeitnehmer*innen in Bildung, Autonomie und Teilhabechancen bereits erheblich gewonnen und sind in modernisierten mittleren Berufen als Facharbeiter*innen bzw. Fachangestellte und als moderne kleinere Selbstständige tätig. Die Angehörigen des modernen Arbeitnehmermilieus verfügen mit anspruchsvollen Qualifikationen und akademischen oder halbakademischen Berufen über noch größere Autonomiespielräume (ebd.) Das hedonistische Milieu 
ganz links im sozialen Raum umfasst Kinder von Angehörigen der beiden Traditionslinien, die gegen die Leistungs- und Pflichtmoral ihrer Eltern rebellieren. Überwiegend befinden sich die Angehörigen dieses Milieus in der Übergangsphase zwischen 20 und 30 Jahren und ist mit zunehmend unsicheren Berufsund Zukunftsperspektiven konfrontiert. Entsprechend begrenzt ist die Lebensplanung. Zu dem Milieu gehören insbesondere Schüler*innen, Auszubildende, einfache Arbeiter*innen und Angestellte, Ausbildungsabbrechende und Arbeitslose. Grundlegend ist der Wunsch nach einem guten Leben und Komfort. Die Hedonist*innen betonen den Lebensgenuss und das Leben im Hier und Jetzt. Sie pflegen einen spontanen Konsumstil und demonstrative Unangepasstheit. In der Freizeitgestaltung geht es vor allem um das Zusammensein mit Freund*innen und Bekannten, mit denen sie viel unternehmen. Insgesamt grenzen sich die Angehörigen der Volks- und Arbeitnehmermilieus durch eine respektable Lebensführung und einen gesicherten und geachteten sozialen Status nach unten $a b-$ sie distanzieren sich als Arbeitnehmer*innen und ,kleine Leute', die es durch eigene Leistung zu etwas gebracht haben (Vester, von Oertzen, Geiling, Hermann, \& Müller, 2001).

Die Angehörigen der unterprivilegierten Volksmilieus (ca. 11 Prozent) verfügen nur über geringe schulische und berufliche Qualifikationen und sind entsprechend häufig als un- und angelernte Arbeiter*innen tätig. Mit ihren beschränkten ökonomischen, kulturellen und sozialen Ressourcen streben sie realistischerweise keinen sozialen Aufstieg an, sondern versuchen mit den Standards der Volksund Arbeitnehmermilieus mitzuhalten, um dadurch mehr soziale Anerkennung zu gewinnen (ebd.). Sie sind sich der Lage der Unsicherheit und Machtlosigkeit bewusst; die Erfahrung sozialer Ohnmacht hat sich bei ihnen seit Generationen verfestigt. Demzufolge verfolgen die Angehörigen der unterprivilegierten Volksmilieus Strategien der flexiblen Gelegenheitsnutzung, der Anlehnung an Stärkere und Mächtigere sowie der Investition in hilfreiche persönliche Beziehungen. Diese Besonderheiten, die von den höheren Milieus wenig respektiert und wertgeschätzt werden, werten sie oftmals positiv (ebd.). Die unterprivilegierten Volksmilieus umfassen insgesamt drei Untergruppen: Die konservativen Statusorientierten, die Schutz in Hierarchien suchen, die arbeitnehmerischen Resignierten, die vor allem auf eine berufliche Ausbildung und gewerkschaftliche Schutzmacht setzen sowie die Unangepassten, die sich stärker an modernen Lebensstilen, Selbstverwirklichung und teilweise auch an Bildung orientieren (Vester, 2015).

Das Milieumodell von Vester, von Oertzen, Geiling, Hermann und Müller (2001) ist nicht ohne weiteres auf die Mentalitäten und Lebensstile von Personen mit Migrationshintergrund übertragbar. Hier bietet die Milieustudie „Migration - Teilhabe - Milieus“ von Geiling, Gardemin, Meise und König 
(2011) eine theoretisch und empirisch umfangreichere Perspektive. Auf Grundlage von knapp 100 qualitativen Interviews untersuchen die Autor*innen speziell die Lebenswirklichkeit von (Spät-)Aussiedler*innen und türkeistämmigen Deutschen in Hannover und Umgebung. Die Milieus der Türkeistämmigen und (Spät)Aussiedler*innen knüpfen unmittelbar an das zuvor vorgestellte Milieu-Konzept an und gliedern die Gesellschaft vertikal in obere, mittlere und untere Milieus und horizontal in kleinbürgerliche und konservative Milieus auf der traditionellen Seite und leistungs- und bildungsorientierte Milieus auf der modernisierten Seite (ebd.) (Abbildung 1.5).

Nur eine sehr kleine Gruppe von Expert*innen aus der Politik und aus auf Einwander*innen ausgerichteten Institutionen kann in der Untersuchung dem oberen Milieu der Elite zugeordnet werden. Die Angehörigen dieses Milieus entsprechen dem Bild selbstbewusster und demokratischer Bürger*innen, die reflexiv mit ihrem eigenen Migrationshintergrund und der Integrationsproblematik umgehen. Mit den gesellschaftspolitisch herausgehobenen Positionen, der Sprache und dem Lebensstil grenzen sie sich von den unter ihnen stehenden sozialen Milieus ab. Die Angehörigen des elitären Milieus stammen entweder aus privilegierten sozialen Verhältnissen in der Türkei oder haben von besonderer Förderung durch Personen ohne Migrationshintergrund aus dem Bildungsbürgertum profitiert. Aufgrund der umfangreichen Ressourcenausstattung ist es ihnen relativ leichtgefallen, ein prestigeträchtiges Studium wie Medizin, Rechts- oder Wirtschaftswissenschaften zu absolvieren. Die Gruppe der Elite schreibt sich ihren Erfolg überwiegend als Resultat der eigenen Leistung zu, teils erscheint es in den Selbstdarstellungen sogar als ein Leichtes, dass Einwander*innen die soziale Unterschichtung ihrer Herkunftsfamilien individuell überwinden können. Zugleich haben die Angehörigen dieses Milieus ein Bewusstsein dafür, dass Personen mit Migrationshintergrund ein Sonderstatus zukommt, unter dem auch sie selbst noch zu leiden haben. So bedeutet ihre Rolle als öffentliche Repräsentant*innen der Bevölkerung mit Migrationshintergrund nicht nur Teilhabe an der Elite, sondern auch Vereinnahmung und Funktionalisierung durch die Mehrheitsbevölkerung. Dagegen wehren sie sich mit Bezug auf ihren eigenen Aufstiegserfolg und lehnen es ab, auf ihre Einwanderungsgeschichte reduziert zu werden. Insofern ist die Elite von latent zum Tragen kommendem Rassismus betroffen. Statt hierbei in Selbstausgrenzungen zu verfallen, fordern sie von der Politik und der Mehrheitsbevölkerung, die Rahmenbedingungen für eine gleichberechtigte Teilhabe von Einwander*innen zu verbessern. Von einer Politik, die nur einseitig den Einwander*innen Pflichten aufbürdet, grenzen sie sich deutlich ab (ebd.). 


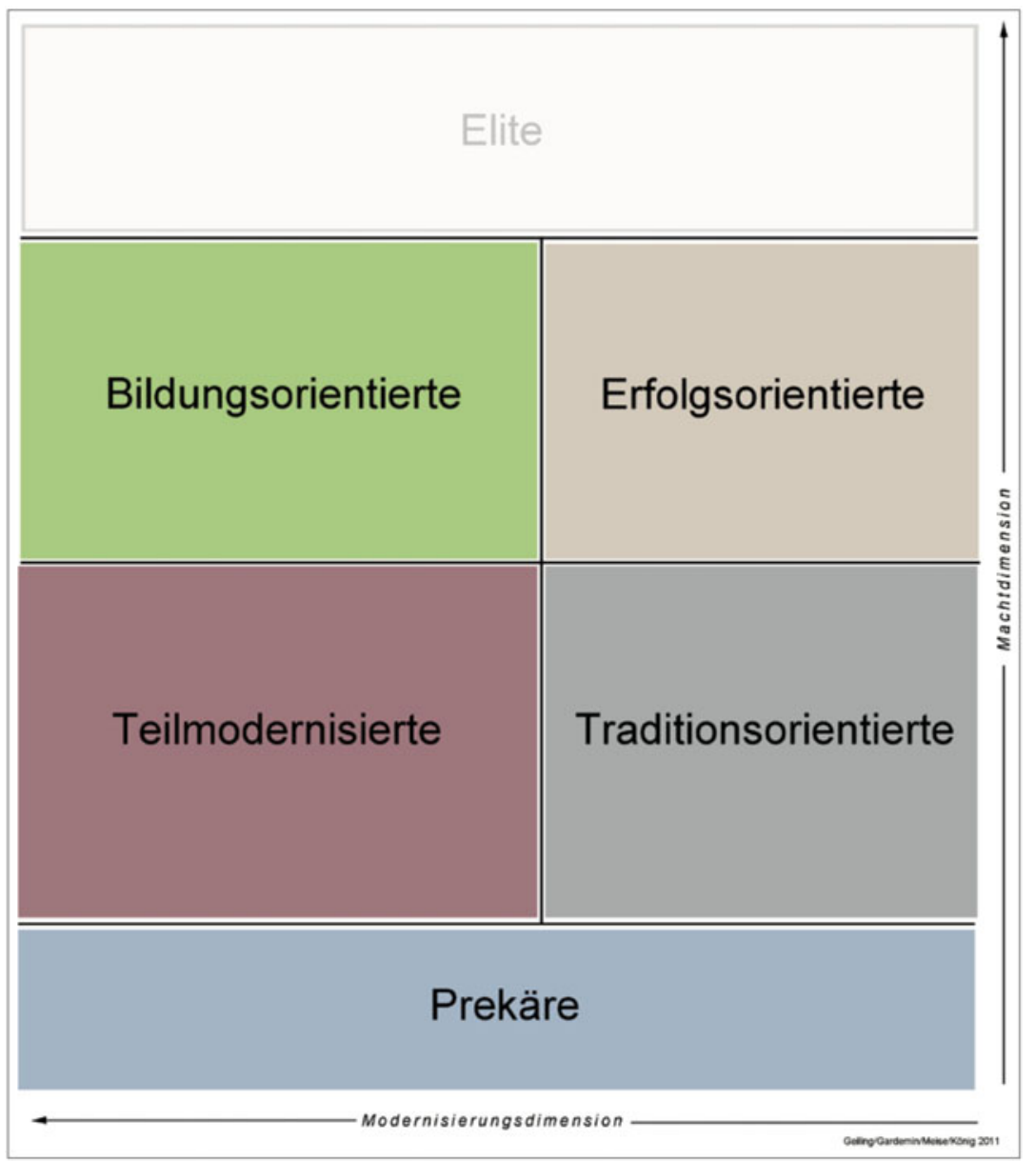

Abbildung 1.5 Soziale Milieus mit Migrationshintergrund (Geiling, Gardemin, Meise, \& König, 2011, S. 47)

Die gesellschaftliche Mitte der Bildungsorientierten besteht aus den drei Teilmilieus bildungsorientierte Humanist*innen, bildungsorientierte Aufsteiger*innen und neue Avantgarde. Die bildungsorientierten Humanist*innen, in denen nur türkeistämmige Deutsche anzutreffen sind, nehmen sich selbst als aufgeklärten und aktiven Teil der Gesellschaft wahr. Kommunikationsarbeit und soziales 
Engagement sind zentral für ihre Lebensweise, sodass der Großteil auch in den beruflichen Bereichen Erziehung, Sozialarbeit oder Therapie tätig ist. Zum Großteil waren die Angehörigen dieses Milieus die ersten ihrer Familie, die die Hochschulreife und akademische Titel erwerben konnten. Der Bildungsaufstieg war dabei mit großer Mühe und teilweise auch mit Rückschlägen verbunden. Der Bezug zur eigenen Familie bleibt für sie eine wichtige Orientierungshilfe geblieben. Gleichwohl die bildungsorientierten Humanist*innen noch nicht in gehobenen Positionen etabliert sind, können sie aufgrund des erworbenen Bildungskapitals relativ selbstbestimmt agieren. Zudem verfügen sie über die finanziellen Möglichkeiten, in ihrer Freizeit Geselligkeit, soziales Engagement und Genuss miteinander zu verbinden. Ihre egalitäre Lebensweise bezieht die traditionellen Werte der Herkunftskultur mit ein. Durch die berufliche Nähe zu sozialen und politischen Institutionen haben sie ihre soziale Sensibilität erhalten können. Die bildungsorientierten Aufsteiger*innen ähneln in ihren Grundüberzeugungen den bildungsorientierten Humanist*innen. Auch sie sind überwiegend in sozialen und pädagogischen Berufen tätig und verfügen über eine hohe soziale Kompetenz und die Fähigkeit zur Selbstreflexion. Im Gegensatz zu den bildungsorientierten Humanist*innen sind Angehörige dieses Milieus in stärkerem $\mathrm{Maß}$ auf Unterstützung und Hilfsangebote angewiesen, wobei die älteren Personen dieser Gruppe als Mentor*innen für die Jüngeren fungieren, indem sie für diese eine vermittelnde Funktion zwischen Herkunftskulturen und aktuellen Anforderungen des sozialen Aufstiegs übernehmen. Der eigene Erfahrungshintergrund gibt den bildungsorientierten Aufsteiger*innen die Möglichkeit, anderen Einwander*innen im Sinne einer Hilfe zur Selbsthilfe Orientierung für deren Lebensentwürfe zu bieten. Das gesamte Teilmilieu der bildungsorientierten Aufsteiger*innen strebt nach höherer Bildung, wenngleich sich die Angehörigen in einem Spannungsverhältnis zwischen traditionellen Erwartungen und modernen Zumutungen bewegen. Dieser Umstand erfordert eine hohe Flexibilität. Sicherheit und Unterstützung finden die bildungsorientierten Aufsteiger*innen in der Familie. Die Angehörigen der neuen Avantgarde sind vorrangig in den Berufsfeldern von Kunst und Kultur beschäftigt. Über die berufliche Selbstständigkeit und kosmopolitische Orientierung versuchen sie einen ganzheitlichen, nicht entfremdeten Lebensstil zu verwirklichen. Individualität, Selbstbestimmung und Selbstverwirklichung sind zentrale Werte für Angehörige dieses Milieus. Die neue Avantgarde betont die harmonischen Seiten des Lebens, ist optimistisch und distanziert sich von vermeintlich banalen materiellen Fragen. Gleichwohl ist der Alltag von pragmatischen Einschränkungen geprägt, denn die Einkommen reichen teilweise kaum zum Leben. So beginnen die Aufstiegswege in die künstlerische Selbstständigkeit meist auch mit einer gewissen Absicherung in Form einer zukunftssicheren 
Ausbildung oder eines erwerbsorientierten Studiums. Die Familie dient dabei als Ressource und verlässlicher Rückhalt (ebd.).

Das Milieu der Erfolgsorientierten gliedert sich in die beiden Teilmilieus der erfolgsorientierten Technokrat*innen und der erfolgsorientierten Aufsteiger*innen. Die erfolgsorientierten Technokrat*innen sind sehr diszipliniert und auf beruflichen Status und ökonomischen Erfolg ausgerichtet. Durch Ehrgeiz und Kenntnis der institutionellen Notwendigkeiten haben sie hoch qualifizierte berufliche Positionen erreicht. Hauptsächlich sind sie in betriebswirtschaftlichen Berufsfeldern oder als selbstständige Unternehmer*innen und Handwerksmeister*innen tätig. Die Angehörigen dieses Milieus, insbesondere die Älteren in dieser Gruppe, nehmen in ihrem sozialen Umfeld ethnische Stigmatisierungen wahr. Sie sind stolz auf das bereits beruflich Erreichte und versprechen sich von ihrer Anpassungsbereitschaft eine Statusverbesserung. Auch die Familie und Freizeit werden ausdrücklich auf das eigene Vorankommen ausgerichtet. Symbole des Wohlstandes, die für sie die verdienten Insignien des mühsamen Aufstiegs darstellen, stellen sie offen zur Schau. Die erfolgsorientierten Aufsteiger*innen sind ähnlich wie die erfolgsorientierten Technokrat*innen statusorientiert. Es ist jedoch noch nicht sicher, dass sie sich dauerhaft in gehobenen Positionen etablieren können, da die Aufstiegswege von starker Konkurrenz gekennzeichnet sind. Entscheidungen treffen die erfolgsorientierten Aufsteiger*innen funktional und zweckgerichtet, wobei diese aufgrund der geringen Vertrautheit mit den Normen und Gepflogenheiten höherer sozialer Milieus nicht immer treffsicher sind. Deshalb sind sie oftmals auf institutionelle Hilfe angewiesen. Auch die Älteren in diesem Milieu geben den Jüngeren Unterstützung und Halt. Grundsätzlich versuchen die erfolgsorientierten Aufsteiger*innen, die Anforderungen der Mehrheitsbevölkerung und die Traditionen der Herkunftskulturen pragmatisch miteinander zu verbinden. Von einer zu starken Modernisierung distanzieren sie sich und setzen stattdessen auf konventionelle Werte. Insgesamt orientieren sie sich am Lebensstil der gehobenen Milieus, die begrenzten Ressourcen zwingen sie mitunter jedoch zur Bescheidenheit (ebd.).

Die Teilmilieus der Individualist*innen und der teilmodernisierten Arbeitnehmer*innen bilden zusammen das Milieu der Teilmodernisierten. Die teilmodernisierten Arbeitnehmer*innen befinden sich in einem Etablierungs- und Modernisierungsprozess, in dem sie althergebrachte Traditionen und Werte mit den Werten der Mehrheitsbevölkerung verbinden. Teilweise konnten die jüngeren teilmodernisierten Arbeitnehmer*innen dabei mittleres Bildungskapital erwerben. Die mehrheitlich Türkeistämmigen dieses Milieus haben sich für respektable Dienstleistungstätigkeiten wie Kranken- und Pflegeberufe qualifiziert. Die Verdienstspannen, Aufstiegsmöglichkeiten und Arbeitszeiten entsprechen jedoch 
nicht den Erwartungen. Die sozialen Positionen sind nicht gefestigt und es besteht die latente Gefahr von Abstiegen unter die Grenze der Respektabilität. Insgesamt sind die Angehörigen dieses Milieus aufgrund eigener Betroffenheit sensibel gegenüber sozialen Unterschieden und Ungerechtigkeiten. Einem weiteren sozialen Aufstieg sind durch gesellschaftliche Schließungsmechanismen vorerst Grenzen gesetzt. Im Vergleich zu den oberen bildungsorientierten Milieus erscheinen die Teilmodernisierten deutlich genügsamer und sicherheitsorientierter. Sie treten im Alltag zwar selbstbewusst auf, sind aber über ihre unmittelbaren Lebenszusammenhänge hinaus auf Unterstützung angewiesen. Die Individualist*innen versuchen sich von traditionellen Zwängen und familialen Erwartungen zu befreien und sich damit selbstbestimmt zu entwickeln. Nicht wenige haben für ihre persönliche Integrität Zerwürfnisse innerhalb der Familie in Kauf genommen. Vorgegebene Aufstiegs- und Leistungserfolge sind ihnen nicht so wichtig wie eine harmonische Verbindung von Beruf, Familie und Freizeit. Das berufliche Spektrum reicht von Taxifahrer*innen und Postzusteller*innen bis hin zu Selbstständigen im Einzelhandel. Arbeitslosigkeit und Gelegenheitstätigkeiten sind in diesen Berufsbiografien häufig anzutreffen. Wesentlichste Ressource ist das soziale Kapital, das sich in der hohen sozialen Vernetzung in den unmittelbaren Lebenszusammenhängen zeigt. Die Individualist*innen genießen das Hier und Jetzt und suchen Nischen und Gelegenheiten statt vorgezeichneter Wege. Mit ihrer Lebenssituation wirken sie insgesamt zufrieden (ebd.).

In dem Milieu der traditionsorientierten Arbeitnehmer*innen befinden sich ausschließlich (Spät-)Aussiedler*innen, die in der kurzen Zeitspanne seit ihrer Einwanderung kaum Möglichkeiten für Ausdifferenzierungen der Lebensweisen gefunden haben. Primär orientieren sie sich an Funktionalität, Anpassung, Sicherheit und Familie. Ihre Lebenssituation bewerten die Angehörigen dieses Milieus aus der Perspektive des Herkunftslandes - dies gibt ihnen Rückhalt und Lebenszufriedenheit. Stabile, geordnete familiale Verhältnisse und Zusammenhalt sind ihnen dabei sehr wichtig. Arbeit muss aus Sicht der traditionsorientierten Arbeitnehmer*innen Sicherheit für die privaten Bedürfnisse bieten und wird nicht als Selbstzweck oder Erfüllung gesehen. In der Regel arbeiten die Traditionsorientierten in geschlechtstypischen Berufen, die oftmals schlecht bezahlt, monoton und unsicher sind. Von Leistungsbereitschaft, Sparsamkeit und Bildungsanstrengungen erhoffen sie sich soziale Sicherheit und Respektabilität (ebd.).

Das Milieu der Prekären besteht aus den beiden Teilmilieus der prekären Arbeitnehmer*innen und der Deklassierten. Die prekären Arbeitnehmer*innen weisen eine ausgeprägte Arbeitnehmer*innenmentalität auf, so sind Strebsamkeit, Arbeitswille und soziale Sensibilität charakteristisch für dieses Milieu. 
Gleichwohl befinden sie sich am unteren Rand der Gesellschaft, außerhalb der respektablen Positionen mittlerer sozialer Milieus. Aufgrund eher geringer Schulbildung und Qualifikationen haben sie meist einfache, unsichere und schlecht bezahlte Anstellungen im produzierenden Gewerbe. Dementsprechend ist der Alltag von der Anstrengung geprägt, ausreichend Geld zu verdienen. Einen gewissen Schutz bieten gewerkschaftliche Strukturen, die jedoch nicht überall gegeben sind. Aufgrund der prekären beruflichen Situation sind die Angehörigen dieses Milieus genügsam und erfindungsreich in der Freizeitgestaltung. Zudem sind die Älteren bemüht, die eigenen Kinder über gute schulische Bildung vor den Zumutungen unsicherer Erwerbsarbeit zu bewahren. Doch die mangelnden deutschen Sprachkenntnisse und die geringe schulische Vorbildung machen es ihnen unmöglich, den Kindern Hilfestellungen in der Schule zu geben. Grundsätzlich orientieren sich die prekären Arbeitnehmer*innen an der modernisierten unteren Mitte der Gesellschaft und versuchen mit ihr Schritt zu halten. Die Deklassierten sind unterhalb der Respektabilitätsgrenze zu verorten und verfügen über die geringsten Ressourcen aller Milieus. Sie sind hohen Risiken wie Arbeitsverlust, arbeitsbedingten Gesundheitsbeschwerden und vielfältigen Benachteiligungen ausgesetzt. Beruflich sind sie aufgrund fehlender Qualifikationen, Unwissenheit über Alternativen, arbeitsrechtlicher Rahmenbedingungen sowie fehlender Unterstützung in körperlich anstrengenden Handlungsfeldern tätig und befinden sich an der untersten Lohngrenze. Im Vordergrund stehen die Notwendigkeiten der alltäglichen Lebensbewältigung, wobei Werte wie Sparsamkeit, Fleiß und Arbeitsmoral zentral sind. Die Bemühungen der Deklassierten werden von der Mehrheit der Gesellschaft kaum gewürdigt, zu wenig können die sie mit den Gewohnheiten der respektablen Milieus mithalten. Eine langfristige Zukunftsplanung ist unter diesen Lebensumständen wenig sinnvoll (ebd.).

\section{Das Bildungssystem - Verstrickung in die Reproduktion gesellschaftlicher Macht- und Herrschaftsverhältnisse}

Grundsätzlich geht Bourdieu von einer außerordentlichen Beharrungskraft vertikaler Klassenunterschiede, d. h. von einer stabilen Differenzierung zwischen den oberen bürgerlichen Milieus, den respektablen Volks- und Arbeitnehmermilieus und den unterprivilegierten Volksmilieus aus. Allerdings ist das Gesellschaftsbild Bourdieus keineswegs statisch, wie bereits die zeitliche Dimension des sozialen Raumes nahelegt. Auch die Milieuforschung verweist insbesondere auf horizontale Dynamiken, die mitunter zum Wandel der Milieus führen (Bremer \& Lange-Vester, 2013). Die Bewegungen innerhalb des sozialen Raumes werden nach Bourdieu durch fortwährende symbolische Kämpfe begründet: Einerseits geht es um den Wert der Kapitalausstattung selbst und anderseits darum, eigene 
Wahrnehmungs- und Bewertungsschemata als legitim durchzusetzen und damit auch die eigene Position im Sozialraum zu sichern oder zu verbessern (Bourdieu, 1985). Jene Macht, der es gelingt, spezifische Bedeutungen, Weltsichten und Sinngehalte als legitim durchzusetzen, indem sie die Kräfteverhältnisse verschleiert, die ihrer Kraft zugrunde liegen, nennt Bourdieu symbolische Gewalt (Bourdieu \& Passeron, 1973). Hierbei entfaltet sich die eigentliche Wirksamkeit der symbolischen Macht weder auf der Ebene physischer Gewalt, noch wird sie offen benannt und aufgezeigt. So handelt es sich in der Regel auch nicht um einen willkürlich geführten politischen Kampf, sondern um dauerhafte, vorwiegend unbewusste Interaktions- und Aushandlungsprozesse in Form ungleicher Normen, Werthaltungen, Praktiken und deren Repräsentationsarbeit (Bourdieu, 1992). Bourdieu illustriert die Dynamiken im sozialen Raum folgendermaßen:

Der Raum, das sind hier die Spielregeln, denen sich jeder Spieler beugen muß. Vor sich haben die Spieler verschiedenfarbige Chips aufgestapelt, Ausbeute der vorangegangenen Runden. Die unterschiedlich gefärbten Chips stellen unterschiedliche Arten von Kapital dar. Es gibt Spieler mit viel ökonomischem Kapital, wenig kulturellem und wenig sozialem Kapital. Die sind in meinem Raumschema rechts angesiedelt, auf der herrschenden, ökonomisch herrschenden Seite. Am anderen Ende sitzen welche mit einem hohen Stapel kulturellen Kapital, einem kleinen oder mittleren Stapel ökonomischem Kapital und geringem sozialen Kapital. das sind die Intellektuellen. Und jeder spielt entsprechend der Höhe seiner Chips. Wer einen großen Stapel hat, kann bluffen, kann gewagter spielen, risikoreicher. Mit anderen Worten: Die Spielsituation ändert sich fortwährend, aber das Spiel bleibt bestehen wie auch die Spielregeln. (Bourdieu, 1992, S. 38)

Bei der Sicherung und Verbesserung der sozialen Position und somit der Reproduktion ungleicher Sozialstrukturen kommt Bourdieu zufolge dem Bildungssystem eine entscheidende Rolle zu. Im Feld der Bildung als Teilbereich des gesamtgesellschaftlichen sozialen Raumes kommen spezifische Interessen, Strukturen und Logiken zum Tragen, die es nachfolgend auszuarbeiten gilt.

Ausgehend von Prozessen wirtschaftlichen Strukturwandels und der Bildungsexpansion im Frankreich der 1960er Jahre, die zu formeller Chancengleichheit und Offenheit des sozialen Wettbewerbs geführt haben, geht Bourdieu (1982) von einer wachsenden Bedeutung von Bildung bei der Reproduktion der herrschenden Klasse aus. Die vermehrte Inanspruchnahme des Bildungsangebots auch solcher sozialen Gruppen, die bislang die Bildungsinstitutionen nur wenig genutzt haben, hat zur Folge, dass sowohl die ökonomisch am besten ausgestattete herrschende Klasse sowie Gruppierungen, deren Reproduktion größtenteils oder ausschließlich über Bildung gewährleistet wird, zur Wahrung des relativen 
Seltenheitsgrades ihrer Abschlüsse und damit zur Sicherung ihrer sozialen Position im noch stärkeren Maße als zuvor im Bildungsbereich investieren müssen (ebd.). Der kollektive Zwang zur Akkumulation von Bildungskapital und die verschärfte Konkurrenz zwischen den Klassen zieht wiederum die Konsequenz nach sich, dass die institutionalisierten Bildungsabschlüsse immer schneller entwertet werden - Bourdieu spricht auch von einer „Inflation der Bildungsprädikate“ (Bourdieu, 1982, S. 222). Inwiefern es den privilegierten, herrschenden Gruppen dennoch gelingt, ihre soziale Lage zu halten, wenn der Bildungstitel notwendige Voraussetzung, und der Zugang zu Bildung formal offen ist, arbeitet Bourdieu gemeinsam mit Jean-Claude Passeron Ende der 1960er Jahre am Beispiel des französischen Bildungssystems in „Die Illusion der Chancengleichheit“ heraus (Bourdieu \& Passeron, 1971.) Die wesentliche Argumentationslinie der beiden Autoren wird im weiteren Verlauf dargelegt.

Das Bildungssystem eröffnet oder verwehrt durch die Vergabe von institutionell anerkannten Bildungszertifikaten Zugang zu begehrten Ausbildungsund Berufschancen und somit $\mathrm{zu}$ attraktiven beruflichen Positionen. Hierbei gewährleistet es, dass die Verteilung der Heranwachsenden auf unterschiedliche soziale Positionen im Verlauf des Qualifikationsprozesses durch schulische Auswahlverfahren entlang des objektiven Leistungskriteriums erfolgt (ebd.). Zur Kanalisierung der Schüler*innen hat das Schulsystem ein vielfältiges Instrumentarium ausgebildet (u. a. Mehrgliedrigkeit des Schulsystems, Überweisung auf die Förderschule, Zurückstellung bei Einschulung, Klassenwiederholung, innerschulische Kursstränge), das offen praktiziert und allgemein akzeptiert wird (Schümer, Tillmann, \& Weiß, 2004). Dem Anspruch nach erfolgt eine sozial gerechte, ausschließlich auf dem Leistungsprinzip beruhende Selektion. Dass es sich hierbei um eine „Illusion der Chancengleichheit“ (Bourdieu \& Passeron, 1971) handelt, markieren nicht zuletzt die PISA-Studien, die eindrucksvoll belegen, dass in kaum einem anderen OECD-Land der schulische Erfolg bzw. Misserfolg so stark von der sozialen Herkunft abhängt wie in Deutschland (Klieme, et al., 2010). Weder die Bildungsexpansion längst vergangener Jahrzehnte, die dazu führte, dass immer größere Teile der Bevölkerung über höhere institutionalisierte Bildungsabschlüsse beziehungsweise Berufsqualifikationen verfügen (Geißler, 2014), noch neuere bildungspolitische Maßnahmen wie der Ausbau von Ganztagsschulen haben nicht die Entkopplung von Bildungsverläufen und sozialer Herkunft bewirkt (Betz, 2015). Die Proklamation des Leistungsprinzips als Grundlage für sozial gerechte schulische Selektionsprozesse ist demnach absurd, dennoch hält sich der „Mythos eines fairen Bildungswettbewerbs“ (Solga, 2005, S. 19) hartnäckig. Der Glaube, dass Bildungserfolg durch individuelle Bildungsfähigkeit und Bildungsbemühungen zustande kommt, folgt einem meritokratischen Verständnis, 
das in weiten Teilen der Gesellschaft tief verwurzelt ist, selbst bei denjenigen, die aufgrund ihrer Herkunft benachteiligt sind. So werden Bildungsunterschiede als biologische Intelligenz- und Begabungsunterschiede definiert, demnach erscheint soziale Ungleichheit als natürliche Unterschiede. Hierbei wird ausgeblendet, dass Begabung und Intelligenz soziale Konstrukte darstellen, ,die eines gesellschaftlichen Definitionsprozesses und eines sozialen Kategorisierungsprozesses in der Schule [...] bedürfen“ (ebd., S. 25). Durch das Erklären von Begabungs- und Leistungsunterschieden als naturgegeben tritt die Definitionsmacht statushöherer Gruppen in den Hintergrund, die entscheiden, anhand welcher Kriterien Leistung beobachtet und gemessen wird (ebd.).

Im Hinblick auf das komplexe Bindungsgefüge zwischen sozialer Herkunft, dem Kriterium der Leistungserbringung und Schulerfolg ist das kulturelle Kapital konstitutiv. Nach Bourdieu ermöglicht es, ,die Ungleichheit der schulischen Leistungen aus verschiedenen sozialen Klassen zu begreifen“ (Bourdieu, 1983, S. 185). Von besonderer Relevanz ist das inkorporierte Kulturkapital, das, wie bereits genannt, vor allem in der familialen Sozialisation erworben und zu einem festen Bestandteil der Person wird (ebd.). Bourdieu und Passeron (1971) zeigen auf, dass die familial geprägten sozialen Handlungspraktiken, wie beispielsweise die Beherrschung der Schul- und Unterrichtssprache, das Auftreten und insbesondere die Einstellung $\mathrm{zu}$ schulischer Bildung unterschiedliche Nähe- und Distanzverhältnisse zu den Erwartungs- und Anforderungsstrukturen des Bildungssystems aufweisen (ebd.). Hierbei zahlen sich kulturelle Gewohnheiten, Fähigkeiten und Interessen der oberen Klassen im Bildungssystem besonders aus: Die kulturellen Voraussetzungen der Heranwachsenden, die bei Schuleintritt noch auf die begünstigte Positionierung der Herkunftsfamilie innerhalb des Sozialraumes verweisen, werden im Laufe der Schulzeit zu einem Bildungsprivileg umgewandelt. Es zeigt sich, dass je nach sozialer Herkunft ,für die einen die Schule der einzige Wissensvermittler ist [, während] bei anderen die hauptsächlich im Familienmilieu erworbene Kultur [...] ausschlaggebend ist" (ebd., S. 37). Demzufolge stellt für Bourdieu die Transmission kulturellen Kapitals in der Familie auch „die am besten verborgene und sozial wirksamste Erziehungsinvestition“ (Bourdieu, 1992, S. 54) im Positions- und Machtkampf innerhalb des sozialen Raumes dar.

Insgesamt wird deutlich, dass das Bildungssystem zwar formell für alle sozialen Gruppen gleichermaßen zugänglich ist, aber die Wahrscheinlichkeit, das Bildungssystem auch erfolgreich zu durchlaufen, für die ohnehin sozial Privilegierten deutlich höher ist. Entsprechend hilft das Bildungssystem nicht, soziale Ungleichheit und Klassenprivilegien abzubauen, sondern trägt entscheidend dazu 
bei, sie zu erhalten. Mithilfe des Habituskonzepts sollen nachfolgend die erwähnten ungleichen Passungsverhältnisse zwischen Familie und Schule konkretisiert werden.

\section{Das Konzept des Habitus - Verbindung zwischen gesellschaftlichen Struktu- ren und Praktiken}

Die zentrale Annahme Bourdieus zur schulischen Reproduktion sozialer Ungleichheit, dass die familial geprägten sozialen Handlungspraktiken sowie insbesondere familiale Einstellungen $\mathrm{zu}$ schulischer Bildung unterschiedliche Passungsverhältnisse zu den Erwartungs- und Anforderungsstrukturen des Bildungssystems aufweisen, wird durch das Habituskonzept elaboriert. Der Habitus stellt hierbei das Bindeglied zwischen den Einstellungen, den symbolischen Praktiken der Lebensführung, und der Struktur ungleicher gesellschaftlicher Bedingungen dar (Bauer, 2012). Die Übereinstimmung zwischen der sozioökonomischen Lage und den symbolischen Praktiken der Lebensführung wird demnach nicht bloß hypothetisch behauptet und empirisch belegt, sondern auch theoretisch erklärt. Mithilfe des Habituskonzepts zeichnet Bourdieu eine dritte Ebene des Sozialraums nach, wobei der Habitus ,den theoretischen Raum der Umwandlung“ (Bourdieu 1982, S. 214) bildet, der aus ähnlichen materiellen und kulturellen Bedingungen entsprechende Verhaltensmuster, Geschmäcker und Lebensstile formt, die als Zuordnungs- und gleichzeitig als Abgrenzungsmerkmal sozialer Gruppen dienen (ebd.).

Generell wird von Bourdieu der Habitus als ein dauerhaftes und übertragbares Dispositionssystem sozialer Akteure bezeichnet, das die Wahrnehmung, das Denken und Handeln strukturiert und somit zum Erzeugungsprinzip der sozialen Praxis wird (Bourdieu, 1987). Die Wahrnehmungsschemata strukturieren die alltägliche Wahrnehmung der sozialen Welt und umfassen in Abgrenzung zu Denkschemata einen sensuellen Aspekt. Zu den Denkschemata gehören hingegen Klassifikationsmuster, mit deren Hilfe die Akteure die soziale Welt interpretieren und kognitiv ordnen. Dazu zählen ihre impliziten ethischen Normen zur Beurteilung gesellschaftlicher Handlungen und ihre ästhetischen Maßstäbe zur Bewertung kultureller Objekte und Praktiken - also ihr Geschmack. Handlungsschemata bringen letztlich die subjektiven bzw. kollektiven Praktiken der Akteure hervor. Im Praxisvollzug sind die Wahrnehmungs-, Denk- und Handlungsmuster eng miteinander verbunden und wirken größtenteils unbewusst (Schwingel, 2003).

Inwiefern der Habitus als Dispositionssystem von Akteuren zwischen den sozialen Positionen und den symbolischen Praxisformen vermittelt, wird durch die Doppelstruktur des Habitus deutlich. Zum einen wirkt der Habitus als ,Modus Operandi“ beziehungsweise als strukturierende Struktur von sozialer Praxis, 
indem er Handlungen, die zur Konstitution von Praxisformen beitragen, sowie unterschiedliche Wahrnehmungen und Bewertungen dieser Praxisformen hervorbringt (Bourdieu, 1987). In der Homologie der Praxisformen und Wahrnehmungsund Denkschemata sieht Bourdieu das Ergebnis eines sozialen Abstimmungsprozesses, den er wie folgt beschreibt:

Der Habitus ist nichts anderes als jenes immanente Gesetz, jene den Leibern durch identische Geschichte(n) aufgeprägte lex insita, welche Bedingung nicht nur der Abstimmung der Praktiken, sondern auch der Praktiken der Abstimmung ist. (ebd., S. 111)

Mit ,Abstimmung der Praktiken' ist gemeint, dass der Habitus aufeinander abgestimmte, wahrnehmbare Praxisformen wie die körperliche Haltung, kulturelle Gebrauchsweisen und die Hervorbringung von Werken generiert. Zugleich erzeugt der Habitus ,Praktiken der Abstimmung', das heißt aufeinander abgestimmte Wahrnehmungs- und Bewertungsschemata, die garantieren, dass die verschiedenen Praxisformen jeweils ähnlich wahrgenommen und bewertet werden (Barlösius, 2004).

In Abgrenzung zur strukturierenden Struktur des Habitus, die ,generative Formel" (Bourdieu, 1982, S. 332) von Praxisformen sowie Wahrnehmungs-, Denkund Handlungsschemata, geht Bourdieu darüber hinaus von einer strukturierten Struktur des Habitus aus. Als ,Opus Operatum“ repräsentiert der Habitus die Dispositionen, die vom Akteur in Abhängigkeit seiner Existenzbedingungen der sozialen Herkunft bzw. seiner sozialräumlich unterschiedlichen Erfahrungs- und Lernvorgänge im Zuge der Sozialisation inkorporiert wurden (Bourdieu, 1987). Demzufolge sind Menschen ,historisch geprägte Lebewesen“ (Wacquant, 2009, S. 6), die von gesellschaftlichen (kulturellen und materiellen) Bedingungen des Daseins beeinflusst werden. Ohne präzisiere Erläuterung hebt Bourdieu für die Habitusgenese das besondere Gewicht frühkindlicher Erfahrungen hervor, die sich am nachhaltigsten auf ihre lebenslange praktische Anwendung auswirken (Bourdieu, 1987)

Bourdieu betont, dass der Habitus zwar die Tendenz der Reproduktion von Existenzbedingungen habe, diese aber nicht als mechanischer Determinismus zu verstehen ist (ebd.). Vielmehr legen die ökonomisch und kulturell verfügbaren Ressourcen eines Akteurs, mithin die Lebensbedingungen seiner Familie und sozialen Klasse, die Grenzen von Erfahrungen und Handlungen bzw. die habituellen Einschränkungen fest, innerhalb derer Kreativität möglich ist: 
Der Habitus ist ein System von Grenzen. Wer z. B. über einen kleinbürgerlichen Habitus verfügt, der hat eben auch, wie Marx einmal sagt, Grenzen seines Hirns, die er nicht überschreiten kann. Deshalb sind für ihn bestimmte Dinge einfach undenkbar, unmöglich; es gibt Sachen, die ihn aufbringen oder schockieren. Aber innerhalb dieser seiner Grenzen ist er durchaus erfinderisch, sind seine Reaktionen keineswegs immer schon im Voraus bekannt. (Bourdieu, 1992, S. 33)

Die implizite Wahrnehmung habitueller Grenzen nennt Bourdieu in Anlehnung an Goffmann den „sense of one's place“ (Bourdieu, 1982, S. 734). Damit gemeint ist der Sinn für die eigene Stellung im sozialen Raum, in dem die objektiven Teilungs- und Strukturprinzipien eingeschrieben sind. Es handelt sich um ein Gespür dafür, was man sich erlauben kann und was einem verwehrt ist. Die vornehmlich unbewusste, selbstverständliche und fraglos hingenommene Übernahme und Akzeptanz der Sozialordnung fungiert als wirksamer Mechanismus für die Aufrechterhaltung der bestehenden Ungleichheitsverhältnisse: Indem sich soziale Akteure das zuschreiben, was ihnen qua Distribution ohnehin zugeschrieben wird, bzw. das abwehren, was ihnen ohnehin verwehrt wird, schließen sie sich von selbst aus (ebd.). Die Grenzen existieren hierbei in der Vorstellung der Akteure, es sind symbolische Grenzen. Zum Undenkbaren der individuellen Lebensführung gehört das Überschreiten dieser Grenzen, das erst das Hinwegsetzen über die materiellen Schranken ermöglichen würde (Bauer, 2012).

Die Präferenz und Bestätigung des Habitus jener Strukturen, deren Produkt er bereits darstellt, nennt Bourdieu auch Homogamie-Effekt (u. a. Bourdieu \& Wacquant, 2006). Laut Bauer (2012) entfaltet der Homogamie-Effekt ,seine Wirksamkeit gerade erst dadurch, dass sich die Akteure lediglich vor krisenhaften Erfahrungen zu schützen versuchen, die eintreten, wenn erprobte Interpretationsund Handlungsmuster aufgegeben werden" (ebd., S. 136). Ein Beispiel hierfür ist, wenn Familien aus sozioökonomisch benachteiligten Lebensverhältnissen bzw. mit niedrigem Schulbildungsniveau trotz höherer Schullaufbahnempfehlung wenig ertragreiche Bildungslaufbahnen wählen oder sogar früher die Schule abbrechen. Die Bildungsmotive sowie entsprechende Bildungsstrategien und wahlen folgen hierbei einer herkunftsspezifischen Logik, sodass und dieses empirisch zu beobachtende Verhalten, das auf den ersten Blick wenig rational erscheint, als „offene Kampfansage“ (Grundmann, Groh-Samberg, Bittlingmayer, \& Bauer, 2003, S. 38) verstanden werden kann, formelle Schulbildungs- und Schulleistungsanforderungen zu unterwandern. Parallel zum Homogamie-Effekt bezeichnet Bourdieu diese konservative Funktion des Habitus als HysteresisEffekt und meint damit den Prozess der dauerhaften Anwendung einmal erworbener Wahrnehmungs-, Denk- und Handlungsschemata, die selbst um den Preis ihrer Dysfunktionalität nicht modifiziert werden (Bauer, 2012). Der Hysteresis-Effekt 
ist also eine Form von Trägheit, die den Habitus dauerhaft stabilisiert (Bourdieu, 1987).

\section{Das Konzept der Sozioanalyse - Möglichkeit der bewussten Weiterentwick- lung habitueller Wahrnehmungs-, Denk- und Handlungsmuster}

Gleichwohl Bourdieu mit dem Habituskonzept darlegt, dass Wahrnehmungs-, Denk- und Handlungsmuster von den sozialen Existenzbedingungen und biografischen Erfahrungen geprägt sind, hierbei zumeist unbewusst wirken und nur schwer veränderbar sind, sind Möglichkeiten der Weiterentwicklung von Habitusschemata in der theoretisch-konzeptionellen Anlage bei Bourdieu mitgedacht (ElMafaalani \& Wirtz, 2011). Die erste Variante kann als „Habitus-Struktur-Konflikt“ (Schmitt, 2010) beschrieben werden, der unbewusste und nicht intendierte Veränderungsprozesse anstößt. Etwa können Individuen in soziale Situationen geraten, in denen sie mit ihren Deutungen und Handlungen nicht weiterkommen. Eine derartige dauerhafte Nicht-Passung von Habitus und sozialem Kontext kann entweder zu Orientierungslosigkeit und Rückzug in das Herkunftsmilieu oder zu einem kreativen Lernprozess und schließlich zu Veränderungen des Habitus führen (El-Mafaalani \& Wirtz, 2011). Angemerkt sei, dass sich Bourdieu zufolge der Habitus in Abhängigkeit von neuen Erfahrungen zwar fortwährend wandelt und die Dispositionen einer ständigen Revision unterworfen sind, ,die aber niemals radikal ist, da sie sich auf Grundlage von Voraussetzungen vollzieht, die im früheren Zustand verankert sind“ (Bourdieu, 2001, S. 207).

Die zweite Variante stellt hingegen eine bewusste Entscheidung zur Veränderung dar, die durch eine sogenannte Sozioanalyse angestoßen wird:

Auch durch die Sozioanalyse kann der Habitus verändert werden, durch den Bewußtwerdungsprozeß, der es dem einzelnen erlaubt, seine Dispositionen unter Kontrolle zu bringen. Aber die Möglichkeit und Wirksamkeit dieser Form der Eigenanalyse sind selber teils durch die ursprüngliche Struktur des betreffenden Habitus bestimmt, teils durch die objektiven Bedingungen, unter denen sich die Bewußtwerdung vollzieht. (Bourdieu \& Wacquant, 2006, S. 167 f.)

Im Zentrum der Sozioanalyse steht demnach die differenzierte Auseinandersetzung mit der eigenen sozialen Herkunft und damit auch mit dem eigenen Habitus. Hierzu gehört die Bewusstmachung habitueller Möglichkeiten und vor allem Grenzen sowie die Reflexion der eigenen Verstrickung in gesellschaftliche Macht- und Herrschaftsverhältnisse. Indem der soziale Akteur sich selbst und strukturelle Zwänge reflektiert, gewinnt er Kontrolle über seine Dispositionen (Schmitt, 2010). 
Diese Art der Selbstanalyse hat Bourdieu mit „Ein soziologischer Selbstversuch“ (2002) an seiner eigenen Person vorgenommen. Die Veröffentlichung, die er ausdrücklich nicht als Autobiografie verstanden sehen will, beginnt mit einer genauen Analyse des wissenschaftlichen Feldes der Philosophie und der Soziologie im Frankreich der 1950er und 1960er Jahren und seine Stellung darin (Brake, 2015). Aus Bourdieus Sicht ist die Soziologie hierbei „ein höchst machtvolles Instrument der Selbstanalyse, die es einem ermöglicht, besser zu verstehen, was man ist, sowie die Stellung begreifen lässt, die man innerhalb der sozialen Welt innehat" (Bourdieu 2002, S. 223). Die Sozioanalyse steht also zunächst einmal im Zusammenhang einer reflexiven Objektivierung von Forschungspraxis. Hier spielt die Idee des Bruchs eine zentrale Rolle: Die Forschenden müssen sich von den vermeintlichen Selbstverständlichkeiten, den unhinterfragt gültigen Wissensbeständen und Begrifflichkeiten im Alltag und im wissenschaftlichen Feld distanzieren. Das heißt, es besteht die Notwendigkeit, mit den Alltagstheorien, den Common Sense-Theorien zu brechen. Des Weiteren besteht die Notwendigkeit, in allen Forschungsschritten mitzuführen, dass das eigene Forschungsinteresse, die methodische Vorgehensweise und der analytische Blick auf das empirische Material von einer jeweils spezifischen sozialen Position aus eingenommen werden. Es geht also darum, die eigene wissenschaftliche Laufbahn auf die Konstruktion des Forschungsgegenstandes zu reflektieren (Brake, 2015). Die Sozioanalyse ist demnach im Forschungsprozess unerlässlich, um die eigene Standortgebundenheit methodisch zu kontrollieren. Bourdieu fasst zusammen, dass es der wissenschaftlichen Reflexivität gelingen muss, ,sich in den Mechanismen des Feldes [...] einerseits und in den Einstellungen der Akteure andererseits zu institutionalisieren" (Bourdieu, 1993, S. 373). Die wissenschaftliche Reflexivität interessiert sich demnach nicht für die Forschungstätigkeit einzelner Akteure, ,,sondern [für] das in die wissenschaftlichen Werkzeuge und Operationen eingegangene soziale und intellektuelle Unbewußte" (Bourdieu \& Wacquant, 2006, S. 63, Hervorhebung im Original, Anmerkung S. R.). So ist wissenschaftliche Reflexivität auch „ein kollektives Unternehmen und nichts, was dem Wissenschaftler individuell aufzubürden wäre" (ebd., Hervorhebung im Original, Anmerkung S. R.).

Für Bourdieu hat die Sozioanalyse vom Grundsatz her eine emanzipatorische Wirkung. Indem sich der soziale Akteur intensiv mit der eigenen Herkunft auseinandersetzt und eine reflexive Brechung eingeht, erkennt er die Gesetzmäßigkeiten und restriktiven Elemente seiner eigenen Denk- und Handlungsmuster. Durch die daraus resultierende praktische Einsicht gewinnt er an Rationalität und Deutungsvermögen (El-Mafaalani \& Wirtz, 2011). Schmitt (2011) gibt hierbei zu bedenken, dass das Bewusstwerden eigener habitueller Grenzen auch entmutigend wirken und die Verantwortlichkeit für eigenes Handeln reduzieren bzw. das Gefühl von 
Ohnmacht gegen strukturelle Ungerechtigkeit fördern kann. Befreiend wirkt die Sozioanalyse dann, wenn sie ein ,Verstehen“ (Bourdieu, 1997) zwischen Personen unterschiedlicher sozialer Herkunft ermöglicht. Damit meint Bourdieu die Fähigkeit, ,sich gedanklich an den Ort zu versetzen, den der Befragte im Sozialraum einnimmt“" (ebd., S. 786). Weiter führt Bourdieu aus, dass es darum geht, ein

generelles und genetisches Verständnis der Existenz des anderen anzustreben, das auf der praktischen und theoretischen Einsicht in die sozialen Bedingungen basiert, deren Produkt er ist: Eine Einsicht in die Existenzbedingungen und Mechanismen [...], eine Einsicht in die untrennbar verwobenen psychischen und sozialen Prägungen, die mit der Position und dem biographischen Werdegang dieser Person im Sozialraum einhergehen. (ebd.)

Ein solches Verständnis ist mehr als „ein wohlwollender Gemütszustand“ (ebd.) und bedeutet nicht im phänomenologischen Sinn das emotionale Hineinversetzen bzw. Hineinprojizieren in den Anderen. Vielmehr geht es um ein Verständnis dafür, weshalb die Person zu einer bestimmten Grundhaltung gegenüber der Welt gelangt ist und welche sozial strukturierenden Prinzipien sich dahinter verbergen (Barlösius, 2004). Insgesamt kann Bourdieus Sozioanalyse bzw. Konzept wissenschaftlicher Reflexivität als ein sehr anspruchsvolles und komplexes Programm bezeichnet werden, das Zeit und Mühe beansprucht, da über viele Jahre inkorporierte Wahrnehmungs-, Denk- und Handlungsmuster aufgebrochen werden (El-Mafaalani \& Wirtz, 2011).

\section{Die pädagogische Arbeit - Habitusprägung und Ausübung symbolischer Gewalt}

In den „Grundlagen einer Theorie der symbolischen Gewalt“ legen Bourdieu und Passeron (1973) dar, dass jede Pädagogik prinzipiell durch eine doppelte kulturelle Willkür gekennzeichnet ist. Mit der ersten Form der Willkür ist gemeint, dass sich Lehrkräfte in der pädagogischen Arbeit an der Definition von Bildungsinhalten der herrschenden Gruppen orientieren (ebd.). Wie bereits erläutert, unterliegt das schulische Bildungsverständnis stets einem gesellschaftlichen Konstruktionsund Wertungsprozess, wobei die Auswahl der institutionellen Bildungsinhalte als natürlich gesetzt erscheinen (Solga, 2005). Institutionalisierte Bildung wird durch staatlich anerkannte Zertifikate und Abschlüsse verbürgt und gilt als legitime Bildung. Nicht anerkannt bzw. negiert werden erfahrungsweltlich vermittelte Bildungsprozesse und -inhalte, die mit den in der Schule dominierenden Leistungsund Qualifikationsanforderungen kaum in Verbindung stehen (Grundmann, GrohSamberg, Bittlingmayer, \& Bauer, 2003). Die zweite Form der Willkür begreift 
pädagogisches Handeln als Durchsetzungs- und Einprägungsarbeit bzw. als Erziehung im Sinne einer Habitusprägung, die den Orientierungen und Vorstellungen statushöherer Gruppen entspricht und Ausdruck und Resultat des zugrundeliegenden Macht- und Herrschaftsverhältnisses zwischen den sozialen Gruppierungen ist (Bourdieu \& Passeron, 1973). Damit ist der Modus der Durchsetzung und Einprägung angesprochen, der, vergleichbar mit der Auswahl der Bildungsinhalte, historisch und kulturspezifisch variabel ist. Deutlich wird dies am Beispiel der körperlichen Züchtigung als Erziehungsmittel, das aus heutiger Sicht eine illegitime Form pädagogischen Handelns darstellt, zu anderen historischen Zeitpunkten jedoch als selbstverständlich und sogar gewünscht galt (Kramer, 2011). In dieser Perspektive ist ,jede pädagogische Aktion [...] objektiv symbolische Gewalt, insofern sie mittels einer willkürlichen Gewalt eine kulturelle Willkür durchsetzt“" (Bourdieu \& Passeron, 1973, S. 13).

Bourdieu und Passeron betonen, dass die symbolische Gewalt in der pädagogischen Arbeit weder bewusst oder mutwillig ausgeübt wird, noch explizit auf die Herrschaftssicherung bezogen sein muss (ebd.). In diesem Zusammenhang sei als Gegenbeispiel zur körperlichen Züchtigung auf die antiautoritäre Erziehung verwiesen. Auch eine repressionsfreie, weisungslose, dem Kind zugewandte Pädagogik beinhaltet den Aspekt der Willkür, insofern sie bei einem bestimmten Stand der Kräfteverhältnisse das einzig wirksame Mittel zur Durchsetzung der kulturellen Willkür darstellt. Pädagogische Orientierungen wie Individualisierung, Subjektorientierung und Kindzentrierung sind nicht nur Mittel der Verschleierung der schulischen Anforderungen, sondern zugleich eine legitime Strategie der Unterwerfung der Schüler*innen (ebd.). Um hier die eigentliche symbolische Wirkung zu entfalten, muss die Durchsetzung der bestehenden Kräfteverhältnisse den Weg über die pädagogische Kommunikation nehmen und ist vor allem auf eine pädagogische Autorität angewiesen. Andernfalls könnte die pädagogische Arbeit die doppelte kulturelle Willkür nicht mehr oder nur noch im Modus roher Gewalt rechtfertigen - die Legitimität der pädagogischen Arbeit ist jedoch umso stärker, je weniger sich die Herrschaftssicherung auf offene Gewaltformen berufen muss (ebd.). Die pädagogische Kommunikation und die pädagogische Autorität beruhen demzufolge im Wesentlichen auf der Verschleierung und Verkennung der doppelten kulturellen Willkür. Darüber hinaus wird insbesondere die pädagogische Autorität zu einer symbolischen Gewaltmacht, ,,die sich in Form eines legitimen Durchsetzungsrechts äußert“ (ebd., S. 23). Bourdieu und Passeron betonen, dass die Anerkennung der pädagogischen Arbeit nicht vorrangig auf einen psychologischen Akt oder auf einer bewussten Zustimmung der an Schule beteiligten Personen beruht - selbst den Lehrkräften ist in der Anerkennung der Legitimität der Bildungsinstitution die Einsicht in die Grundlagen der doppelten Willkür ihres 
Handelns verwehrt. Vielmehr entfaltet die pädagogische Autorität eine umfassende symbolische Gewaltmacht, wenn sie eine selbstverständliche und zwanglose Anerkennung findet (ebd.).

Wesentlich in der Theorie der symbolischen Gewalt ist demnach die pädagogische Praxis, in der Lehrkräfte soziale Bedingungen schaffen, die zwischen kultureller Nähe oder kultureller Ferne zur durchgesetzten kulturellen Willkür der pädagogischen Arbeit changieren. Bourdieu und Passeron markieren differente Varianten der kulturellen Passung zwischen dem primären Habitus, der in der familialen Sozialisation und dem Herkunftsmilieu erzeugt wird, und der sekundären pädagogischen Arbeit. Der Erfolg jeder schulischen Erziehung hängt dann von der Distanz ab, die den Habitus, den sie einprägen will, von dem Habitus trennt, der durch die vorhergehende primäre Sozialisation eingeprägt worden ist (ebd.). Prototypisch formuliert bestehen zwei Möglichkeiten: Entweder trifft die pädagogische Arbeit auf Schüler*innen, deren primärer Habitus eine relative Nähe zum schulisch sekundär anvisierten Habitus aufweist und die sich entsprechend das, was ihnen vermittelt werden soll, schon angeeignet haben. Oder aber die pädagogische Arbeit trifft auf primäre Habitusformen, die mehr oder weniger deutlich vom sekundären Habitus der Schule abweichen. Im ersten Fall handelt es sich im Sinne einer „Reedukation“ (ebd., S. 61) um eine Bestätigung und Verstärkung der bereits in der Primärsozialisation erworbenen habituellen Dispositionen. Im zweiten Fall bedeutet die sekundäre pädagogische Arbeit einen Bruch mit den Erfahrungen und Fähigkeiten der Primärsozialisation und der größere Abstand zwischen dem primären und dem sekundären Habitus nimmt den Charakter der „Dekulturation“ an (ebd.). Aus dieser Perspektive wird deutlich, dass der besondere Erfolg der pädagogischen Arbeit eigentlich nur bedingt eine Leistung der Schule ist, da er auf eine vorangegangene erfolgreiche Habitusprägung in der Familie aufbaut (Bauer, 2012).

\section{Ungleichheitsbezogene Bildungsforschung im Anschluss an Pierre Bourdieus Konzept der kulturellen Passung}

Die Bezugnahme auf Arbeiten Bourdieus innerhalb der empirischen Bildungsforschung reduziert sich zumeist auf die isolierte Betrachtung des kulturellen Kapitals der Schüler*innen und ihrer Familien. Dadurch geraten jedoch lediglich schulextern zurechenbare Faktoren für Bildungsbenachteiligung in den Blick (Kramer \& Helsper, 2010). Bourdieus komplex angelegtes Theorem der kulturellen Passung zwischen den Haltungen des familialen Herkunftsmilieus und den schulischen Anforderungs- und Anerkennungsstrukturen wird bislang kaum empirisch untersucht. Hervorzuheben ist hierbei für Deutschland die Studie von 
Grundmann, Groh-Samberg, Bittlingmayer und Bauer (2003), die lebensweltliche Bildungsprozesse in der Familie und unter Gleichaltrigen sowie die daraus resultierenden Anschlussmöglichkeiten im Bildungssystem untersucht. Es geht den Autor*innen vor allem darum, nachzuzeichnen, wie ,sich soziale Strukturen im konkreten Habitus der Individuen niederschlagen und dabei auch nachhaltig die Persönlichkeitsentwicklung beeinflussen“ (Grundmann, Dravenau, Bittlingmayer, \& Edelstein, 2006, S. 12). In ihrem Ansatz erweitern die Autor*innen den Bildungsbegriff über schulisch vermittelte Bildungsinhalte hinaus und verankern ihn unter Bezugnahme auf die Milieuforschung sozialstrukturell (Vester, von Oertzen, Geiling, Hermann, \& Müller, 2001). Unter dem Begriff der milieuspezifischen Handlungsbefähigung fassen die Autor*innen ,individuelle Kompetenzen, Dispositions- und Handlungsmuster, die an die Bedingungen der sozialen Herkunft angepasst sind, also milieuspezifisch variieren" (Grundmann, Groh-Samberg, Bittlingmayer, \& Bauer, 2003, S. 27), zusammen. Grundlegend für die Untersuchung ist demnach die Annahme, dass unterschiedliche Milieus auf differente Erfahrungsräume, Sinn- und Anerkennungsstrukturen verweisen, die wiederum konstitutiv für die Bildungsaneignung sind (ebd.). Die Autor*innen ermitteln entsprechend ,grundlegende Unterschiede in den Passungschancen bzw. Konfliktpotentialen“ (ebd., S. 37) für ausgewählte Sozialmilieus. So ist bspw. in den akademischen Oberklasse-Milieus ,eine optimale Abstimmung aller Realitätsbereiche und ihrer Handlungsrationalitäten am wahrscheinlichsten“ (ebd., S. 37), da familiale und schulische Bildungsstrategien nahezu zwanglos ineinander aufgehen. Für die unteren Klassenmilieus erweisen sich demgegenüber die schulischen Bildungsangebote und -anforderungen als wenig passend $\mathrm{zu}$ den milieuspezifischen Handlungsbefähigungen (ebd.). Die Höherbewertung institutioneller Bildung gegenüber außerschulischen Bildungsinhalten und -prozessen in der Familie und in den Milieus wird von den Autor*innen als eine zentrale Ursache für die Entstehung und Verfestigung von Bildungsungleichheit identifiziert (Grundmann, Dravenau, Bittlingmayer, \& Edelstein, 2006).

In diesem Kontext zu verorten ist auch die Studie von Jünger (2008) zu schulischen Logiken von Kindern aus sozial benachteiligten und privilegierten Milieus als Ursache der persistenten Bildungsungleichheit. So kann Jünger feine Unterschiede hinsichtlich der in der familialen Sozialisation erworbenen Lernmotivation und der Verantwortung für Lernleistungen aufzeigen. Für nichtprivilegierte Kinder hat die Schule eine existenzsichernde Funktion. Sie haben das Leistungsprinzip internalisiert, dem zufolge der Schulerfolg auf eigenen Anstrengungen beruht. Ihr Lernbegriff ist funktional: Lernen dient der Vorbereitung für den späteren Beruf und nicht des Lernens willen oder gar zum Vergnügen. Daraus 
resultiert ein enormer Druck, das eigene Bildungsideal umzusetzen. Den Kindern aus sozial benachteiligten Lebensverhältnissen fehlt der Autorin zufolge der Zugang zum Lernen und die entsprechenden Bildungsstrategien. Zum Teil wird der Druck auch durch die hohe Erwartungshaltung der Eltern verstärkt, gleichwohl die Familie keine schulische Hilfestellung anbieten kann. Im Gegensatz dazu lernen sozial privilegierte Kinder mit Leichtigkeit und Spaß und können ohne belastenden Leistungsdruck auf die familiale Unterstützung zurückgreifen. Ein weiterer relevanter Unterschied ist, dass die Kinder aus privilegierten Familien relativ genaue und positive Zukunftserwartungen aufweisen. Sie sind zudem in der Lage, der Schule und den Lehrkräften gegenüber eine kritische Haltung einzunehmen. Selbstbewusst treten sie den Lehrkräften gegenüber und fordern guten Unterricht ein (ebd.).

Die Arbeitsgruppe von Helsper und Kramer erforscht ebenfalls das Zusammenspiel von milieuspezifischen Bildungsvorstellungen und -strategien der Schüler*innen sowie Strukturen und Anforderungslogiken der Schule. Anhand einer Längsschnittuntersuchung untersuchen die Wissenschaftler*innen schul- und bildungsbezogene Orientierungen von Schüler*innen beim Übergang von der Grundschule in die weiterführende Schule. Anhand von Fallstudien entwirft die Forscher*innengruppe eine Typologie von kindlichen Habitusformen, die von einer explizit formulierten Bildungsdistinktion bis hin zu einer Distanz- und Fremdheitshaltung zu Schule und institutionalisierter Bildung reicht (Kramer, Helsper, Thiersch, \& Ziems, 2009). So lässt sich der Habitus der Bildungsexzellenz und -distinktion nur bei Schüler*innen rekonstruieren, die auf ein exklusives Gymnasium mit zusätzlicher Eingangsprüfung wechseln. Kennzeichnend ist eine umfassende Bildungsorientierung, die sich auf hochkulturelle Inhalte wie bspw. anspruchsvolle Zeitungen richtet. Diese Schüler*innen fühlen sich dem Schulischen überlegen und durch das schulische Lernen unterfordert. Sie folgen einer ausgesprochenen Leistungsorientierung und absolvieren die Schulzeit mit Leichtigkeit und ohne Anstrengung. Die enormen Ansprüche bezüglich schulischer Leistung und Bildungsperfektion bergen hierbei die Gefahr des subjektiven Gefühls des Versagens auf höchstem Leistungsniveau. Grundsätzlich setzen sich diese Schüler*innen mit ihrem speziellen Bildungsgeschmack und ihren herausragenden Spitzenleistungen von ihren Mitschüler*innen ab und fühlen sich eher der Welt der Erwachsenen zugehörig (ebd.). Der Habitus der Bildungsstrebenden grenzt sich vom Habitus der Bildungsexzellenz und -distinktion dahingehend $\mathrm{ab}$, dass es etwas nicht Selbstverständliches noch zu erreichen gilt. Demzufolge ist dieser Habitus in einem Spannungsverhältnis zwischen schon Erreichtem und noch nicht Realisiertem zu verorten. Auf der einen Seite werden für die Familien mehr oder weniger fremde Bildungsorte und -ziele angestrebt, auf der anderen 
Seite sind im hohen Stellenwert von Bildung, sehr guten Schulleistungen und der strebenden Bildungshaltung bereits Elemente des Angestrebten enthalten. Die Schüler*innen dieses Habitus stammen aus bildungs- und aufstiegsorientierten Familien und befinden sich vor allem an Gymnasien. Die Autor*innen differenzieren hierbei hinsichtlich der Deutlichkeit sowie der Eigen- bzw. Fremdbestimmung des Bildungsstrebens drei unterschiedliche Dimensionen dieses Habitus: der Habitus des exklusiven Strebens, der Habitus des moderaten Strebens und der Habitus des (leidvoll) auferlegten Strebens (ebd.). Der Habitus der Bildungskonformität und -notwendigkeit umfasst Schüler*innen, die angesichts ihrer angepassten Haltung, der Fokussierung auf den Schulabschluss sowie ihrer unauffällig verlaufenden Lernbiografie bisher sowohl in der Schul- und Bildungsforschung als auch im Schulkontext wenig Beachtung finden. Hierbei stammen die Schüler*innen dieses Habitus überwiegend aus schulbildungsfernen Herkunftsmilieus und stehen schulischen Inhalten und Regeln entsprechend fremd gegenüber. Gleichwohl verbürgen sie die schulischen Anforderungsstrukturen in hohem Maße und orientieren sich vor allem an der Leistungsmitte. Grundlegend ist der Anspruch, unter den Mitschüler*innen nicht aufzufallen und als anständiger und guter Schüler bzw. als anständige und gute Schülerin zu gelten. Neben der schulkonformen Orientierung kennzeichnet dieser Habitustyp eine formale Abschlussorientierung. So dient die Schule als funktionaler Qualifizierungsraum, der über die Aushändigung von institutionell anerkannten Bildungszertifikaten eine Berufsausbildung ermöglicht. Mitunter wird Schule auch von einigen Schüler*innen als Zwang erlebt, sodass nur das notwendige schulische Pflichtprogramm durchlaufen wird (ebd.). Einen Großteil der Schüler*innen ordnen die Wissenschaftler*innen in ihrer Längsschnittstudie dem Habitus der Bildungsfremdheit zu. Die Schüler*innen der Gesamt-, Sekundar- und Hauptschulen weisen insbesondere eine Fremdheit gegenüber institutioneller Bildung auf und präferieren Schulen, die einen mittleren oder unteren Abschluss sowie Integrationsmöglichkeiten und außerschulische Bildungsangebote anbieten. Aufgrund der differenten Lebenswelten von Schule und Familie besteht stets die Gefahr, in der Schule zu scheitern. Negative Schulerfahrungen schlagen sich vor allem im Selbstkonzept der Kinder nieder. Auch bei diesem Habitustyp werden drei Untertypen herausgearbeitet, die sich im Umgang mit der Bildungsfremdheit unterscheiden: der Habitus der Spannung zwischen schulischer Bildungskonformität und -fremdheit, der Habitus der schulischen Bildungsferne und angedeuteter Opposition sowie der Habitus der schulischen Bildungsferne und -hilflosigkeit (ebd.). Zusammenfassend entstehen je nach Schulkultur ,spezifische Schule-Milieu-Passungen bzw. Schule-Milieu-Abstoßungen“ (Kramer \& Helsper, 2010, S. 110). In der Längsschnittuntersuchung entlang der Schulkarriere vom Ende der vierten Klasse bis 
zum Ende der neunten Klasse können Kramer, Helsper, Thiersch und Ziems (2013) darüber hinaus aufzeigen, wie sich die bereits früh in der Familie ausgebildeten bildungsbezogenen Habitusformen der Schüler*innen im zeitlichen Verlauf ändern resp. wann und durch welche schulischen Anforderungsstrukturen diese unter Druck geraten bzw. verfestigen werden (ebd.).

Mittels der Analyse von Begrüßungsreden der neuen Schüler*innen bei Schuljahresbeginn skizzieren Helsper, Kramer, Hummrich und Busse (2009) ferner idealtypische sekundäre Habitus unterschiedlicher Schulen. Exemplarisch sei an dieser Stelle der geforderte Schüler*innentypus einer stark reformpädagogisch orientierten Gesamtschule erwähnt, der sich durch eine kritische, reflexive Haltung auszeichnet. Der Schüler bzw. die Schülerin soll sich nicht scheuen, das Entthematisierte und Tabuisierte mutig anzusprechen, soll unbequem sein, sich nicht unterwerfen lassen, sich zugleich um andere sorgen, Ängste und Nöte mitempfinden und sich durch eine Haltung des sozialen Engagements im Dienst an der Gemeinschaft auszeichnen. Der entworfene modellhafte Schüler*innenhabitus weist starke Homologien mit der Lebensführung des liberal-intellektuellen Milieus und des Alternativmilieus auf und ermöglicht somit Schüler*innen dieser beiden zentralen Bezugsmilieus eine optimale schulische Passung. NichtPassungen entstehen insbesondere bei dem konservativ-technokratischen und den kleinbürgerlichen und traditionalen Arbeitermilieus, die eher konventionellen und autoritären Mustern folgen und stark hierarchiegebunden sind, sowie den am Materiellen, Konsum und an hedonistischen Ausschweifungen orientierten Milieus (ebd.).

Das Lehrer*innenhandeln als Durchsetzungs- und Einprägungsarbeit im Sinne einer Habitusprägung (Bourdieu \& Passeron, 1973), die den Orientierungen und Vorstellungen statushöherer Gruppen entspricht, ist Bourdieu und Passeron zufolge deshalb so wirksam, weil Lehrkräfte selbst ,das perfekteste Produkt des Produktionssystems [bilden] das zu reproduzieren unter anderem ihre Aufgabe ist" (ebd., S. 212). Mit Blick auf die Positionierung im sozialen Raum vermerkt Bourdieu bereits in „Die feinen Unterschiede“ (1982), dass die Positionen der Lehrkräfte durch ein relativ hohes kulturelles und soziales, aber ein vergleichsweise niedrigeres ökonomisches und auch symbolisches Kapital gekennzeichnet sind und demnach zur herrschenden Klasse zählen (ebd.). Hinzu kommt, dass Lehrkräfte

durch ihre eigene erfolgreiche Schulzeit belegt haben, dass sie zur kulturellen Willkür der pädagogischen Einprägungsarbeit in keinem grundsätzlich antagonistischen Verhältnis stehen, sondern vermutlich eher jenes System selbst zu reproduzieren 
trachten, das ihren eigenen schulisch-beruflichen Erfolg ermöglicht hat. (Kramer, 2015, S. 352)

Befunde zur sozialen Herkunft der Lehrkräfte in Deutschland bestätigen weiterhin Bourdieus Aussage zur sozialen Position der Lehrkräfte. So erfasst Schumacher (2002) die Milieuzugehörigkeit von im Beruf stehenden sowie angehenden Lehrkräften der Primarstufe. Die Befragten gehören zu einem außerordentlich hohen Anteil dem liberal-intellektuellen Milieu (68,3 Prozent) sowie dem konservativ-technokratischem Milieu (11,3 Prozent) der SinusLebensweltforschung an. Lediglich geringe Anteile der Lehramtsstudierenden und Lehrer*innen stammen aus den Arbeitermilieus oder aus dem aufstiegsorientierten Milieu (ebd.). Zwar verweisen rezente Befunde auf eine größere sozial verschiedene Zusammensetzung der Lehrkräfte, in Bezug auf Milieubezüge der Schüler*innen handelt es sich jedoch um eine vergleichsweise geringe Heterogenität. Zudem gibt es bestimmte Verteilungsschwerpunkte: Je gesellschaftlich höher angesehen die Schulform ist, desto höher ist die soziale Herkunftsgruppe von Lehrkräften und Schüler*innen (Lange-Vester \& Teiwes-Kügler, 2014).

Empirische Studien, die dezidiert den Einfluss der sozialen Herkunft der Lehrkräfte auf ihre pädagogische Arbeit in den Analysefokus stellen, entwickeln sich erst in jüngerer Zeit. Etwa leitet Schumacher (2002) aus der jeweiligen Milieuzugehörigkeit der Lehrkräfte Vorstellungen von der Schul- und Unterrichtsgestaltung ab: Lehrkräfte des liberal-intellektuellen Milieus präferieren beispielsweise ein offenes, aktives und kooperatives Schul- und Klassenklima, offene Lehrverfahren sowie eine bewusst differenzierte und am Individuum orientierte Aufbereitung der Unterrichtsinhalte. Zudem befürworten diese Lehrkräfte ein Mitspracherecht für Schüler*innen bzgl. der Unterrichtsgestaltung. Die Autorin kommt zu dem Schluss, dass ein deutlicher Zusammenhang zwischen sozialer Herkunft und pädagogischen Grundorientierungen sowie Deutungsmustern vorliegt (ebd.).

Einen weiteren aufschlussreichen Ansatz für die vorliegende Arbeit leistet der Arbeitszusammenhang von Bremer, Lange-Vester und Teiwes-Kügler. Die Forscher*innengruppe legt auf Grundlage einer Vielzahl an Einzelinterviews und erweiterten Gruppendiskussionen sowie gestützt auf das Konzept der sozialen Milieus nach Vester, von Qertzen, Geiling, Hermann und Müller (2001) ein breites Spektrum von Lebensprinzipien und Handlungsmuster dar, die an den jeweiligen sozialen Ort der Lehrkräfte gebunden sind und an die Schüler*innenschaft herangetragen werden (u. a. Lange-Vester, 2015; Bremer \& Lange-Vester, 2014; Lange-Vester \& Teiwes-Kügler, 2014; Lange-Vester \& Teiwes-Kügler, 2013). Die Befunde verweisen auf durch ,unterschiedliche Grade des Verstehens bzw. 
Nicht-Verstehens, der Wertschätzung und Anerkennung“ (Lange-Vester \& TeiwesKügler, 2014; S. 199) gekennzeichnete Interaktionsbeziehungen. So konstatieren Lange-Vester und Teiwes-Kügler (2014), dass Schüler*innen, die weniger Übereinstimmung mit den Haltungen der jeweiligen Lehrkraft aufweisen, aus dem Blick geraten oder aus einer defizitären Perspektive wahrgenommen werden. Lange-Vester (2015) arbeitet zudem drei Habitusmuster von Lehrkräften heraus, die mit milieuspezifischen Haltungen korrespondieren: Eigenverantwortung und Integration, Disziplin und Ordnung sowie Emanzipation und Leistung. Über die Milieugrenzen hinweg zeichnet sich bei den Lehrpersonen eine problemorientierte Sichtweise auf Orientierungen und Praktiken der unteren sozialen Gruppen ab (ebd.).

Aktuelle Forschung im deutschsprachigen Raum zu Lehrkräften mit Migrationshintergrund kann überdies zeigen, dass die Programmatik, verstärkt Lehrkräfte mit Migrationshintergrund zur Verbesserung des Schulerfolgs von Schüler*innen mit Migrationshintergrund einzustellen, mit ambivalenten Effekten einhergeht und nicht - wie unterstellt - aufgrund der eigenen biografischen Erfahrungen zwangsläufig positiv ist (u. a. Fabel-Lamla \& Klomfaß, 2014; Akbaba, Bräu, \& Zimmer, 2013; Georgi, Ackermann, \& Karakas, 2011). Etwa untersucht Rotter (2014) das berufliche Fremd- und Selbstkonzept von Lehrkräften mit Migrationshintergrund. Die Autorin rekonstruiert mithilfe themenzentrierter Interviews verschiedene Typen, die sich darin unterscheiden, welche Bedeutung dem Merkmal Migrationshintergrund für ihr berufliches Handeln beigemessen wird. So definieren sich Lehrkräfte mit Migrationshintergrund, die dem Typus pädagogisch-professioneller Lernbegleiter zuzuordnen sind, vor allem fachwissenschaftlich und schreiben sich selbst keine spezifischen Funktionen bezüglich Schüler*innen mit Migrationshintergrund zu bzw. lehnen diesbezügliche Erwartungen ab. Der Migrationshintergrund spielt in diesem Typus keine Rolle. Eine zweite Gruppe von Lehrkräften mit Migrationshintergrund, der situative Sowohlals-auch Typus, übernimmt je nach Situation bereitwillig die an sie herangetragene Vorbild- und Vermittlungsfunktion. Lehrkräfte mit Migrationshintergrund, die dem kompetenten ,Migrationsanderen“ Typus angehören, nennen von sich aus spezifische Funktionen für Schüler*innen mit Migrationshintergrund und leiten diese aus einem (vermeintlich) gemeinsamen Erfahrungshintergrund ab. Dem Migrationshintergrund kommt ein zentraler Stellenwert zu (ebd.).

Edelmann (2006) arbeitet anhand einer qualitativen Befragung von Schweizer Primarlehrkräften mit und ohne Migrationshintergrund den pädagogischen Umgang mit Schüler*innen mit Migrationshintergrund heraus. Als Ergebnis stehen sechs verschiedene Typen: (1) der abgrenzend-distanzierte, (2) der stillschweigend-anerkennende, (3) der individuell-sprachorientierte, (4) der 
kooperativ-sprachorientierte, (5) der individuell-synergieorientierte und (6) der kooperativ-synergieorientierte Typus. Die Sichtweisen und Orientierungen des pädagogischen Handelns changieren von einer Vielfalt ignorierenden Haltung bis hin zu einer Orientierung, die durch eine reflexive Berücksichtigung der Heterogenität in der gesamten pädagogischen Tätigkeit gekennzeichnet ist. Miteinbezogen ist auch, ob es sich um eine Einzelstrategie oder um eine teamorientierte bzw. in der Schulkultur verankerte Strategie handelt. Insgesamt weisen von den 40 befragten Lehrkräften 15 Lehrkräfte nach Selbstauskunft einen Migrationshintergrund auf. Die Lehrkräfte mit Migrationshintergrund treten bis auf den abgrenzend-distanzierten Typus in allen Typen auf. Zudem werten sie ihre persönlichen Migrationserfahrungen und den eigenen biografischen Hintergrund als wichtige Ressource für ihr pädagogisches Handeln. Insbesondere Empathie mit Schüler*innen und Eltern mit Migrationshintergrund sowie eine Vorbildfunktion für Schüler*innen mit Migrationshintergrund bilden zentrale Aspekte dieser Einschätzung. Des Weiteren stellt Edelmann fest, dass in Bezug auf den eigenen Bildungserfolg Lehrkräfte mit Migrationshintergrund hohe Leistungsanforderungen und -erwartungen an Schüler*innen mit Migrationshintergrund stellen (ebd.).

Die beiden exemplarisch präsentierten Untersuchungen von Rotter (2014) und Edelmann (2006) zeigen, dass biografische Erfahrungen von Lehrkräften mit Migrationshintergrund zum Teil erhebliche Bedeutung für das berufliche Selbstkonzept und somit auch für die pädagogische Praxis haben. Darüber hinaus dokumentieren die Studien, dass aufgrund der steigenden Anzahl von Lehrkräften mit Migrationshintergrund von einer zunehmenden Heterogenität der Lehrer*innenschaft auszugehen ist. Die Forschung zu Lehrkräften mit Migrationshintergrund verweist darüber hinaus auch auf die Erfordernis, unterschiedliche Passungsverhältnisse zwischen Lehrpersonen mit Migrationshintergrund und Schüler*innen mit Migrationshintergrund näher zu beleuchten.

\section{Zwischenfazit}

Wie die knapp skizzierten konzeptionellen Annahmen und die daran anschließenden Studien zeigen, wird der Schule und den Lehrkräften in der theoretischen Perspektive von Bourdieu ein eigenständiger Stellenwert zur Entstehung und Verstärkung der Bildungsungleichheit eingeräumt. Kramer (2015) resümiert, dass Lehrkräfte von diesem Standpunkt aus als „Reproduktionsagenten“ (ebd., S. 344) erscheinen, insofern sie durch ihr pädagogisches Handeln an der Perpetuierung sozialer Ungleichheitsverhältnisse beteiligt sind. Dabei handelt es sich nicht um eine bewusste Benachteiligung, sondern vielmehr um das Ergebnis inkorporierter sozialer Strukturen im Habitus, die zu spezifischen Wahrnehmungsweisen, 
Einstellungen und Handlungspraktiken auch in der pädagogischen Arbeit führen. Demzufolge ist es der Habitus der Lehrpersonen, der durch die Nähe zur schulisch repräsentierten kulturellen Willkür selbst wiederum diejenigen Schüler*innen bestätigt und anerkennt, die den institutionellen Anforderungen besonders nahekommen (ebd.).

Insgesamt verdeutlichen die empirischen Untersuchungen, die an Bourdieus Vorstellung einer kulturellen Passung anknüpfen, einerseits, welches Potenzial zur Erklärung für den Reproduktionszusammenhang von sozialen Herkunftsbedingungen und Schulerfolgsaussichten in den Überlegungen von Bourdieu liegt, und andererseits, welche Forschungslücken derzeit noch bestehen. So gilt es grundsätzlich, die Varianten der kulturellen Passung zwischen Schule und Familie stärker herauszuarbeiten und dabei dezidiert den Einfluss der sozialen Herkunft der Lehrkräfte auf die pädagogische Arbeit in die aktuelle ungleichheitsorientierte Bildungsforschung mit einzubeziehen (vgl. hierzu auch: Bremer \& Lange-Vester, 2014; Kramer, 2011; Kramer \& Helsper, 2010). Denn obwohl Bourdieu und Passeron $(1971 ; 1973)$ hervorheben, wie eng das pädagogische Handeln mit Fragen der Sicherung sozialer Privilegierung und Reproduktion sozialer Verhältnisse verwoben ist und als Durchsetzungs- und Einprägungsarbeit im Sinne einer Habitusprägung den jeweils herrschenden Vorstellungen entspricht, sind Ausgangspunkt der meisten bisher vorliegenden empirischen Analysen die milieuspezifischen bzw. habitualisierten Bildungsorientierungen der Schüler*innen und deren Anschlussfähigkeit an schulische Anforderungs- und Anerkennungsstrukturen (u. a. Grundmann, Groh-Samberg, Bittlingmayer, \& Bauer, 2003; Kramer, Helsper, Thiersch, \& Ziems, 2009; Jünger, 2008). Die wenigen Untersuchungen, die sich ausdrücklich den Habitus- und Milieumustern der Lehrkräfte und deren Bedeutung für pädagogische Auffassungen und Praktiken (u. a. Lange-Vester, 2015; Lange-Vester \& Teiwes-Kügler, 2014; Schumacher, 2002) widmen, verweisen auf die Vielfalt und Komplexität der Handlungsprinzipien von Lehrkräften sowohl auf der Ebene der Schulform als auch auf der Ebene der Einzelschule.

\subsubsection{Bezugspunkte in der empirischen Bildungsforschung zu Orientierungen und Praktiken der Lehrkräfte im Hinblick auf den Umgang mit sozial benachteiligten Schüler*innen}

Aufgrund der noch im Aufbau stehenden Forschung zur Rolle der Lehrkräfte bei der Entstehung, Verstärkung und Überwindung sozialer Ungleichheit im 
Bildungssystem scheint es für die vorliegende Arbeit lohnenswert, weitere ausgewählte empirische Studien aus der ungleichheitsorientierten Bildungsforschung zu betrachten, die mit unterschiedlicher methodischer Herangehensweise und theoretischer Rahmung der Frage nach der Herstellung von Bildungsungleichheit nachgehen und dabei die sozialen Praktiken im schulischen Alltag zum Untersuchungsgegenstand haben. Im Weiteren werden Untersuchungen herangezogenen, die explizit die Relevanz der Eigenlogik in konkreten Interaktionen zwischen Lehrkräften und Schüler*innen in den Blick nehmen. Hierbei folgt eine Fokussierung auf den deutschsprachigen Raum.

Zunächst wird exemplarisch auf Studien eingegangen, die Licht in die Herstellung von schulischer Leistung bringen. Etwa zeichnen Gellert und Hümmer (2008) anhand von Videoanalysen einer Unterrichtsstunde zu Beginn des fünften Schuljahres eines Gymnasiums und unter Rückgriff auf die von Bernstein (1996) entfaltete bildungssoziologische Theorie regulativer Prinzipien nach, dass Unterschiede in mathematischen Leistungen nicht allein auf ungleiche kognitive Fähigkeiten zurückzuführen sind, sondern es sich um (inter-)subjektive Konstruktionen handelt. Dadurch, dass der Mathematiklehrer von Schulbeginn an ex- und implizit Verhaltensregeln sowie Erwartungen an eine elaborierte mathematische Fachsprache und mathematischen Ausdruck einführt, verlangt er den Schüler*innen eine enorme Decodierungsleistung ab. Die Verknüpfung von mathematischen Kompetenzen und einer Versprachlichung auf hohem Niveau sind entscheidende Selektionsmechanismen: Der Lehrer fördert Schüler*innen, die aufgrund ihrer primären Sozialisation mit komplexen sprachlichen Auseinandersetzungen in familialen Interaktionen vertraut sind, d. h. Schüler*innen, bei denen schulische und familiale Habitusformen übereinstimmen (Gellert \& Hümmer, 2008). Ähnlich wie Gellert und Hümmer (2008) bezieht sich Jäger (2014) ebenfalls auf die Diskurstheorie von Bernstein und arbeitet mittels teilnehmender Beobachtung die Sprechweisen von Lehrkräften am allerersten Schultag in zwei sozialräumlich kontrastiven Schulkontexten heraus. Dabei richten die Lehrkräfte ihren Interaktionsstil an die vermuteten bildungssprachlichen Kompetenzen der verallgemeinerten Schüler*innenschaft aus und schaffen somit für die Kinder ihrer Klasse je unterschiedliche Lernbedingungen (ebd.).

Auch auf Basis teilnehmender Beobachtung analysiert Kalthoff (2000) mündliche Bewertungen von Internatsschüler*innen im laufenden Unterrichtsgespräch. Kalthoff zeigt, dass Lehrkräfte bei der Erarbeitung neuen Unterrichtsstoffes Schüler*innen unterschiedliche Zuständigkeiten und somit Kompetenzen zuweisen, indem sie eng begrenzte Rederechte an die Schüler*innen delegieren. Die Auswahl der Schüler*innen und die Kommentierungen ihrer Beiträge erfolgen einerseits auf ihrem erworbenen Wissen und andererseits auf den Erfordernissen 
der aktuellen Gesprächssituation (ebd.). Daran anschlussfähig sind die ethnografischen Studien von Zaborowski, Meier und Breidenstein (2011) zur Praxis der Leistungsbewertungen verschiedener Schulformen. Neben den nahezu permanenten Stellungnahmen zu Schüler*innenäußerungen im Unterricht werden außerdem schriftliche und mündliche Prüfungen, Zeugniskonferenzen und Zeugnisse in den Blick genommen und hinsichtlich ihrer Bedeutung für den schulischen Alltag untersucht. In Teilstudien stellen die Autor*innen detailliert heraus, dass die Praktiken schulischer Leistungsbewertungen eigenen Logiken folgen und nicht einzig in der Selektionsfunktion der Schule aufgehen. Etwa beleuchtet Meier (2011) ausgehend von der Zeugniskonferenz einer fünften Gymnasialklasse, in der die Lehrkräfte die überdurchschnittlich guten Schulleistungen loben, wie Schüler*innen und Lehrkräfte gemeinsam im Unterricht am Schulerfolg bzw. an guten Noten arbeiten. Dem Autor zufolge richten sich die Schüler*innen dabei stark an den ex- und impliziten Erwartungshaltungen der Lehrkräfte aus. Die Lehrkräfte hingegen halten unabhängig von den Noten und auch im Falle temporären Versagens an der Idee des, guten' Schülers bzw. der ,guten' Schülerin fest und unterstellen den Kindern eine generelle Leistungsfähigkeit. Meier folgert, dass

erst wenn die schulischen Leistungen so schlecht sind, dass sie weder durch Kulanz-Praktiken noch Umdeutungen zu ,beheben" sind, werden diese Kinder schlussendlich durch Sitzenbleiben oder Abstufungen aussortiert. Damit bleibt das Gymnasium die Schule mit den erfolgreichen Schülern und bestätigt sich als diejenige Schulform, die Schulerfolg ermöglicht. (ebd., S. 161)

Diese Befunde unterscheiden sich deutlich von denjenigen, die Zaborowski (2011) schildert. Die Autorin geht in ihrer Teilstudie der Frage nach, wie eine Sekundarschule, die immanente Strukturprobleme zu bewältigen hat, mit Leistungsbewertungen im Schulalltag umgeht. Die Rekonstruktionen zeigen, dass sich die Unterrichtskultur zwischen ,der Forderung nach Wohlverhalten der Schülerschaft auf der einen Seite und einer in sich brüchigen Form der Leistungsethik auf der anderen Seite“ (ebd., S. 317) bewegt. Dem vermeintlich unangepassten Verhalten vieler Schüler*innen sowie deren schlechten Schulleistungen wird mit Kontrollund Disziplinierungspraktiken begegnet. In der beobachteten Sekundarschule werden individuelle Probleme der Schüler*innen ausgeblendet, stattdessen ist der Unterricht von Misstrauen in die Leistungsfähigkeit sowie Leistungsbereitschaft der Schüler*innen geprägt. Nach Zaborowski dienen die Handlungsroutinen der Lehrkräfte vor allem der Verantwortungsentlastung für die schlechten schulischen Leistungen. Abschließend argumentiert Zaborowski, dass die Lehrkräfte ,sich als Agenten eines funktionierenden Systems [sehen], das Schüler entsprechend ihrer 
Leistungen dorthin sortiert, ,wo sie hingehören'. Sie reproduzieren somit die bereits erfolgte Selektion und führen sie (in der Aufteilung nach Klasse sechs) weiter" (ebd., S. 320).

Studien zum theoretischen Ansatz des „doing difference“ (West \& Fenstermaker, 1995) können überdies Einblick geben, wie soziale Differenzen in Bildungsungleichheit überführt werden. Im Sinne Mehans (2012) werden dabei „constitutive practices“ (ebd., S. 274), also Praktiken, die Ungleichheitsverhältnisse im Alltäglichen hervorbringen und stützen, fokussiert. Beispielsweise rekonstruieren Jäger und Biffi (2011) mithilfe von teilnehmender Beobachtung sowie Interviews mit Lehrkräften und Schüler*innen, wie das Fremdbild des Erstklässlers ,Amirs' entsteht. Bereits zum Schuleintritt setzt die Lehrerin das Verhalten des Schülers in Beziehung zu normativen Vorgaben. Im Rahmen der Interaktionen mit den Schüler*innen, die durch die spezifischen Erwartungen der Lehrerin strukturiert sind, demonstriert die Lehrerin ihre Autorität im schulischen Diskurs und reproduziert das institutionelle Machtgefälle: Sie stellt die sozialen Normen auf und kontrolliert dieses zugleich. Jäger und Biffi fassen zusammen, dass die Lehrerin den Schüler „durch den an Mittelschichtnormen orientierten impliziten Verhaltenscode" (ebd., S. 40) benachteiligt. In diesem Zusammenhang sei auch die Untersuchung von Khan, Sertl, Raggl, Stefan und Unterköffler-Klatzer (2012) erwähnt. Anhand von Gruppendiskussionen mit Lehrkräften von schweizerischen Volks- und Mittelschulen arbeiten die Autor*innen kollektive, gruppenbezogene Normalisierungsstrategien heraus. Hierbei konstruieren die Lehrkräfte Heterogenität im Modus der Definition von Abweichungen und Schwierigkeiten einzelner Schüler*innen in Kontrast zu einer Normalitätsfolie, die durch habituelle Homologie Selbstverständlichkeit besitzt. Mit der dokumentarischen Methode (Bohnsack, 1989) zeigt sich diese kollektive Normalisierung inhaltlich begründet in gemeinsamen Erfahrungsräumen von Lehrkräften mit ähnlichen habituellen Dispositionen und Milieubezügen (Khan, Sertl, Raggl, Stefan, \& Unterköffler-Klatzer, 2012).

Die Relevanz sozialer Herkunftsverhältnisse im Vollzug gerät in der Studie von Fölker und Hertel (2015) zu Praktiken des Umgangs mit Heterogenität und Segregation von Schüler*innen an Schulen in sozialräumlich benachteiligter Lage in den Blick. Fölker und Hertel analysieren auf Grundlage von Fallstudien verschiedene Wahrnehmungs- und Deutungsmuster, die Lehrkräfte auf Basis ihres (Alltags-)Wissens auf ihre Schüler*innenschaft einnehmen. Die Spannweite reicht von einer vollständigen Ausblendung sozialer Hintergründe über stereotype Orientierungen bis hin zu Sichtweisen, die insbesondere die sozioökonomische Benachteiligungslage der Kinder fokussieren. Damit einher gehen unterschiedliche Bewertungen der Schüler*innen und ihrer Leistungen. 
Beispielshalber identifizieren die Autor*innen ethnisierende Zuschreibungen für Schulprobleme muslimischer Schüler*innen. Als Schnittmenge verschiedener Schüler*innenklientel-Konstruktionen von Lehrkräften und anderen Professionellen im schulischen Setting legen Fölker und Hertel darüber hinaus eine Tendenz zur Aberkennung der Erziehungs- und Bildungsfähigkeit der Eltern dar (vgl. hierzu auch: Fölker, Hertel, \& Pfaff, 2015b). Dieser Befund erscheint hoch relevant für die vorliegende Arbeit. So kann auch Jäger (2014) Vorbehalte an der Erziehungsfähigkeit der Eltern im sozialstrukturell benachteiligten Schulkontext rekonstruieren. Ganz selbstverständlich stellt die Lehrerin ihren pädagogischen Expertinnenstatus und schulische Ansprüche über diejenigen der Familie und sieht sich veranlasst, Kindern wie auch Eltern gegenüber klare Regeln und Vorschriften aufzustellen. Jäger weist darauf hin, dass kein Zweifel an der Berechtigung der Lehrerin, unmittelbar auf den Privatraum ,Familie‘ einzuwirken, besteht (ebd.). Zu ähnlichen Ergebnissen kommen ferner Wiezorek und Pardo-Puhlmann (2013), die mit Hilfe von zwei Fallstudien defizitorientierte Normalitätskonstruktionen im (schul-)sozialpädagogischen Handlungsfeld rekonstruieren. Unter Rückgriff auf die begriffliche Trias ,Armut, Bildungsferne und Erziehungsunfähigkeit" markieren die Autorinnen eine Missachtung des elterlichen Bemühens, Erziehungsverantwortung zu tragen sowie die Abwertung bzw. Vorenthaltung von grundlegender Anerkennung familialer Muster der Selbstverwirklichung. Die negativen Klassifikationen stellen hierbei zentrale Bezugspunkte des eigenen professionellen Selbstverständnisses dar. Infolgedessen orientiert sich das pädagogische Handeln stark an einer „lebensweltlichen Fürsorgeleistung“ (ebd., S. 206). Hierbei sind die rekonstruierten Familienbilder nicht erfahrungsgesättigt, sondern familiale Hintergründe der Schüler*innen werden als bekannt vorausgesetzt (ebd.).

In einer aktuellen Studie untersucht Weitkämper (2019), welche Rolle Lehrkräften bei der Hervorbringung, Stilllegung und Variation von Bildungsungleichheit zukommt. Datengrundlage bilden teilnehmende Beobachtung, Interviews mit Lehrkräften und Fragebogen für Schüler*innen in inklusiv beschulenden Grundschulen. Der Autor illustriert, wie durch Prozesse eines un/doing authority Lehrkräfte soziale Ordnungsvorstellungen durchsetzen. In diesem Sinne werden Praktiken der ,Bebilderung ' und Klassifikation in ihrer ermöglichenden wie begrenzenden Weise im Kontext schulischer Anerkennungsverhältnisse nachgezeichnet. Weitkämper kann zum Beispiel zeigen, dass die ,Migrationszugehörigkeit' in Abgrenzung zum ,Deutschsein“ als problematisch angesehen 
wird, ,Inklusionskinder ${ }^{\star}$ außerhalb der Leistungsnorm thematisiert und als , unnormal' adressiert werden, Schüler*innen in ,Akademikerkind' bzw. ,NichtAkademikerkind" unterschieden werden sowie dass trotz Bevorzugung von ,intellektuellen ' Herkunftsverhältnissen auch ein ,Arbeiterkind' erfolgreich in der Schule sein kann, wenn es sich den Erwartungen der Lehrkräfte anpasst bzw. die Lehrkräfte als Autoritäten anerkennt (ebd.). Ähnlich wie Zaborowski (2011) kommt Weitkämper (2019) zu dem Schluss, „,dass soziale Differenzverhältnisse für Lehrkräfte schulische Diskriminierungs- und Legitimierungsgelegenheiten bereitstellen“ (ebd., S. 319) und schulischer Misserfolg mithilfe eines Migrationshintergrundes oder eines nicht-akademischen Elternhauses begründet werden kann. (ebd.).

\subsection{Zusammenfassung und Schlussfolgerungen für die eigene Untersuchung}

Aus den überblicksartig dargestellten empirischen Befunden der Vergleichsstudien und amtlichen Schulstatistiken geht zunächst einmal hervor, dass die Strukturbzw. Systemlogik des deutschen Bildungssystems zur Entstehung und Verfestigung sozialer Ungleichheit beiträgt. Hierzu zählen vor allem die Mehrgliedrigkeit des Schulsystems sowie der frühe Zeitpunkt der Verteilung der Schüler*innen auf verschiedene Schulformen. Der Übergang zur weiterführenden Schule gilt als zentrale Weichenstellung innerhalb der Bildungsbiografie von Schüler*innen: Zum einen lässt der einmal bestrittene Bildungsweg sich nachträglich kaum korrigieren. Wenn es zu einem Schulwechsel kommt, dann handelt es sich zumeist um einen Abstieg in eine niedrigere Schulform (Berkemeyer, Bos, Manitius, Hermstein, \& Khalatbari, 2013). Zum anderen hat die Schulformzugehörigkeit großen Einfluss auf die weitere Lern- und Leistungsentwicklung: Aufgrund der sozialen Zusammensetzung der Schüler*innenschaft, der ungleichen Bildungsziele und Unterrichtskulturen sowie der unterschiedlichen Ausbildung der Lehrkräfte bieten die Schulformen „differenzielle Lern- und Entwicklungsmilieus“ (Baumert, Stanat, \& Watermann, 2006), die wiederum zu deutlichen Leistungsunterschieden zwischen den institutionell getrennten Bildungsgängen führen. Letztlich erreichen die Schüler*innen in Abhängigkeit ihrer sozialen Herkunft unterschiedliche Schulabschlüsse (Berkemeyer, Bos, Manitius, Hermstein, \& Khalatbari, 2013).

Die Selektion durch die Lehrkräfte geschieht dabei nicht allein auf Basis des gesellschaftlich proklamierten Leistungsprinzips. So konnte im Kontext des auf Boudon zurückgehenden Rational-Choice-Ansatzes nachgezeichnet werden, dass 
Lehrkräfte leistungsfremde Kriterien wie zum Beispiel Begabung und Motivation (Anders, McElvany, \& Baumert, 2010) sowie gute Umgangsformen und positives Sozialverhalten (Schumacher, 2002) zur Beurteilung der schulischen Lern- und Leistungsfähigkeit heranziehen. Hierbei erhalten Schüler*innen aus sozioökonomisch benachteiligten Familien auch bei einer statistischen Kontrolle der Testleistungen und des Arbeitsverhaltens systematisch schlechtere Noten und Schullaufbahnempfehlungen durch die Lehrkräfte (Stubbe, Bos, \& Schurig, 2017). Prinzipiell liegt jedoch aufgrund der theoretisch-konzeptionellen stärkeren Gewichtung der sekundären Herkunftseffekte aus der Perspektive des Rational-Choice-Ansatzes der Fokus auf den Bildungsentscheidungen der Eltern, sodass Lehrkräfte im Vergleich für die Entstehung und Verstärkung sozialer Bildungsungleichheit kaum in den Blick genommen werden (Kramer, 2015).

Im Gegensatz dazu weist Bourdieu den Lehrkräften eine entscheidende Rolle bei der Erzeugung und Perpetuierung sozialer Ungleichheitsverhältnisse zu. Hierbei legt er gemeinsam mit Passeron dar, dass die sozial selektive Wahrnehmung und Auslese „nicht Ausdruck einer bewussten Absicht [ist], sondern Ergebnis inkorporierter sozialer Strukturen im Habitus, die zu spezifischen Wahrnehmungs, Deutungs- und Handlungspraktiken auch im pädagogischen Handeln in der Schule führen“ (Kramer, 2015, S. 353). So fördern Lehrkräfte aufgrund der eigenen habituellen Nähe zur schulisch repräsentierten kulturellen Willkür diejenigen Schüler*innen, die in der Familie bereits an die Orientierungen und Praktiken der legitimen Kultur herangeführt wurden bzw. die diese zumindest mit Leistungsund Anstrengungsbereitschaft und dem Ziel des sozialen Aufstiegs verbürgen. Die Alltagspraktiken und Bildungsstrategien von Schüler*innen, die in weniger privilegierten Familienverhältnissen aufwachsen, sind hingegen kaum anschlussfähig an die schulischen Erwartungen und Anforderungen (Kramer, 2013). Im Vergleich zum breiten Forschungsstand des Rational-Choice-Ansatzes liegen nur wenige empirische Studien vor, die die Passung zwischen dem in der Familie bzw. sozialen Milieu erworbenen primären Habitus und dem durch die Schule geforderten sekundären Habitus analysieren. Der Fokus der Studien liegt hierbei auf den Bildungsorientierungen der Schüler*innen und deren milieuspezifischen Umgang mit schulischen Erwartungen und Anforderungen (u. a. Kramer, Helsper, Thiersch, \& Ziems, 2009; Jünger, 2008; Grundmann, Groh-Samberg, Bittlingmayer, \& Bauer, 2003). Eine überschaubare Anzahl von Untersuchungen der letzten Jahre belegt ferner, dass mit der sozialen Herkunft in Verbindung stehende biografische Erfahrungen Einfluss auf das berufliche Selbstverständnis und das pädagogische Handeln der Lehrkräfte haben (u. a. Lange-Vester, 2015; LangeVester \& Teiwes-Kügler, 2014; Schumacher, 2002). In diesem Zusammenhang geraten auch zunehmend Lehrkräfte mit Migrationshintergrund in den Blick. Etwa 
verweisen die Untersuchungen von Rotter (2014) und Edelmann (2006) auf unterschiedliche Bedeutungszuschreibungen der eigenen Einwanderungsgeschichte für das berufliche Selbstkonzept von Lehrkräften mit Migrationshintergrund. Insgesamt wurde über die Habitusmuster von Lehrkräften und deren Einfluss auf die pädagogische Arbeit bislang kaum geforscht. Zwar konnte in den letzten Jahren gezeigt werden, wie (zunehmend) heterogen die Lehrer*innenschaft ist und welche Bedeutung die habituellen Orientierungen und biografischen Erfahrungen für die pädagogische Arbeit haben, dennoch fehlen Studien, die diesen Zusammenhang systematisch analysieren.

Einen weiteren Beitrag zum Verständnis über Mechanismen der Herstellung von Bildungsungleichheit leisten neben Interviews und Gruppendiskussionen darüber hinaus teilnehmende Beobachtung und Videoaufnahmen in Klassenräumen und auf Schulhöfen zum Umgang mit Schüler*innen ungleicher sozialer Herkunft. Die exemplarisch ausgewählten Studien, die zum Teil Bourdieus Thesen und Konzepte aufgreifen und überdies theoretische Schärfungen und Weiterführungen bzw. Verknüpfungen mit weiteren theoretischen Ansätzen vornehmen, bieten einen ergänzenden praxeologischen Zugang zur Ungleichheitsproblematik. So können die exemplarisch ausgewählten Untersuchungen mit dem Fokus auf Lehrer*innen-Schüler*innen-Interaktionen zeigen, wie Bildungsungleichheit innerhalb kürzester Zeit hergestellt wird und dabei mit sozialen Differenzkategorien verknüpft und plausibilisiert werden. Etwa zeigt Jäger (2014) anhand des ersten Schultags in einer Schule mit Schüler*innen aus vorwiegend sozial privilegierten Familien und in einer Schule mit Schüler*innen aus vorwiegend sozial benachteiligten Familien, dass die Lehrerinnen durch ihren Sprachstil den beteiligten Akteuren unterschiedliche Positionen in der sozialen Ordnung zuweisen. Die Untersuchung von Gellert und Hümmer (2008) zum Mathematikunterricht in einer fünften Gymnasialklasse demonstriert weiterhin, dass die Erfüllung von impliziten Verhaltenserwartungen eine ebenso große Rolle für die Leistungsbeurteilung spielt wie die fachbezogenen Fähigkeiten der Schüler*innen. Khan et al. (2012) zeichnen des Weiteren anhand von Gruppendiskussionen mit Lehrkräften nach, wie entlang von Normalitätsvorstellungen bestimmte Verhaltensweisen von Schüler*innen und Eltern als , unangemessen " oder als , angemessen ' bewertet werden.

Für die eigene empirische Arbeit können aus den Erklärungen und Befunden zur Verstrickung der Lehrkraft in Reproduktionsprozesse sozialer Ungleichheit zwei wichtige Aspekte abgeleitet werden: 
(1) Zwar führen die strukturellen bzw. systemimmanenten Rahmenbedingungen dazu, dass Lehrkräfte bestimmten Bewertungs- und Entscheidungszwängen unterliegen, aber es bestehen zugleich Ermessensspielräume, innerhalb dessen milieuspezifische Erwartungen und Vorstellungen von Lehrkräften wirksam werden und Lehrkräfte entsprechend handeln. Bourdieus Konzept der Sozioanalyse scheint eine Möglichkeit zu bieten, wie Lehrkräfte ihre Handlungsfreiheiten auch so nutzen können, dass sie einer Verfestigung der sozialen Ungleichheit durch das Bildungssystem entgegenwirken: Indem sich Lehrkräfte mit der eigenen sozialen Herkunft bewusst befassen und auf diese Weise die Bedingungen reflektieren, denen sie bei der pädagogischen Arbeit unweigerlich unterliegen, können sie sich Bourdieu zufolge gegenüber den Mechanismen des schulischen Feldes immer wieder neu verhalten.

(2) Angesichts dessen, dass weder Lehrkräfte noch Schüler*innen eine homogene soziale Gruppe bilden, scheint es zu kurzgegriffen, Lehrkräften entweder eine Reproduktions- oder eine Transformationsfunktion hinsichtlich Bildungsungleichheit zuzuschreiben. So zeigen die bisherigen empirischen Untersuchungen ein breites Spektrum an beruflichen Selbstkonzepten und an Sensibilität für die unterschiedlichen Lernvoraussetzungen, Potenziale und Bedürfnisse der Schüler*innen. Zudem muss berücksichtigt werden, dass es neben dem Unterrichten weitere Bereiche der pädagogischen Arbeit gibt, wie beispielsweise die Zusammenarbeit mit den Eltern und die Kooperation mit außerschulischen Institutionen und Akteuren, die Lehrkräfte ungleich ausgestalten. Schließlich sei noch auf verschiedene schulische Settings verwiesen, in denen ganz unterschiedliche Akteure zusammentreffen. Zu beachten wären u. a. wirtschaftliche, soziale und kulturelle Rahmenbedingungen im Einzugsbereich von Schulen, die die Zusammensetzung der Schüler*innenschaft und die damit einhergehende Gestaltung und Qualität der Unterrichtsprozesse sowie die Schulkultur beeinflussen. Insgesamt sprechen die Studien dafür, dass sich Lehrkräfte in einem Spannungsfeld zwischen Reproduktion und Abbau von sozialer Ungleichheit bewegen und unterschiedliche Anknüpfungsmöglichkeiten und Bezüge für Schüler*innen eröffnen. 
Open Access Dieses Kapitel wird unter der Creative Commons Namensnennung 4.0 International Lizenz (http://creativecommons.org/licenses/by/4.0/deed.de) veröffentlicht, welche die Nutzung, Vervielfältigung, Bearbeitung, Verbreitung und Wiedergabe in jeglichem Medium und Format erlaubt, sofern Sie den/die ursprünglichen Autor(en) und die Quelle ordnungsgemäß nennen, einen Link zur Creative Commons Lizenz beifügen und angeben, ob Änderungen vorgenommen wurden.

Die in diesem Kapitel enthaltenen Bilder und sonstiges Drittmaterial unterliegen ebenfalls der genannten Creative Commons Lizenz, sofern sich aus der Abbildungslegende nichts anderes ergibt. Sofern das betreffende Material nicht unter der genannten Creative Commons Lizenz steht und die betreffende Handlung nicht nach gesetzlichen Vorschriften erlaubt ist, ist für die oben aufgeführten Weiterverwendungen des Materials die Einwilligung des jeweiligen Rechteinhabers einzuholen.

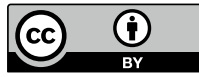

